\title{
Cárie e fluorose dentária em adolescentes de 12 e 15 anos em Salvador, Bahia, no ano de 2001.
}

\author{
Maria Cristina Teixeira Cangussu
}

\begin{abstract}
Tese apresentada à Faculdade de Saúde Pública da Universidade de São Paulo como requisito parcial para a obtenção do título de Doutor em Saúde Pública.
\end{abstract}

Área de concentração: Serviços de Saúde Pública

Orientador: Prof. Doutor Roberto A. Castellanos Fernandez

São Paulo

2003 
A Regis, que ao abrir mão da minha presença e de horas de convivio, cultivou, acima de tudo, o respeito aos grandes sonhos, dos quais hoje faz parte. Pelo nosso amor...

A Gabriela, filha tão desejada e querida, fruto dessa união;

Aos meus pais, Ayrton e Maria Luiza, por estarem sempre presentes, com carinho, atenção e amor;

Aos meus tios queridos Antenor (in memorian) e Maria Teresa, segundos pais, por terem me recebido de braços abertos $e$ por tantos e tantos momentos felizes;

Aos meus irmãos Ayrtinho, Sergio e, Eduardo; primos quase irmãos, Cláudio, Marco Aurélio e Alessandra, e meus familiares, com quem pude contar sempre. 


\section{AGRADECIMENTOS}

Iniciar e concluir este percurso só foi possível devido a participação do Prof. Roberto Castellanos, meu orientador. Por sua orientação atenta, leitura crítica e por me fazer crescer e amadurecer científica e tecnicamente, muito além do que achava que fosse possível, serei sempre muito grata. Mas acima de tudo, por ter me recebido de braços abertos, pela confiança que depositou em mim e neste trabalho durante todo o curso;

A Faculdade de Saúde Pública da Universidade de São Paulo, minha casa durante este período. A todos os professores, funcionários e corpo técnico-administrativo, pela formação e apoio indispensáveis;

Em especial, ao professor Paulo Capel Narvai, que foi para mim um exemploacadêmico e profissional. Foi um prazer imenso partilhar momentos e poder contar contigo sempre que possível;

Ao professor José Leopoldo Antunes, pelas relevantes contribuições no exame de qualificação;

Aos amigos e grandes companheiros que fiz em São Paulo: Cecília, Carol, Rui, Bettina, Eliete, Paulo Garretha, Rosa, Mariza, Silmara, Marco, Suzana, João Paulo, Maria Amélia, Raquel, Adriana, Henrique e tantos outros...

A Sra. Adelina, que me abriu a sua casa e seu coração;

A Wladithe, grande amiga para sempre, com quem dividi o espaço e a vida, horas incontáveis de estudo e diversão, e tornou a minha vida na cidade tão mais prazerosa;

Ao Gizelton e a Célia, amigos incondicionais, não tenho palavras....

A Vera, Pedrinho e toda a sua família. Os muitos momentos que passei com vocês foram fantásticos;

Aos meus colegas e amigos do Departamento de Odontologia Social da Universidade Federal da Bahia, que assumiram uma carga extra de trabalho, permitindo o meu afastamento e possibilitando a conclusão deste curso, o meu muito obrigado;

A Bel, que foi um exemplo em toda a minha carreira acadêmica. Inicialmente como uma mestra, introduzindo-me ao campo da saúde bucal coletiva. Obrigado por estar atenta, ser o abraço carinhoso e amigo e pela disponibilidade, mesmo nos momentos em que estava muito sobrecarregada. Espero ainda poder dividir muito com você.... 
As amigas Bia e Maria Helena por serem fonte de inspiração e porto seguro, e por tantos e tantos momentos divertidos;

A Eliane, companheira sempre. Por me estimular a buscar novos horizontes, por sua paciência e olhar atento, e por todas as contribuições que deu a este trabalho e em minha vida;

A Celina, pela confiança, apoio pessoal e por aguçar ainda mais o meu senso crítico, pelo exemplo de uma relação profissional ética;

Aos professores e colegas de trabalho Antônio Pitta, Mariângela, Goretti, Sônia Chaves, Mônica, Fabiana, Carlos, Augusto César, Marcelo, Marcos, Lana, Sônia Vidal, Iandira e Antístenes;

A Mirela Brandão, coordenadora de Odontologia da Secretaria Municipal de Saúde de Salvador;

A equipe de organização técnica e coleta de dados: Cristiane Rivas, Cláudio Ferreira Júnior, Luciano Cincurá S. Santos, Márcia Pinheiro, Mônica Lopes, Carolina Ribeiro, Alexandre Barros, Catiúscia Duplat, Flávia Aquino, Eve Rios de Lima, Silvana Albuquerque, Cristiane Castro, Cristina Pinho e Fernanda Trindade. Sem a participação, esforço e empenho de cada um de vocês este trabalho nem existiria. Muito obrigado!

A Carlos Mauricio Cardeal Mendes, por suas contribuições na análise e interpretação dos dados;

A todos os estudantes, pais, professores, coordenadores pedagógicos e diretores que permitiram a realização deste trabalho;

A Edna, Alexandre, Léo, Sara, Kátia, Karina, Carlos Eugênio e Dejaci, Jorge e Lílian, Bruno e Cristina e todos os amigos que me apoiaram com paciência, palavras amigas e bom humor;

A Ana Maria e Roberta, por disponibilizarem seu tempo livre para me permitir concluir este trabalho;

A CAPES, que através do programa PICDT vinculado a Universidade Federal da Bahia, forneceu o auxílio financeiro através da bolsa- auxílio durante todo o curso. 


\section{RESUMO}

Cangussu MCT. Cárie e fluorose dentária em adolescentes de 12 e 15 anos em

Salvador, Bahia, no ano de 2001. São Paulo; 2003 [Tese de Doutorado- Faculdade de

Saúde Pública -Universidade de São Paulo].

OBJETIVO: Determinar a prevalência e a severidade da cárie e fluorose dentária em escolares de 12 e 15 anos de idade em Salvador-BA, em 2001, segundo distrito sanitário e tipo de estabelecimento de ensino de forma a identificar iniqüidades em saúde.

METODOLOGIA: Desenvolveu-se um estudo transversal com uma amostra probabilística sorteada em múltiplo estágio, pré-estratificada pelos 12 distritos sanitários e tipo de escola (pública ou privada), calculada a partir dos dados disponíveis de cárie dentária para o município (1996) com um nível de significância de 5\% e um erro de $20 \%$. Com uma equipe de sete examinadores previamente calibrados, foram examinados 1.750 escolares aos 12 anos e 1.563 escolares aos 15 anos de idade, utilizando a metodologia recomendada pela Organização Mundial da Saúde para cárie e fluorose dentária. Dados sobre acesso e cobertura dos serviços de saúde foram obtidos através de um questionário aplicado aos estudantes e às Secretarias Municipal e Estadual de Saúde. Apresentou-se as estatísticas descritivas (CPO-D, percentual de indivíduos livres de cárie, composição percentual do índice CPO-D) aos 12 e 15 anos para o municipio e por distrito. Para a análise segundo tipo de estabelecimento de ensino e por distrito sanitário utilizou-se: teste do qui-quadrado, $t$ de Student, análise bivariada e de regressão logística não condicional, utilizando um nível de significância de $5 \%$ para todas as testagens estatísticas.

RESULTADOS: A amostra teve predominância da etnia parda (71,2\% aos 12 anos e $73,2 \%$ aos 15 anos) e do sexo feminino (54,5\% aos 12 anos e 57,7\% aos 15 anos). Quase a metade dos escolares teve acesso ao dentista no último ano $(49,6 \%)$, sendo que destes, $15,4 \%$ no setor público, $31,3 \%$ no setor privado ou conveniado e $2,9 \%$ outros tipos de financiamento. Quase $40 \%$ dos escolares de 12 anos e 27,7\% aos 15 anos relataram ter participado de programas coletivos com o uso do flúor nos últimos 2 anos. Observou-se um CPO-D de 1,44 e 49\% das crianças livres de cárie aos 12 anos de idade, e um índice de 2,66 aos 15 anos. Os distritos com menor prevalência de cárie foram o de Pau da Lima, Cajazeiras e Subúrbio Ferroviário, e os de piores condições, Itapoã e Liberdade, sendo a variável acesso ao dentista no último ano relevante nesta distribuição. Identificou-se discrepâncias na distribuição dos recursos físicos, humanos e práticas de saúde coletiva desenvolvidas nos distritos. Não foram detectadas diferenças estatisticamente significativas no CPO-D e percentual de individuos livres de cárie entre escolares da rede pública e privada em ambas idades, com diferenças apenas na composição percentual do índice.

Em relação a fluorose, observou-se a predominância da forma "muito leve", em ambas idades e tipos de escolas, com $31,4 \%$ e $27,6 \%$ das crianças aos 12 e 15 anos de idade respectivamente apresentando esta alteração no município. Foram encontradas diferenças significativas na proporção de escolares livres de fluorose, favorável à 
escola pública, como também diferenças na distribuição entre os distritos sanitários, estatisticamente significantes $(p<0,05)$, sendo o da Liberdade o de pior condição.

CONCLUSÕES: Em escolares é baixa a prevalência de cárie dentária no município, embora possam ser encontradas iniqüidades na distribuição da doença em áreas geográficas distintas. Existe pouca sistematização institucional das práticas coletivas desenvolvidas em cada distrito, o que implicaria na redefinição das prioridades assistenciais e organização de um sistema de informação efetivo. Não foram encontradas diferenças na prevalência e severidade da cárie dentária entre escolares das redes pública e privada. A fluorose dentária parece ainda não se constituir um problema de saúde pública no município. Foram encontradas diferenças na prevalência desta alteração entre os distritos sanitários, assim como maior ocorrência em escolares da rede privada, reforçando a necessidade de vigilância à saúde.

Descritores: Cárie dentária, Índice CPO-D, Levantamentos Epidemiológicos, Fluorose dentária, Adolescentes. 


\section{SUMMARY}

Cangussu MCT. Cárie e fluorose dentária em adolescentes de 12 e 15 anos em

Salvador, Bahia, no ano de 2001 [Dental caries and fluorosis among teenagers of 12 and 15 years old in Salvador, Bahia]. São Paulo (BR); 2003 [Tese de Doutorado -

Faculdade de Saúde Pública -Universidade de São Paulo].

OBJECTIVE: To determine the prevalence and severity of dental caries and fluorosis among 12 and 15 years- old students in Salvador, Bahia, according to health sanitary district and teaching establishment, in order to identify the inequalities in health.

METHODOLOGY: We developed a transversal study with a multiple stage raffled probabilistic sample, pre-stratified by the 12 sanitary districts and type of teaching establishment (private or public), calculated from the available data on dental caries for the county during the year of 1996 , by the Health Ministry, with a significance level of $5 \%$ and error of $20 \%$. With a team of previously calibrated examiners, 1750 twelve-year old students and 1563 fifteen-year old students were examined by using the methodology recommended by the World Health Organization for dental caries and fluorosis. Data on the access and coverage of healthcare services were obtained from a questionnaire applied to students and Municipal and State Health Offices as well. Descriptive statistics (DMFT, caries-free individual percentage, DMFT index percentile composition) were presented for the 12 and 15 year-old individuals for both county and district. For the analysis according to type of teaching and by sanitary district, we used: Chi-square test, Student t-test, bivariate analysis, and non-conditional logistic regression, using a significance level of $5 \%$ for all statistic testing.

RESULTS: The sample was predominant for mulatto individuals $(71.2 \%$ on 12 years old and $73.2 \%$ on 15 years old) and female gender (54.5\% on 12 years old and $57.7 \%$ on 15 years -old). Almost half of the students had had access to dental care during the last year-old (49.6\%), being $15.4 \%$ in the public healthcare sector, $31.3 \%$ in private or company healthcare system and $2,9 \%$ other resources. Almost $40 \%$ of 12 years- old students and $27.7 \%$ of the 15 years old have reported participation in collective programs with use of fluorine during the last 2 years. A DMFT of 1.44 was observed and $49 \%$ of caries-free children of 12 years old, and an index of 2.66 for the 15 years old children. The districts with lower prevalence of caries were Pau da Lima, Cajazeiras and Subúrbio Ferroviário. The worst conditions were found in Itapoã and Liberdade, being the variable "access to dental service" in the last years relevant to the distribution. Discrepancies were identified in the distribution of physical and human resources as well as in the public healthcare practices developed in the districts. Statistically significant differences between the DMFT and the percentage of caries-free individuals among students of private and public schools of both ages with differences only in the index percentile composition were not detected.

Regarding fluorosis, the predominance of a "very slight" form was observed for both ages and type of schools, with $31.4 \% \%$ and $27.6 \%$ of 12 and 15 years-old children 
respectively presenting this alteration in the county. Significant differences were found in the proportion of fluorosis-free students, more favorably in the public school, as well as statistically significant differences in the distribution among the sanitary districts, $(p<0,05)$, being the district of Liberdade the one with worst condition.

CONCLUSIONS: The prevalence of dental caries is low among the schoolchildren in the township, although inequalities can be found in the distribution of the disease in different geographical areas. There is little institutional systematization of the collective practices developed in each district, which would implicate in the redefinition of assistance priorities and the organization of an effective information system. We have not found differences in the prevalence and severity of dental caries among students of both private and public schools. Dental fluorosis is not regarded as a public health problem in the township, and we have found differences in the prevalence of such alteration among the sanitary districts, as well as a larger occurrence among students of private schools, reinforcing the need for health surveillance.

Descriptors: Dental caries, DMFT index, Epidemiological surveys, Dental fluorosis, Adolescents. 


\section{ÍNDICE}

1 INTRODUÇÃO

2 REVISÃO DE LITERATURA

2.1 Cárie dentária 9

2.2 Fluorose dentária $\quad 29$

3 OBJETIVOS $\quad 38$

4 HIPÓTESES DE TRABALHO

4.1 Cárie dentária $\quad 39$

$\begin{array}{ll}\text { 4.2 Fluorose dentária } & 40\end{array}$

\section{METODOLOGIA}

5.1 Local do estudo

5.2 Tipo de estudo $\quad 44$

5.3 População de estudo $\quad 46$

5.4 Calibração da equipe $\quad 49$

5.5 Aspectos éticos $\quad 51$

5.6 Coleta de dados

$\begin{array}{ll}5.7 \text { Processo de análise } & 56\end{array}$

6 RESULTADOS

6.1 Caracterização da população de estudo

6.2 A cárie dentária no município de Salvador 67

6.3 Cárie dentária segundo distrito sanitário $\quad 71$

6.4 Cárie dentária segundo tipo de escola 83

$\begin{array}{ll}\text { 6.5 Fluorose dentária } & 86\end{array}$ 


\section{DISCUSSÃo}

7.1 A cárie dentária no município de Salvador

7.2 Cárie dentária segundo distrito sanitário

7.3 Cárie dentária segundo tipo de escola

7.4 Fluorose dentária

8 CONCLUSÕES

9 REFERÊNCIAS BIBLIOGRÁFICAS

\section{ANEXOS}

Anexo 1- Mapa do município de Salvador com a distribuição dos distritos sanitários, 1996.

Anexo 2- Ficha de coleta dos dados individuais

Anexo 3- Ficha de coleta dos dados secundários

Anexo 4- Modelo do termo de consentimento

Anexo 5- Critérios para classificação do grupo étnico 


\section{LISTA DE TABELAS}

NÚMERO DA TABELA, TÍTULO

PÁGINA

1- Probabilidade de sorteio das escolas segundo categoria de ensino e distrito sanitário em Salvador, Bahia, 2001.

2- Distribuição da população de estudo, aos 12 e 15 anos de idade, segundo distrito sanitário em Salvador, Bahia, 2001.

3- Distribuição percentual das perdas amostrais de participação, aos $12 \mathrm{e}$ 15 anos de idade, segundo distrito sanitário em Salvador, Bahia, 2001.

4- Caracterização da população de estudo aos 12 e 15 anos de idade 66 segundo tipo de escola, sexo, etnia, visita ao dentista no último ano, tipo de financiamento da mesma, participação em programas com uso do flúor e local de moradia nos primeiros 5 anos de vida em Salvador, Bahia, 2001.

5- Condição dentária: CPO-D e intervalo de confiança a $95 \%$, composição percentual do índice e Índice de Cárie Significativo em escolares de 12 e 15 anos de idade em Salvador, Bahia, 2001.

6- Condição dentária: CPO-D e intervalo de confiança a $95 \%$, percentagem de indivíduos livres de cárie e intervalo de confiança a $95 \%$ e Índice de Cárie Significativa em escolares de 12 anos de idade segundo distrito sanitário em Salvador, Bahia, 2001.

7- Percentual da população de estudo aos 12 anos de idade segundo sexo, etnia, visita ao dentista no último ano, participação em programas coletivos e local de moradia nos primeiros 5 anos de vida por distrito sanitário de Salvador, Bahia, 2001 ( $\mathrm{n}=1750)$.

8- Modelo reduzido da regressão logística para a associação entre prevalência de cárie dentária (CPO-D $=0)$ aos 12 anos de idade segundo distrito sanitário, ajustado por sexo e acesso ao dentista no último ano, Salvador, Bahia, 2001.

9- Condição dentária: CPO-D e intervalo de confiança a 95\%, percentagem de indivíduos livres de cárie e intervalo de confiança a $95 \%$ em escolares de 15 anos segundo distrito sanitário em Salvador, Bahia, 2001.

10- Percentual da população de estudo aos 15 anos de idade segundo sexo, etnia, visita ao dentista no último ano, participação em programas coletivos e local de moradia nos primeiros 5 anos de vida por distrito sanitário de Salvador, Bahia, 2001. 
11- Modelo reduzido da regressão logística para a associação entre prevalência de cárie dentária $(C P O-D=0)$ aos 15 anos de idade segundo distrito sanitário, ajustado por sexo, participação em programas nos últimos dois anos e tipo de financiamento no acesso ao dentista, Salvador, Bahia, 2001.

12- Caracterização da rede assistencial e práticas desenvolvidas pela Secretaria Municipal de Saúde de Salvador, Bahia, 2001.

13- Condição dentária: CPO-D, desvio padrão, percentagem de indivíduos livres de cárie e medidas de dispersão em escolares da rede pública e particular aos 12 e 15 anos de idade, Salvador, Bahia, 2001.

14- Modelo reduzido da regressão logística para a associação entre prevalência de cárie dentária (CPO-D=0) aos 12 anos e 15 anos de idade segundo tipo de escola, ajustado por tipo de financiamento no acesso ao dentista, Salvador, Bahia, 2001.

15- Distribuição da fluorose dentária (índice de Dean) aos 12 e 15 anos de idade em Salvador, Bahia, 2001.

16- Percentual de casos de fluorose dentária (índice de Dean) em escolares de 12 anos de idade segundo distrito sanitário em Salvador, Bahia, 2001.

17- Percentual de casos de fluorose dentária (índice de Dean) em escolares de 15 anos de idade segundo distrito sanitário em Salvador, Bahia, 2001.

18- Modelo reduzido da regressão logística para a associação entre prevalência de fluorose dentária (Índice de Dean $<=1$ ) aos 12 anos de idade segundo distrito sanitário, ajustado por tipo de financiamento do acesso ao dentista Salvador, Bahia, 2001.

19- Modelo reduzido da regressão logística para a associação entre prevalência de fluorose dentária (Índice de Dean $<=1$ ) aos 15 anos de idade segundo distrito sanitário ajustado por sexo, Salvador, Bahia, 2001.

20- Distribuição da fluorose dentária em escolas públicas e privadas aos 12 e 15 anos de idade em Salvador, Bahia, 2001. 


\section{LISTA DE FIGURAS}

NÚMERO DA FIGURA, TÍTULO

PÁGINA

1- Concordância entre distrito de localização da escola e distrito de

residência de escolares de 12 e 15 anos de idade em Salvador, Bahia, 2001.

2- Percentual de escolares aos 12 e 15 anos de idade que referem ter ido ao dentista no último ano em Salvador, Bahia, 2001.

3- Percentual de escolares aos 12 e 15 anos de idade que relatam ter participado de programas coletivos nos últimos 2 anos em Salvador, Bahia, 2001.

4- Evolução do CPO-D aos 12 anos de idade em Salvador, Bahia nos 68 levantamentos de base populacional, no período 1986-2001.

5- Distribuição percentual dos valores CPO-D aos 12 anos de idade em Salvador, Bahia, $2001(\mathrm{n}=1750)$.

6- Distribuição percentual dos valores do CPO-D aos 15 anos de idade em Salvador, Bahia, $2001(\mathrm{n}=1563)$.

7- Distribuição percentual do CPO-D por grupo dentário aos 12 anos de idade em Salvador, Bahia, 2001.

8- Distribuição percentual do CPO-D por grupo dentário aos 15 anos de idade em Salvador, Bahia, 2001.

9- Coeficiente de prevalência de cárie dentária aos 12 e 15 anos de idade em Salvador, Bahia, 2001.

10- CPO-D e intervalo de confiança a $95 \%$ em escolares de 12 anos de idade segundo distrito sanitário, Salvador, Bahia, 2001.

11- Percentual de escolares livres de cárie e intervalo de confiança a $95 \%$ aos 12 anos de idade segundo distrito sanitário em Salvador, Bahia, 2001.

12- CPO-D e intervalo de confiança a $95 \%$ em escolares de 15 anos de idade segundo distrito sanitário, Salvador, Bahia, 2001. 
13- Percentual de escolares livres de cárie e intervalo de confiança a 95\% aos 15 anos de idade segundo distrito sanitário em Salvador, Bahia, 2001.

14- Composição do índice CPO-D segundo distrito sanitário aos 12 anos de idade em Salvador, Bahia, $2001(n=1.750)$.

15- Composição do índice CPO-D segundo distrito sanitário aos 15 anos de idade em Salvador, Bahia, $2001(\mathrm{n}=1.563)$.

16- Composição do indice CPO-D em escolares da rede pública e privada aos 12 anos de idade em Salvador, Bahia, $2001(n=1.750)$.

17- Composição do índice CPO-D em escolares da rede pública e 84 privada aos 15 anos de idade em Salvador, Bahia, $2001(n=1.563)$. 


\section{LISTA DE SÍMBOLOS E ABREVIATURAS}

BR: Boca do Rio

BRT: Brotas

BRV: Barra-Rio Vermelho

CAJ: Cajazeiras

CB: Cabula-Beiru

$\mathrm{CH}$ : Centro Histórico

CONDER: Companhia de

Desenvolvimento e Regulação

CPO-D: média de dentes

cariados, perdidos e obturados

numa população

DP: Desvio Padrão

FDC: Fundação para o

Desenvolvimento da Ciência

FDI: Federação Dentária

Internacional

IBGE: Instituto Brasileiro de

Geografia e Estatística

IC: Intervalo de Confiança

ICV: Índice de Condições de

Vida

IDH: Índice de

Desenvolvimento Humano

IDI: Índice de Desenvolvimento

Infantil

IS: Índice de Salubridade
ISC: Instituto de Saúde Coletiva

ITA: Itapoã

ITG: Itapagipe

LIB: Liberdade

MEC: Ministério da Educação e

Cultura

OMS: Organização Mundial da

Saúde

OR: Odds Ratio

PACS: Programa de Agentes

Comunitários de Saúde

PL: Pau da Lima

ppmF: parte por milhão de

fluoreto

PSF: Programa de Saúde da

Família

SCV: São Caetano-Valéria

SF: Subúrbio Ferroviário

SiC: Índice de Cárie Significante

SM: Salários-mínimos

SUS: Sistema Único de Saúde

TF: Thylstrup e Fejerskov

UFBA: Universidade Federal da

Bahia 


\section{INTRODUÇÃO}

\section{A EQÜIDADE EM SAÚDE}

O estudo da iniqüidade e da distribuição dos indivíduos no espaço geográfico e de seus reflexos nas condições de saúde está presente na epidemiologia desde o século XIX, nos trabalhos de autores clássicos como Farr, Engels e Virchow. Farr, na Inglaterra, estudou o meio urbano como um ambiente danoso à saúde, assim como desenvolveu o conceito de "distritos saudáveis", utilizando seus achados para mobilizar reformas sanitárias e de saúde. Engels discutiu as condições de vida e saúde da classe trabalhadora naquele mesmo país, considerando os efeitos destas na saúde como cumulativos de uma estrutura social de classes e decorrente do processo de urbanização. Virchow, na Alemanha, abordou o ambiente social e seu papel na determinação de epidemias, concluindo que seria necessário modificar o papel dos serviços de saúde oferecidos à população para conseguir maior resolutividade dos problemas (WAITZKIN 1981).

O termo eqüidade, conceitual e historicamente, está relacionado a questão da justiça, dos deveres e direitos do homem/cidadão e do Estado no sentido de eliminar ou corrigir desigualdades, que nascem das condições de inferioridade fisica, econômica ou social (ALMEIDA 2002).

O termo eqüidade em saúde é discutido, atualmente, a partir de duas vertentes: as diferenças entre os padrões de adoecimento, morte e qualidade de vida entre grupos, e os diferenciais na provisão, distribuição e acesso ao sistema e serviços de saúde. Na primeira abordagem, assume-se que uma parcela da morbi-mortalidade 
desta população é injusta, isto é, evitável ou prevenível, e que existem variáveis sociais, econômicas e de trabalho que tornam certos grupos mais vulneráveis (WHITEHEAD 2000).

Já a eqüidade associada ao cuidado em saúde, envolve a disponibilidade do acesso ao sistema e serviços de saúde; o uso adequado destes serviços em relação aos problemas de saúde, bem como a garantia de qualidade para todos. Resgata, então, a discussão de como formular as politicas e planejar os serviços de saúde em prol da resolutividade frente aos problemas, visto que, em muitos locais, os serviços e práticas de saúde tendem a se distribuir de forma inadequada, com tendência a localização nos grandes centros urbanos, em regiões de melhor renda e com diferenciação em relação a determinados grupos da população (WHITEHEAD 2000).

Entretanto, como destaca ALMEIDA (2002), ao se considerar injustiça e as formas de intervenção sobre a mesma, não se pode desconectar o contexto geral da sociedade, isto é, os valores e princípios morais, éticos e político-ideológicos que orientam a política setorial num país, em um dado momento histórico. Na conjuntura atual de reformas setoriais, como coloca a autora, o princípio da eqüidade tem sido muito associado aos objetivos de eficiência, traduzidas nas políticas de focalização nos mais pobres (grifo da autora) e de privatização.

A eqüidade em saúde não foi um campo muito explorado até 1978, quando na Conferência de Cuidados Primários em Saúde, em Alma Ata, resgatou-se a necessidade de sistemas de saúde com maior cobertura, mais resolutivos, eqüitativos e adequados às necessidades de saúde da comunidade. Tornou-se evidente, então, a demanda por estudos sobre eficiência e sustentabilidade dos sistemas sociais e de 
saúde e a análise da situação de saúde de grupos populacionais para a identificação das iniqüidades e proposição de políticas para a sua redução (GWATKIN 2000).

A partir dos anos 70 e nos anos 80, aumentaram significativamente a magnitude e a natureza dos problemas que afetam as populações, com o agravamento das dificuldades econômicas vividas nos países em desenvolvimento e mudanças nos padrões econômicos e sociais em todo o mundo (críticas e reformulações das políticas de bem-estar social, abertura política e econômica no Leste Europeu). Entretanto, também se intensificaram os esforços em desenvolver estratégias para solucionar os problemas e estabelecer diretrizes para a reforma do setor saúde, este como um elemento mediador capaz de minorar o impacto social das mudanças políticas e econômicas (MENDES 1996). O debate conceitual da eqüidade retoma força, no âmbito das políticas de reforma e de questionamento da extensa intervenção estatal no setor saúde e, na década de 90 , este debate amplia-se preconizando a reforma do Estado e dos sistemas de saúde para atuarem de forma mais eficiente e efetiva frente ao aumento inquestionável das desigualdades (ALMEIDA 2002).

Isto é, mesmo considerando que houve melhoria no estado de saúde humana em todo o globo nos últimos 50 anos, mantém-se ou agrava-se o abismo entre os distintos grupos sociais, conseqüência da economia global, da ordem social e da fragilidade dos sistemas em garantir justiça social (GERSCHMAN e VIANNA 1997)

Um dos estudos mais discutidos mundialmente em relação às iniqüidades sociais e seu impacto no estado de saúde é o Black Report, que aprofunda a análise das relações entre gênero e mortalidade, etnia e mortalidade, moradia e bem-estar urbano e mortalidade, ocupação e mortalidade além de explorar também as diferenças 
no perfil de morbidade e utilização de serviços de saúde. Os resultados, segundo os autores, descrevem:

\begin{abstract}
"As taxas de mortalidade são maiores em homens do que em mulheres em idade produtiva e essa diferença vem aumentando com o passar dos anos (....) as taxas de mortalidade de homens e mulheres da Classe III e IV estão se deteriorando (....) os diferenciais entre classes nas idades de 10 a 14 anos estão aumentando nos últimos dez anos, podendo ser observado um gradiente de classes em doenças do aparelho respiratório e nas doenças infecciosas e parasitárias (....) assim como existem diferenças na disponibilidade e uso de serviços de saúde em áreas mais pobres, resultando num uso desigual dos serviços, decorrente de um complexo de causas - baixa provisão, custo (financeiro, psicológico) e estilo de vida, especialmente dos serviços preventivos."
\end{abstract}

(BLACK et al. 1982,p.64, 74, 75, 76).

KLEINBAUM et al. (1982) descrevem que o objetivo final da epidemiologia, independente dos métodos utilizados, é contribuir para a melhoria da saúde das populações a partir da descrição do processo saúde-doença e da identificação dos fatores causais, tornando possível, a partir da produção e acúmulo de dados empíricos e conhecimentos, direcionar a tomada de decisão em saúde pública. Nesta perspectiva, ABELIN et al. (1987) afirmaram que o processo de adoecimento, de cuidados a saúde e da promoção da saúde não existe num vácuo sócio-cultural, institucional e político, e sim refletem valores, crenças, conhecimentos e práticas da população e de grupos profissionais. Seria necessário, então, o conhecimento da 
complexa rede social de forma a tornar decisões adequadas nas políticas de saúde, segundo os preceitos estabelecidos pela Organização Mundial de Saúde, que preconiza a reorientação de políticas e serviços para as reais necessidades de saúde da população a partir da identificação de prioridades, em busca da eqüidade em saúde.

Ao retomar a discussão da iniqüidade social e em saúde no Brasil, algumas características políticas, sociais e de desenvolvimento são relevantes. Observa-se no país uma das mais desiguais distribuições de renda do mundo, com um desenvolvimento originado a partir de uma economia primário-exportadora, baseada na monocultura, valorização de latifúndios e atividades ligadas à exportação desses bens. Mesmo quando o processo industrial foi introduzido, em meados do século XX, este surgiu a partir do financiamento propiciado pelo ciclo cafeeiro, com grande concentração da estrutura produtiva e financeira e crescimento desproporcional do setor de serviços, que reforçou a concentração de capital e terra e, conseqüentemente, os diferenciais de morbi-mortalidade na população (PINTO 1976).

A partir da década de 80, e por toda a década de 90 , no Brasil, assim como em quase toda a América Latina, se incorpora, no discurso e políticas governamentais, a proposta do Estado Mínimo, baseada no mercado, na propriedade privada e na subordinação da política à economia, com ações como a liberalização da economia, a privatização do patrimônio público e investimento do capital no mercado internacional, de modo a tornar a economia interna competitiva internacionalmente. Estas propostas foram viabilizadas através de políticas de ajuste estrutural, especialmente sob o estigma do combate ao processo inflacionário (GERSCHMAN e VIANNA 1997). 
Nesta lógica, o Estado reduz sua possibilidade de regular o mercado e as atividades produtivas no país e a capacidade de administrar as crises sociais, econômicas e políticas que se colocam. Abre mão da sua função de desenvolvimento da economia de serviços, modos de produção e consumos diferenciados e definição das relações de trabalho, isto é, da intervenção estatal como forma de solucionar as desigualdades sociais (GERSCHMAN e VIANNA 1997).

Durante este mesmo periodo, foi promulgada no Brasil a Constituição de 1988, que incorporou a saúde como um direito social e dever do Estado, vinculada à realização de políticas sociais econômicas e a um Sistema Único de Saúde (SUS) (BRASIL 1988), sendo divergente as propostas contidas na mesma com a discussão mundial de reforma do setor saúde e eqüidade. Assume, segundo DALLARI (1995), a opção pelo "Estado democrático", destinado a assegurar o exercício dos direitos sociais, normatizador da sociedade e responsável pela implementação de políticas públicas. Entretanto, na prática, continua privilegiando, através das políticas, o consenso neoliberal, a eficiência e eficácia como instrumentos de redução dos custos, a liberdade de escolha e a competição entre o público e o privado, criando no país uma dicotomia sobre o papel do "Estado predador versus Estado do bem- estar social" (MENDES 1996, GERSCHMAN e VIANNA 1997).

Desenvolvem-se, então, inúmeros estudos investigando os diferenciais no estado de saúde da população, associando-os aos indicadores sociais, com diversos objetivos: desde subsidiar o planejamento local, políticas e programas de saúde, como o de obter elementos que alavanquem mudanças do modelo de desenvolvimento instituído, ao retratar piores condições de saúde em relação a outros países da 
América Latina e Caribe (PAIM e COSTA 1986, VICTORA et al. 1994, AKERMAN 1997, CASTELLANOS 1997, WALDMAN et al. 1997, NEDEL et al. 1999, SILVA et al. 1999, SOUZA et al. 1999).

Dentre os principais indicadores de saúde aplicados para mensurar as desigualdades estão os coeficientes de mortalidade, com suas mais diversas discriminações: mortalidade infantil (preferencialmente a mortalidade perinatal), a razão de mortalidade proporcional, a mortalidade por causas, além de índices compostos como anos potenciais de vida perdidos (NEDEL et al. 1999) e as brechas redutiveis de mortalidade (CASTELLANOS 1997). Têm-se utilizado, de forma menos sistemática, indicadores de morbidade e de utilização de serviços de saúde através de inquéritos populacionais, estudos de alto potencial analítico e grande interesse para a mobilização de estratégias, embora os mesmos tenham alto custo e razoável complexidade metodológica (ILLSLEY e BAKER 1991, BORRELL 1997).

MORAES (1994) descreve que a lógica de se trabalhar exaustivamente com os dados existentes no país e criar novas fontes de informação, na perspectiva de melhoria da qualidade de vida e na percepção das iniqüidades em saúde é de suma importância para a construção de sistemas de saúde que busquem como princípio a eqüidade. Isto porque, no Brasil, existe ainda escassez na produção de dados epidemiológicos e, aqueles existentes, são pouco explorados na produção de informação em saúde. Deste modo, possibilitar-se-ia subsidio estratégico para implantação de modelos de atenção mais justos, vinculados às demandas e necessidades de saúde da comunidade. 
Uma das possibilidades de recuperar uma abordagem epidemiológica é o uso do espaço geográfico como categoria analítica, tornando possível compreender, de forma dinâmica, a complexa relação e interações que permeiam a ocorrência da saúde e doença na população. A epidemiologia reassumiria um modelo interpretativo sistêmico, visto que a distribuição espacial da doença poderia captar a dinâmica da estrutura epidemiológica (COSTA e TEIXEIRA 1999).

BARMES (1999) afirma que, de modo geral, os dados e a lógica com que são coletadas as informações na saúde bucal, sejam elas nos estudos individuais ou agregados, não tem privilegiado o planejamento, programação e definição de estratégias para o controle das doenças e melhoria do estado de saúde das populações, não contribuindo para um impacto na qualidade de vida.

Neste sentido, este estudo visa descrever os indicadores de cárie dentária e fluorose dentária para o município de Salvador, utilizando o distrito sanitário como espaço geográfico relevante para a determinação das condições de saúde bucal de adolescentes de 12 e 15 anos, visto que nos mesmos são definidas as políticas e práticas de saúde no âmbito público. Além disso, considerou-se importante a análise segundo tipo de estabelecimento de ensino, como variável discriminadora do nível sócio-econômico, de forma que, juntamente a análise espacial, seja possível identificar tendências e prioridades de intervenção na saúde bucal do município, para garantir o acesso, cobertura e resolutividade na atenção à saúde bucal e contribuir para a organização das práticas e alocação de investimentos neste setor. 


\section{REVISÃO DA LITERATURA}

\section{A EQÜIDADE EM SAÚDE BUCAL}

Em saúde bucal, os principais problemas de interesse para a coletividade são: cárie dentária, doença periodontal, fluorose dentária, oclusopatias, câncer e anomalias congênitas, incluindo as fissuras lábio-palatais, definidos a partir de critérios como a prevalência da doença na população, o interesse social despertado pela mesma, a possibilidade de intervenção e controle da patologia e o custo envolvido (CHAVES 1986, PINTO 1992). Neste trabalho, somente a cárie e a fluorose dentária serão discutidos, em suas interfaces com a eqüidade em saúde.

\subsection{Cárie dentária}

A cárie é uma doença multifatorial, que, além dos fatores físicos e biológicos da cavidade bucal como os microorganismos, saliva e anatomia dentária, tem fatores comportamentais, demográficos e sócio-culturais como hábitos de higiene e dietéticos, idade, sexo, e o grau de desenvolvimento do país e seus investimentos nos setores saúde e educação como determinantes (DUMMER 1990).

PETERSON (1990) e LOCKER (1993) destacam que se têm usado as mais distintas explicações teóricas para as desigualdades, quando se discute as variáveis sociais em saúde bucal. Entre elas a instrumental, que utiliza empiricamente variáveis como ocupação, renda e escolaridade, a teoria da seleção natural; o materialismo ou 
estruturalismo, que atribui os diferenciais a processos históricos de como os meios de produção propiciaram medidas distributivas; e a cultural/ comportamental, baseada em diferenças individuais ou coletivas no conhecimento, atitudes e comportamento em relação à saúde.

Os diferenciais na prevalência e severidade da cárie dentária, decorrentes de condições de vida das populações, foram investigados sistematicamente desde o início do século XX (MITCHELL 1933, HYDE 1944), sendo que os resultados descritos na literatura foram conflitantes durante muitas décadas.

MANSBRIDGE (1959) descreveu maior prevalência de cárie dentária em crianças de 9 a 13 anos que freqüentavam escolas particulares (segundo o autor, elemento discriminador do nível sócio-econômico mais alto), embora neste mesmo grupo estivesse presente uma menor taxa de perda dental. Resultados similares também foram descritos por ROWE et al. (1976) nos Estados Unidos e DE LA ROSA (1978), no México, com crianças de 6 a 15 anos.

Entretanto, outros autores da década de 70 e 80 relatavam uma situação oposta, isto é, uma maior freqüência de cárie dentária em escolares de menor nivel sócio-econômico. MARTINSSON (1975), analisando escolares de 14 anos de idade em Malmü, na Suécia, encontrou uma associação entre a alta ocorrência de cárie dentária e níveis sócio-econômicos muito baixos, resultado semelhante ao obtido por BARNARD (1976), na Austrália, em que crianças oriundas da classe operária mostraram maior prevalência de cárie, gengivite e maior necessidade de tratamento. HAUSEN et al. (1981) também encontraram menor freqüência da doença em crianças 
de nivel social mais alto, sendo que as diferenças entre as classes intermediária e baixa foram pequenas.

Existe também estudo que assinala uma ausência de associação da cárie dentária com indicadores sociais como o de SGAN-COHEN et al. (1984), que descrevem apenas uma maior necessidade de tratamento restaurador em classes sociais de menor renda.

Mais recentemente, os trabalhos são quase unânimes em detectar piores condições de saúde bucal em crianças de menor renda, sendo que os autores já identificam o acesso a fluoretos, através da fluoretação das águas de abastecimento público ou da pasta fluoretada, como elemento capaz de minimizar os diferenciais entre classes ou níveis sócio-econômicos (TREASURE e DEVER 1994, SLADE et al. 1996, GELBIER 1998).

A utilização dos serviços de saúde e a participação em práticas de promoção da saúde bucal também têm se destacado como fatores associados aos diferenciais de morbidade da cárie dental. Como elementos limitadores do cuidado à saúde bucal tem-se o alto custo da assistência odontológica (VARGAS e MANSKI 1999), as dificuldades de acesso aos serviços em áreas mais carentes, pouca adesão às práticas preventivas nos estratos sociais de menor renda (PRENDERGAST et al. 1999) e a imigração, associada com diferenças sociais, de limitações na mobilidade social e barreiras linguísticas (WITTENBERG 1994, SLADE et al. 1996, LOCKER et al. 1998, HJERN et al. 2001).

Vale ressaltar que os estudos que analisam o impacto dos serviços de saúde na prevalência e severidade da cárie dentária têm destacado a relevância de medidas 
preventivas como estratégias de educação em saúde, a fluoretação das águas de abastecimento público, o uso de dentifrícios fluorados e bochechos com flúor em detrimento de medidas assistenciais, de baixo impacto epidemiológico (PINTO 1989, TREASURE e DEVER 1994, NADANOVSKY e SHEIHAM 1995, SLADE et al. 1996, GELBIER 1998, GAUGHWIN et al. 1999).

DIEHNELT e KYAK (2001), analisando o gasto per capita com saúde e o CPO-D (média de dentes permanentes cariados, perdidos e obturados numa população) em 109 países com economia de mercado descrevem um alto índice de cárie associado ao baixo investimento no setor saúde. Os autores destacam a importância dos sistemas de saúde como mediadores das desigualdades em saúde, reduzindo o impacto das diferenças sociais e econômicas.

A deteç̧ão dos diferenciais na condição de saúde bucal através do uso de categorias analíticas como o espaço social, definido por limites geográficos, administrativos ou indicadores sociais como descrevem os estudos de BRAGAMIAN e RUSSEL (1971), ELLEY e LANGFORD (1992), NADANOVSKY e SHEIHAM (1995), AMSTUTZ e ROZIER (1995), PETRIDOU et al. (1996) e JONES et al. (1997) ainda é pouco comum nos estudos epidemiológicos em saúde bucal.

BRAGAMIAN e RUSSEL (1971) examinaram 1.486 estudantes negros e brancos, de 14 a 17 anos de idade, da zona urbana em duas regiões dos Estados Unidos - área norte (Detroit) e área sul (Columbia) através do índice CPO-D. Entretanto, os autores não encontraram diferenças significativas entre as duas áreas geográficas, com um CPO-D igual a 10,42 e 11,01 respectivamente, bem como 
também não foram identificadas diferenças em relação a etnia e acesso a assistência à saúde.

ELLEY e LANGFORD (1992) utilizaram o indicador "ACORN", que é um sistema de classificação de áreas, composto de características demográficas, sociais, econômicas e de moradia a partir de dados do censo demográfico, comparando os períodos de 1987 e 1989/90 como forma de mapear áreas de risco social e, por conseguinte, prioritárias de intervenção. Os autores associaram este indicador à história de cárie dental em 2.482 crianças de cinco anos de idade. Embora os autores tenham encontrado associação positiva entre as piores áreas e precária condição de saúde bucal, o gradiente da associação foi reduzido na condição social intermediária.

NADANOVSKY e SHEIHAM (1995) analisaram a taxa de redução do CPOD, ajustada entre 1960-85, aos 12 ou 14 anos de idade, em 18 países industrializados, e associaram-na a indicadores sócio-econômicos e à presença de serviços odontológicos, discriminada a partir da taxa de dentistas em relação à população. Foram consideradas relevantes as variáveis: nivel educacional do país, o acesso à pasta dental fluoretada, explicitando que a renda ou posição social exerce importância fundamental na opção do consumo de métodos preventivos, no acesso a assistência odontológica e nas restrições impostas em relação ao estilo de vida, com as maiores reduções anuais descritas para a Dinamarca (13\%), Finlândia (8\%), Noruega (7\%) e Holanda, Suécia e Reino Unido, com 6\%. Os autores defendem a importância dos estudos ecológicos na avaliação do estado de saúde das populações e identificação de variáveis globais, embora explicitem suas limitações para comparações entre países em função da validade dos dados. 
AMSTUTZ e ROZIER (1995) reforçam que, para qualquer área da saúde, identificar indivíduos que poderão desenvolver as doenças é um elemento essencial para direcionar melhores decisões nas políticas, e para isso, identificar marcadores de grupos populacionais, e não só individuais é uma etapa necessária. Com este objetivo, estudaram agregados de 335 classes de escolares, selecionadas de 250 escolas da Carolina do Norte, ponderadas por região geográfica, com um total de 6.650 estudantes de ensino fundamental, tentando associar a prevalência de cárie dental com variáveis como idade, sexo, participação nos programas nacionais de saúde, nivel educacional dos pais, exposição ao flúor, acesso e distribuição do sistema de saúde, região geográfica e densidade populacional do local. Os autores encontraram associação positiva entre a maior experiência de cárie dentária e aumento da média de idade da classe $(r=0,21)$, a taxa de dentistas na população na região $(r=0,25)$, o percentual da cobertura do $M E D I C A I D(r=0,19)$, e associação negativa em relação a densidade populacional da região $(r=-0,37)$ e o tempo de exposição ao flúor na água $(r=0,29)$, reforçando a importância do sistema de saúde em minimizar as iniqüidades no estado de saúde bucal.

PETRIDOU et al. (1996) dividiram a cidade de Atenas em três áreas e examinaram 380 alunos de 12 a 17 anos de três escolas, uma de baixa renda, uma de alta renda e uma da zona rural e estudaram a composição da dieta e a importância do estilo de vida em cada local em relação à prevalência de cárie dental. Aos 12-13 anos de idade, o CPO-D foi de 3,7 , com $24,3 \%$ das crianças livres de cárie. Os autores concluíram através da regressão múltipla que a severidade da doença é maior na zona rural $(\beta=1,3)$, seguida da zona urbana de menor renda, e que a dieta não foi um 
elemento importante na diferenciação entre os grupos, visto que a ingestão de açúcar, óleos, carboidratos e gordura mostrava-se alta em todas as categorias.

JONES et al. (1997) confirmaram a associação entre cárie dental e privação social mensurada pelo índice Carstairs- $Z$ (densidade populacional habitacional, desemprego masculino, percentual de lares sem carro e percentual de lares nas Classes IV e V, isto é, trabalhadores que executavam trabalhos manuais e sem formaçào escolar de nível superior) em 15 áreas de saúde na Escócia. Na idade de 12 anos, os autores descreveram um $\mathrm{CPO}-\mathrm{D}=2,08$ nas 5.920 crianças examinadas, e encontraram um alto coeficiente de correlação $(r=0,72)$ ao índice Carstairs-Z, propondo maior ênfase em ações preventivas nas regiões de maior risco.

Revisando os estudos no Reino Unido sobre a eqüidade na distribuição da cárie dentária, WATT e SHEIHAM (1999) descreveram que, aos 12 e 15 anos de idade, os maiores índices de cárie (CPO-D) estavam associados a privação material, às classes sociais de menor renda $(\mathrm{OR}=3,4)$ e ao absenteísmo aos serviços de saúde $(\mathrm{OR}=1,3)$. Os mesmos autores identificaram também que, na área norte, encontravam-se, em todas as idades, os piores indicadores em relação a área sul. Especificamente aos 12 anos, o CPO-D descrito para a primeira foi de 1,9 e para a segunda de 0,8 , e estas diferenças eram decorrentes da privação material e do uso de estratégias de ação pouco adequadas para estes grupos, pelos serviços de saúde.

É consenso que houve mudanças nos padrões da cárie dental nos últimos 20 anos, com um declínio significativo no mundo ocidental (BARMES 1999), incluindo o Brasil (MOYSÉS 2000), estando os altos índices da doença restritos a populações de alto risco, marginalizadas, de menor renda, imigrantes e residentes das áreas rurais. 
NADANOVSKY e SHEIHAM (1995) atribuem esta redução, no mundo, a mudanças no padrão de consumo de açúcar, adoção de diversos métodos preventivos, com a difusão do uso dos fluoretos, expansão da cobertura do tratamento odontológico, mudanças nos critérios diagnósticos, bem como a difusão no uso de antibióticos e melhorias na higiene bucal. Já no Brasil, NARVAI (1996) relata que a redução da ocorrência de cárie dentária seria decorrente de políticas como a fluoretação das águas de abastecimento público, difusão do flúor tópico por meio de programas escolares, adição de flúor aos dentifrícios e uma maior cobertura e resolutividade dos serviços de saúde.

Diversos autores descrevem diferenças nos índices de cárie dentária em jovens, utilizando como indicadores discriminatórios a renda per capita (MALTZ e SILVA 2001), a ocupação do chefe da família (RIBEIRO 1974), o tipo de escolapública ou privada (WITT 1992, KNUPP 1997, NARVAI et al. 2000), áreas geográficas definidas pela renda ou por indicadores sociais compostos (PATUSSI 2000, MOYSÉS 2000) e diferenças no acesso aos serviços de saúde (PINTO 1989, CÉSAR et al. 1999), geralmente identificando piores condições de saúde bucal nos grupos de menor renda e piores indicadores sociais.

No Brasil, o primeiro estudo sobre a experiência de cárie dentária, utilizando o índice CPO-D, data de 1952, quando Chaves e Fraenkel realizaram um levantamento na cidade de Aimorés (MG), em 955 crianças de 7 a 14 anos das cinco escolas existentes, encontrando uma média de 9,17 dentes cariados, perdidos ou obturados aos 12 anos de idade e compararam os resultados a outros levantamentos realizados pelo mesmo grupo neste ano no Rio de Janeiro (CPO-D=12,44 aos 12-14 
anos de idade) (CHAVES e FRAENKEL 1956). FREIRE (1956) relatou também que, num estudo de avaliação da fluoração das águas de abastecimento público em Baixo Guandú, em um primeiro inquérito utilizando o índice CPO-D em 1953, encontrou um valor de 8,61 aos 12 anos de idade e 12,71 aos 15 anos de idade, num total de 921 crianças examinadas. Já no exame realizado em 1956, envolvendo 636 escolares, o autor descreve uma redução da prevalência de cárie dentária, com um CPO-D de 7,26 e 8,61 aos 12 e 14 anos de idade respectivamente, visto que, neste ano, não foram examinados adolescentes aos 15 anos de idade.

Neste periodo, desenvolvia-se nestas e em outras regiões do país o Sistema Incremental de Atendimento, introduzido em 1952 pela Fundação SESP, em Aimorés (MG), baseado na assistência odontológica para escolares de forma programada e sistemática, com o objetivo de aumentar ao máximo a produtividade na forma de número de pacientes atendidos, e reduzir as necessidades de tratamento em crianças de 6 a 14 anos. $\mathrm{O}$ mesmo também pressupunha a complementariedade de uma fase preventiva, com aplicações tópicas de flúor até o início da década de 70 e posteriormente o uso de bochechos fluorados, além da recomendação da fluoretação das águas de abastecimento público (DINIZ 1987, MARTILDES 1992).

A possibilidade de uma estratégia racionalizadora na prestação da assistência odontológica fez com que o mesmo se transformasse num modelo de atendimento no Brasil até a década de 80 , focalizando prioritariamente crianças de 7 a 12 anos de idade, especialmente nos programas de odontologia escolar. Entretanto, avaliações do mesmo realizadas em municípios dos estados da Bahia e São Paulo não identificaram impacto epidemiológico na redução dos índices de cárie dentária, em relação às 
crianças que não possuiam nenhuma assistência odontológica sistemática, como relataram os estudos de DINIZ (1987) e MARTILDES (1992).

DINIZ (1987), descreveu os resultados do sistema incremental na Bahia, observando que não foram registradas alterações favoráveis no nível de saúde bucal. $\mathrm{O}$ autor reforça a incapacidade/iniqüidade do modelo na seleção das crianças para entrada no sistema, além da importância de se identificar o risco de ataque de cárie para definição de estratégias de ação. Identificou em 1979, em Xique-Xique/BA, um CPO-D de 5,3 aos 12 anos de idade; e de 8,0 em Itajuipe/BA, não detectando diferenças no índice em relação a outros municípios do estado sem o programa.

Neste mesmo periodo SILVA et al. (1984) publicaram um estudo em que os autores examinaram a condição dos primeiros molares permanentes em 1.202 crianças de escolas públicas, de 7 a 14 anos, divididas em 7 grupos etários, em Salvador, Bahia, a partir do indice CPO-D. Os autores identificaram o alto grau de comprometimento dos primeiros molares permanentes ( $85 \%$ aos 12 anos de idade), com cerca de $8 \%$ dos mesmos indicados para extração, sem diferenças entre os sexos.

MARTILDES (1992), em São José dos Campos/SP, comparou três grupos de 120 escolares: o primeiro submetido ao programa incremental clássico, o segundo a um programa incremental, em que a fase preventiva foi modificada para uma associação de métodos de acordo com a atividade de cárie; e, um terceiro grupo controle, que não teve nenhuma assistência odontológica sistemática. Foram encontrados valores de CPO-D de 4,04; 4,87 e 5,71 respectivamente, aos 12 anos de idade. $\mathrm{O}$ autor concluiu que, após o teste estatístico das médias, não houve diferença significativa entre os CPO-D's dos grupos, embora em todos tenha sido observada 
uma redução do índice epidemiológico descrito para o município no ano de 1979, que foi um $\mathrm{CPO}-\mathrm{D}=8,05$.

A maior crítica ao sistema incremental foi, de uma forma geral, a falta de eficácia da fase preventiva do programa, que não incorporou de forma significativa a educação sanitária e a evolução do conhecimento científico e técnico da odontologia preventiva, perpetuando uma assistência individual e curativa, de baixo impacto epidemiológico (DINIZ 1987, MARTILDES 1992, NARVAI 1994) e a exclusão da maior parte da população, que dependia de políticas que privilegiavam a prática clínica privada, de alta tecnologia, cara e inacessível à população, já que, no setor público, predominava a assistência mutiladora e emergencial, restrita à remoção de focos infecciosos.

No ano de 1974, como parte do esforço no controle da cárie dentária, foi aprovada a lei federal 6050 que determinavava às empresas responsáveis pelo tratamento da água a fluoretar as águas de abastecimento público, onde houvesse estação de tratamento. A lei foi regulamentada em 1975, embora também determinasse que "no local em que não existe a possibilidade da fluoretação, outros processos preventivos deveriam ser utilizados" (BRASIL 1975).

Na década de 80 relatava-se o grave perfil epidemiológico da população brasileira, resultado de um modelo de atenção ineficaz e ineficiente, onde predominava a descoordenação, má distribuição da rede assistencial e dos recursos, baixa cobertura, enfoque curativo e o caráter mercantilista e monopolista do atendimento odontológico, aspectos descritos na I Conferência Nacional de Saúde Bucal (BRASIL.MS 1986), mesmo com o registro de algumas experiências 
municipais positivas, com ênfase nas necessidades de saúde da população e descentralização dos serviços.

O debate sobre os modelos de atenção e a consolidação de um novo referencial teórico-metodológico na determinação do processo saúde-doença bucal ganha amplitude com o movimento da Reforma Sanitária Brasileira, na busca por um modelo de prática que incluísse a saúde bucal no campo das demandas e necessidades de saúde da população e que tivesse resposta e respaldo no setor público. Só foi sistematizado, contudo, por NARVAI (1994):

\begin{abstract}
'Politização dos agentes etiológicos- o corpo biológicoa boca incluída- tem usos diferentes segundo classes sociais e a respectiva inserção dessas classes e suas frações no processo produtivo (...) os agravos biológicos à saúde são condicionados pelos distintos modos de viver- modos sociais de viver- os quais, por sua vez, são engendrados pela e na própria sociedade humana"
\end{abstract}

(BOTAZZO apud NARVAI 1994, p. 73,74).

Entretanto, ainda são poucos os trabalhos que discutem iniqüidade na distribuição das doenças bucais em populações, com ênfase na incorporação da epidemiologia na prática dos sistemas e serviços de saúde.

O primeiro estudo de abrangência nacional e que resgatou no pais a discussão dos diferenciais das doenças bucais foi realizado pelo Ministério da Saúde em 1986 em 16 das 27 capitais brasileiras, representativos para as cinco macro-regiões, segundo faixa de renda familiar- até 2 , de 3 a 4 e 5 ou mais salários-mínimos (SM). Este levantamento estudou a cárie dentária, doença periodontal e uso e necessidade de 
prótese nas idades de 6 a 12 anos (escolares), e nas faixas etárias de 15-19 anos (escolares) e 35-44 anos e 50-59 anos, identificados a partir de visitas domiciliares (BRASIL.MS 1988).

Como resultado descreveu-se uma grave condição de saúde bucal da população brasileira em todas as faixas etárias. $\mathrm{Na}$ idade de 12 anos, o CPO-D encontrado foi de 6,65 para o Brasil, com uma relação inversa entre o índice de cárie e a renda familiar: 6,98 até $2 \mathrm{SM} ; 6,45$ entre 3 e 4 SM e 5,87 no estrato de 5 e mais SM. Quando se analisou somente a região Nordeste, o CPO-D foi de 6,90, e houve discrepâncias nas distintas faixas de renda: $\mathrm{CPO}-\mathrm{D}=6,98$ no estrato até $2 \mathrm{SM} ; 6,11$ de 3 a 4 SM e de 7,9 no de 5 e mais SM (BRASIL.MS 1988).

Já na faixa etária de 15 a 19 anos, obteve-se tanto para o Brasil como para a região Nordeste uma relação inversa entre o CPO-D e a renda familiar. No Brasil o índice foi de 13,$54 ; 12,67$ e 11,90 nos estratos de até $2 \mathrm{SM}$, de 3 e $4 \mathrm{SM}$ e 5 e mais SM respectivamente, e para a região Nordeste os valores encontrados foram próximos, de 13,$14 ; 12,14$ e 10,78 nesta mesma ordem.

Dez anos após o primeiro estudo, foi repetido, nas grandes capitais, o levantamento em escolares de 6 a 12 de idade, que, apesar das críticas que recebeu quanto ao pequeno número da amostra examinada, a exclusão de unidades amostrais, insuficiências na calibração das equipes e pouca abrangência nacional, revelou a significativa redução da cárie dental no país (BRASIL.MS 1996, OLIVEIRA 1998), cumprindo inclusive a meta proposta pela OMS para o ano 2.000 , de no máximo três dentes acometidos por cárie aos 12 anos de idade. Observou-se também, em vários municípios com baixos índices de cárie, a formação do grupo de polarização, isto é, 
um percentual pequeno de crianças concentrando altos índices da doença, constituindo-se grupos específicos de risco.

Entretanto, grandes diferenças na distribuição da cárie dentária foram detectadas entre as regiões e os distintos municipios. Os maiores índices, na idade de 12 anos, foram registrados na região Norte (CPO-D=4,27), seguida da Nordeste, com $\mathrm{CPO}-\mathrm{D}=2,88$ (exceções às cidades de Aracaju, com 1,50 e Salvador, 1,53). Na região Centro-Oeste o CPO-D foi de 2,85 (com melhores condições relativas ao Distrito Federal, 1,90); na Sul, 2,41 e Sudeste, 2,06 (BRASIL.MS 1996).

Em 2002, a OMS propôs para os países que houvessem cumprido a meta estabelecida para o ano 2.000 , a utilização de um novo índice denominado "SiC" (Significant Caries Index), estabelecendo para o ano de 2.015 uma nova meta de uma média de 3 dentes atingidos por cárie segundo este indicador (WHO 2002). Este índice, proposto por BRATTHALL, no ano 2.000, é representado pelo cálculo da média apenas nos indivíduos que apresentam os 30\% maiores valores do CPO-D na distribuição da doença, na idade de 12 anos. Segundo o autor, esta forma de apresentação representaria melhor a população de alta atividade de cárie, grupo alvo para as estratégias de controle e prevenção da doença e evitaria as grandes distorções do CPO-D, provocadas pelo grande número de individuos livres de cárie nos grupos em que este índice já é baixo, permitindo que, em populações em que já existe o controle da cárie dentária através de estratégias como o uso extensivo do flúor e ações de saúde coletiva, fossem adotadas medidas específicas para áreas geográficas e, posteriormente, individuos de alto risco. 
BRATTHALL (2000) exemplifica com os resultados do CPO-D de alguns países no ano 2.000 e o cálculo do novo índice, como os Estados Unidos- 2,00 e 5,21; França- 2,1 e 4,63; Alemanha- 1,7 e 4,3; reforçando que o baixo CPO-D poderia induzir nestes paises a suspensão de medidas de controle para a doença, e o SiC reforça a necessidade da continuidade das mesmas, além da adoção de outras medidas de risco.

Apesar da proposta ter sido pouco discutida no Brasil, o indicador tende a ser adotado internacionalmente para a comparação, por permitir a identificação de subgrupos de alto risco e ser de extrema relevância para o controle da cárie dentária.

Resgatando o uso de variáveis sócio-econômicas como preditoras da ocorrência de cárie dental em populações, a partir dos dados do levantamento de 1996 disponibilizados pelo Ministério da Saúde para cada macro-região, MOYSÉS (2000) tentou correlacionar o IDH (Índice de Desenvolvimento Humano), reflexo da renda, educação, atenção à infầncia, habitação e longevidade ao CPO-D por macro-região do país. $\mathrm{O}$ autor considerou que, apesar de nacionalmente, o IDH corresponder a 0,809 (considerado alto) existem desigualdades marcantes no país, sendo os menores IDH's registrados para as regiões Norte e Nordeste, com o índice de 0,548.

Ele encontrou uma correlação de $22 \%$ entre os dois indicadores, mostrando razoável poder explicativo do IDH, e o alto potencial desta abordagem para detecção dos diferenciais entre os grupos, de forma a estabelecer práticas programáticas e intervenções locais. Afirma, também, que maior correlação pode não ter sido possível porque, mesmo dentro de cada macro-região, são significativas as diferenças entre os municípios, com uma grande heterogeneidade entre os estratos (MOYSÉS 2000). 
RIBEIRO (1974) analisou 539 estudantes leucodermas matriculados em escolas oficiais de Guaratinguetá (SP), na idade de 12 a 15 anos, coletando o índice CPO-D e o nível sócio-econômico, obtido pela ocupação dos pais, dicotomizado posteriormente em dois niveis (alto e baixo). $\mathrm{O}$ autor observou que os estudantes de nível sócio-econômico alto, aos 12 anos de idade, apresentaram um CPO-D=9,0, enquanto que nos de nível sócio-econômico baixo este valor correspondeu a 10,28. Aos 15 anos de idade esta relação se inverteu, com um CPO-D=14,02 no nível alto e 13,56 no baixo, embora em ambas as idades o número de dentes perdidos fosse menor no maior nível sócio-econômico.

Mais recentemente, PERES et al. (2000) investigaram dois grupos de 50 crianças de 12 anos de idade em Florianópolis (SC): um livre de cárie ou com apenas um dente comprometido pela cárie e outro com cinco ou mais dentes afetados, na tentativa de associar a severidade da doença a indicadores de renda, densidade populacional do domicílio, ocupação e escolaridade dos pais, procura por serviço odontológico e dieta. Os autores relataram uma maior proporção de crianças com maior severidade da cárie nas famílias com renda abaixo de cinco salários-mínimos $(\mathrm{OR}=3,56)$ e nas famílias que relataram um consumo de doces maior do que duas vezes ao dia $(\mathrm{OR}=4,41)$.

Na faixa etária escolar, no país, a principal abordagem em relação à diferenciação de nível sócio-econômico se dá através da dicotomização entre escolares freqüentadores de escolas públicas e de escolas privadas. WITT (1992) desenvolveu um estudo, em Porto Alegre, com 180 crianças de duas escolas privadas, consideradas como de alto nível sócio-econômico e uma escola pública, de baixo 
nível sócio-econômico, testando as diferenças entre o CPO-D e CPO-S entre os dois estratos. A autora encontrou um CPO-D de 2,8 para sua população, sem diferenças estatisticamente significativas entre a escola pública $(3,1)$ e as escolas privadas $(2,5)$, com uma maior concentração das superficies restauradas no maior nível sócioeconômico. Quando analisado o CPO-S, a diferença observada foi significativa (4,9 e 3,6 respectivamente), sendo que $83 \%$ das lesões estavam concentradas nos primeiros molares permanentes.

KNUPP (1997) descreveu que, em 400 escolares de 7 a 10 anos de idade, de Niterói, de níveis sócio- econômicos distintos determinados pelo tipo de escola (pública e privada) e sua localização geográfica no municipio, foi encontrada apenas uma tendência de que os maiores índices de cárie estivessem naqueles de mais baixo nível sócio-econômico (escolas públicas), com apenas 17,3\% das crianças livres de lesão. A única diferença percebida foi uma maior severidade da cárie em crianças de escolas públicas e maior acesso ao tratamento restaurador nas escolas privadas.

Resultado semelhante foi descrito por NARVAI et al. (2000), no município de São Paulo, ao examinar 2.491 escolares de 103 unidades de ensino da rede pública e privada, nas idades de 5 a 12 anos em um levantamento no ano de 1996 . Os autores não encontraram diferenças significativas nos índices de cárie em escolares de estabelecimentos públicos ou privados, com um CPO-D de 2,33 e 1,95 respectivamente. Entretanto os autores destacam que, quando se analisa a composição dos valores do índice, os dentes cariados apresentam percentagens maiores em escolas públicas comparativamente às escolas privadas, com uma situação inversa em relação aos dentes obturados. Detectou-se também a grande redução da doença cárie 
entre os anos de 1986 e 1996, com um percentual de 68,2\% e a presença do fenômeno de polarização, reafirmando a necessidade de propôr metodologias para identificar grupos mais vulneráveis.

Embora se coloque seguidamente o baixo poder discriminatório do tipo de financiamento da escola como forma de análise, autores como MOURA et al. (1996) e MALTZ e SILVA (2001) conseguiram detectar diferenciais no estado de saúde bucal, com piores indicadores da doença (prevalência de cárie) em estudantes de escolas públicas.

MOURA et al. (1996), em Araraquara, examinando 240 escolares de 6 a 11 anos (120 da rede pública e 120 da particular) encontrou, aos 11 anos de idade, um $\mathrm{CPO}-\mathrm{D}=7,95$ em alunos de escola pública e de 1,95 nos de escola privada, diferença esta estatisticamente significativa, embora o CPO-D encontrado nas escolas públicas estivesse muito acima dos padrões relatados em outros levantamentos epidemiológicos no município e no estado de São Paulo. Descrevem também, como nos estudos anteriores, um maior percentual do componente cariado na rede pública e maior percentual de individuos livres de cárie na rede privada.

MALTZ e SILVA (2001) analisaram o CPO-D e variáveis sócioeconômicas (nível educacional, renda familiar, número de pessoas residentes no domicílio, acesso à tratamento odontológico e a compostos fluorados) em uma amostra de mil escolares de 12 anos de idade, de escolas públicas e privada de Porto Alegre (RS), região que possui água fluoretada desde 1975, com uma concentração média de 0,7 a $1 \mathrm{mg} / \mathrm{l}$. As autoras identificaram um maior CPO-D e menor proporção de indivíduos livres de cárie nos alunos da rede pública- 2,48 e 27,5\% 
respectivamente, em relação àqueles da rede privada $(1,54$ e 47,5\%) e também uma associação com a alta severidade da doença nas crianças cujos pais possuíam baixa escolaridade. Destaca-se, também, que a composição do índice CPO-D é diferenciada entre os dois grupos, já que nas escolas privadas não existiam unidades perdidas e havia um predomínio do tratamento executado, enquanto nas públicas predominava o componente cariado, indicando a dificuldade de acesso ao tratamento restaurador neste grupo.

Como forma de superar as dificuldades da abordagem individual e resgatar o espaço geográfico e histórico na determinação social das doenças bucais, PATUSSI (2000) realizou, no Distrito Federal, um estudo de associação entre 5 zonas, discriminadas pela renda média familiar e a prevalência de cárie dentária, examinando 1.025 escolares de 12 anos de idade, sendo 174 na zona A, 221 na B, 210 na C, 222 e 198 nas zonas $D$ e $E$ respectivamente.

A região $A$, com melhor condição sócio-econômica, foi a que apresentou os indices mais favoráveis de cárie dentária, com um CPO-D=1,8 (1,5-2,1)95\%IC e $43,7 \%$ de crianças livres de cárie. Os piores resultados foram encontrados no estrato de renda intermediário (C), com um CPO-D=3,5 (3,1-3,8)95\% IC e 16,2\% de crianças livres de cárie, enquanto nas zonas B, D e E os valores do CPO-D variaram entre 2,5 e 2,9 , sem diferenças estatisticamente significativas, e com $24,3 \%$ a $30 \%$ de crianças livres de cárie.

O autor afirmou que o Distrito Federal tem algumas peculiaridades em relação a outros locais no país: é a região que concentra a maior renda per capita do país e tem a menor taxa de analfabetismo. Mesmo com estas características, está presente 
nos escolares pertencentes às áreas de maior renda, melhor condição de saúde bucal, maior percentual de dentes restaurados e menor de dentes cariados. Entretanto, o próprio autor apontou que outras variáveis, como a distribuição da rede assistencial, não foram consideradas neste estudo, bem como a qualidade dos serviços prestados.

BALDANI et al. (2002) correlacionaram, por meio da regressão linear simples, o CPO-D aos 12 anos de idade fornecidos por 357 municípios de estado do Paraná com índices globais como o Índice de Desenvolvimento Humano-IDH, Índice de Condições de Vida-ICV (composto por vinte indicadores em cinco dimensões: renda, educação, infância, habitação e longevidade), Índice de Salubridade-IS (ranking composto por 29 indicadores sociais, de saúde e de serviços, organizados nas categorias de mortalidade, morbidade, sócio-ambientais e oferta de serviços), Índice de Desenvolvimento Infantil-IDI (cobertura vacinal contra sarampo, grau de escolaridade dos pais, renda familiar, acesso a água tratada, entre outros) além de outros indicadores relativos à renda, moradia e escolaridade.

Os autores identificaram que a maior parte dos municípios (45,94\%) apresentava alta prevalência de cárie, com um CPO-D=5,38; e 28,01\% classificavamse como de prevalência moderada, com uma relação inversa entre severidade da doença e porte do município. Os níveis de cárie dentária e os indicadores globais de desenvolvimento apresentaram correlação negativa, indicando a tendência de municipios com melhores condições de vida apresentarem menores índices do agravo, e esta mesma correlação negativa se repetiu para as medidas de renda, indicadores de escolaridade, percentual de ligações à rede de abastecimento de água e aglomeração domiciliar. 
Avaliou-se, nesse mesmo trabalho, as médias do CPO-D entre os municípios que apresentavam flúor no sistema de abastecimento público de água em relação aos que não aplicavam este método, encontrando diferenças significativas nos valores

obtidos do índice- 5,05 e 5,95 respectivamente (BALDANI et al. 2002), reforçando a efetividade deste método no controle da doença e como instrumento para minorar as iniqüidades em saúde bucal.

\subsection{Fluorose dentária}

A fluorose dentária origina-se da exposição do germe dentário durante o seu processo de formação a altas concentrações do íon flúor. Como conseqüência, têm-se defeitos de mineralização do esmaite dentário, com alterações de coloração e forma em casos mais graves, com severidade diretamente associada à quantidade de fluoreto ingerida (DEN BESTEN 1999).

Além da dosagem de flúor, têm-se como fatores que interferem na severidade da doença os períodos de remodelamento ósseo, pois constituem-se fases de maior absorção do flúor; o baixo peso corporal ou estado nutricional deficiente, alterações da atividade renal e da homeostase do cálcio. Dentre os fatores ambientais, a altitude é considerada o fator mais relevante (DEN BESTEN 1999). Nesse sentido, a alteração é mais freqüente em dentes de mineralização tardia (dentição permanente), em crianças de baixo peso ou precário estado nutricional, o que pode concentrar a doença em áreas de maior risco a estes problemas, sendo as faixas etárias da primeira e segunda infầncia consideradas críticas à ingestão de excesso do flúor sistêmico e, conseqüentemente, dos seus efeitos maléficos (FEJERSKOV et al. 1994). 
Revisando os diferenciais na prevalência e distribuição da fluorose dentária segundo condição social, econômica ou de saúde, destaca-se o estudo de VILLA e GUERRERO (1996), que analisou crianças de 8 anos de idade, no Chile, estratificadas por nivel sócio- econômico. Os autores identificaram maior prevalência de fluorose em crianças do estrato social de renda mais baixa, justificada pelos diferentes níveis de ingestão dietética, especialmente o chá preto, diferenças no aleitamento e uso de alimentos e bebidas com flúor e nos padrões de ingestão de água e acesso aos dentifrícios fluoretados.

Os estudos epidemiológicos desenvolvidos no mundo, na década de 90 , descrevem diferenças na prevalência da fluorose, que variam desde a quase ausência da doença nas populações $(0,2 \%)$, até proporções maiores que $90 \%$ (AKPATA et al. 1997, DOWNER 1994). Em geral, as altas prevalências estão presentes em locais onde existem fontes naturais com alto teor de flúor ou ingestão de múltiplas fontes desse ín e, historicamente, tem apresentado a fluorose de forma endêmica em todas as faixas etárias em regiões da África (EL NADEF e HONKALA 1998, KLOSS e HAIMANOT 1999), Arábia Saudita (AKPATA et al. 1997), Singapura (LO e BAGRAMIAN 1996), EUA, Canadá e Brasil (CLARCK et al. 1994, CORTES et al. 1996, SELWITZ et al. 1996).

A alteração tem apresentado prevalências e severidade maiores em idades mais jovens em estudos em um mesmo local, o que tem alertado à comunidade científica para a necessidade de um acompanhamento contínuo e efetivo, para a detecção de uma possivel tendência secular de aumento da prevalência da fluorose dentária (HEINTZE et al. 1998). Entretanto, ainda existe discordância entre os 
achados: SELWITZ et al. (1995) descrevem que na Suíça não foi encontrado nenhum indício de aumento na prevalência ou severidade da fluorose dentária. Já LEWIS e BANTING (1994) identificam, nos Estados Unidos, um claro aumento de cerca de $33 \%$ da prevalência da doença em regiões com água fluoretada, comparada ao percentual de $9 \%$ nas áreas onde este método não é utilizado, acompanhada de incremento na severidade.

Apenas dois estudos realizados no Brasil indicam um aumento da ocorrência da fluorose dentária. PEREIRA et al. (1998) detectaram, em Piracicaba, município com água fluoretada, e em Iracemápolis, sem água fluoretada, um incremento de $52 \%$ e $41 \%$, respectivamente, em relação a levantamentos anteriores realizados pelos próprios autores. Já MALTZ et al. (1998), em Porto Alegre, verificaram o aumento de $24 \%$ da fluorose dentária no período de 1987 a 1997, em crianças de 8-9 anos de idade, embora os autores argumentem que o aumento da prevalência tenha sido nas formas mais leves, não implicando risco à saúde.

Quando se destaca a relação entre a prevalência de fluorose e determinantes sócio-econômicos os resultados são conflitantes. Supõe-se que o maior acesso a produtos fluorados poderia predispor a uma maior severidade da mesma, embora se descreva que, na presença de alterações do estado nutricional, poderia ocorrer a absorção completa do flúor e, conseqüentemente, um aumento na prevalência da alteração. Observa-se que, nos estudos desenvolvidos no país, nenhuma das duas hipóteses foi confirmada (MALTZ e SILVA 2001, SAMPAIO et al. 1999).

SAMPAIO (1993), utilizando o índice TF (Thylstrup e Fejerskov) em diversos municípios da Paraíba, analisou 437 escolares de 6 a 14 anos em Itabaiana, 
encontrando uma prevalência de 15,6\%. Examinou também 74 escolares desta mesma idade em São Félix, e descreveu um percentual de fluorose de 10,8\% e, em Mogeiro, estudando 98 crianças, relatou uma prevalência de 1,0\%. Neste mesmo estado, no municipio de Princesa Izabel, FORTE et al. (2001), também utilizando o índice TF, examinaram 142 escolares de 10 a 15 anos, e relataram uma prevalência de $20,0 \%$ de fluorose, sendo que desta $77 \%$ correspondiam ao grau 1 .

O estado de São Paulo é aquele com o maior número de estudos publicados com este índice. ADDE (1997) investigou 416 alunos de escolas públicas da zona norte da capital e encontrou $15,1 \%$ de prevalência desta alteração, predominando o grau muito leve. RIBAS et al. (1999) também em escolas públicas do bairro da Penha, examinaram 553 crianças de 6 a 12 anos e descreveram uma prevalência de 29,5\%. BUSCARIOLO (2001), analisando crianças de 6 a 16 anos da região sul da cidade de São Paulo, relata uma prevalência de $48,6 \%$, predominando também o grau muito leve.

Já no interior do estado, TOMITA et al. (1995), na cidade de Piratininga, estudaram a fluorose dentária em 270 escolares de 6 a 14 anos, encontrando uma prevalência de 34,4\% desta alteração. HEINTZE et al. (1998) examinaram indivíduos de 5 a 24 anos em três cidades- Garça $(n=206)$, Bauru $(n=167)$ e Itápolis $(n=172)$ e descrevem prevalências de $13,3 \% ; 6,8 \%$ e $1,7 \%$ respectivamente.

Na região sul, MALTZ e FARIAS (1998) examinaram 435 crianças de 8 e 9 anos nas cidades de Porto Alegre (RS) e Arroio do Tigre (RS) e descreveram uma prevalência de $7,7 \%$ e $0,2 \%$ para estes municípios. ELY e PRETTO (2000), num estudo em que analisaram a fluorose dentária em 2.002 escolares de 7,9, 12 e 14 anos, 
em seis cidades do Rio Grande do Sul (Faxinal do Soturno, Campinas das Missões, São Sepé, Santa Rosa, Agudo e Giruá) encontraram mais de $80 \%$ das crianças livres desta alteração.

Em Brasília, CAMPOS et al. (1998) analisaram a condição oral de 833 crianças de 8 a 12 anos e descreveram 14,6\% de prevalência de fluorose dentária, valor inferior ao de $22,3 \%$, descrito por MALTZ e FARIAS (1998) para o Distrito Federal: OLIVEIRA e MILBOURNE (2001), também utilizando o índice TF em 266 crianças de 7 a 12 anos na cidade do Rio de Janeiro, mas examinando apenas os incisivos superiores, encontraram uma prevalência de 7,9\%, com 77,0\% dos casos atribuidos ao grau 1.

Utilizando o índice de Dean, NARVAI et al. (1997) examinaram 2.491 crianças de escolas públicas e privadas, aos 12 anos de idade do município de São Paulo e relataram uma prevalência de $21,8 \%$, sendo que apenas $3,7 \%$ correspondiam ao grau moderado. No interior do estado, GASPAR et al. (1995) analisaram 211 crianças em Piracicaba e 200 em Iracemápolis, nas idades de 10 a 14 anos, encontrando uma prevalência de $20,9 \%$ e $4,5 \%$ de fluorose, respectivamente. BUENDIA e ZAINA (1997), em Presidente Prudente, estudaram 1.053 crianças de 8 a 13 anos, tendo como resultado uma prevalência de 17,5\%. Já MARCELINO et al. (1999), examinando 317 crianças de 12 a 14 anos de idade, em Araçatuba, relatam que $24,0 \%$ das crianças apresentaram fluorose dentária em algum grau.

Em 1998, a Secretaria de Estado da Saúde de São Paulo, em parceria com universidades, desenvolveu o Levantamento Epidemiológico em Saúde Bucal, oportunidade em que a fluorose dentária também foi avaliada em escolares de 5,12 e 
18 anos de idade. Para todo o estado foi descrita uma prevalência de $11,2 \%$ desta alteração aos 12 anos e 7,9\% aos 18 anos. Os percentuais tiveram variação nos municípios com e sem água de abastecimento público fluoretada, correspondendo a $15,2 \%$ e 5,0\%, respectivamente, em crianças de 12 anos de idade. Em praticamente todas as Diretorias Regionais de Saúde a prevalência de fluorose não excedeu $20 \%$ nas idades estudadas, com exceção da DIR II (Santo André), que aos 12 anos apresentou um valor de $82,8 \%$, discrepante com o resultado descrito nesta mesma região aos 18 anos e também no restante do estado (SÃO PAULO 1999).

SILVA e PAIVA (1995), em Belo Horizonte, fizeram um levantamento em 518 escolares entre 7 e 14 anos de idade e encontraram uma prevalência de $25,5 \%$ desta alteração. Já MENDONÇA et al. (1998), neste mesmo município, relataram uma prevalência de $34,4 \%$ ao examinar 797 escolares de 7 a 10 anos.

ALCÂNTARA (1998), também utilizando o Índice de Dean para mensurar a fluorose dentária em 360 crianças de 7 a 14 anos, de escolas públicas de Curitiba, relatou uma prevalência de $25,6 \%$, com predominância do grau muito leve, representando $13,9 \%$.

Nos trabalhos publicados no Brasil, apesar dos diferentes índices utilizados, em regiões onde a concentração de flúor na água é considerada ótima $(0,7$ a 1,0 ppmF), são encontrados, de modo geral, percentuais de fluorose dentária abaixo dos $30,0 \%$. Prevalências acima deste valor têm sido atribuidas ao efeito combinado do uso e ingestão de produtos dentários e outras fontes de ingestão de fluoretos (TOMITA et al. 1995, CORTES et al. 1996, SECRETARIA MUNICIAPL DE SAÚDE DE CURITIBA 1997, MENDONÇA et al. 1998, GONINI 1999, FORNI 
2000). Locais onde existe um excesso de concentração de fluoreto nos mananciais de águas de abastecimento público também registram a presença de altas prevalências de fluorose dentária (UCHÔA e SALIBA 1970, ANDO et al. 1973, ALCAIDE e VERONEZI 1979, CAPELLA et al. 1989, CORTES et al. 1996).

Observa-se, que os estudos que detectam maiores prevalências de fluorose dentária utilizam em sua maioria o indice TF (FEJERSKOV et al. 1994) e a proporção de individuos que apresentam as formas moderada e severa ainda é pequena, aumentando somente em áreas de fluorose endêmica.

Entretanto, é sugestivo que exista a possibilidade de um maior risco do acometimento da população pela difusão maciça do uso dos fluoretos na atualidade (CLARCK et al. 1994), especialmente os dentifricios fluoretados, que tiveram o seu uso regulamentado e difundido no pais somente na década de 90 , embora SOUZA et al. (1998) descrevam a dificuldade, no país, de garantir o acesso ao uso continuado do flúor, seja através dos dentifrícios ou outros veículos de uso tópico devido as grandes diferenças sociais e econômicas.

Em Salvador, REIS et al. (1999) realizaram um levantamento da prevalência de fluorose dentária (Índice de Dean) em 4 escolas, 2 públicas e 2 privadas, com crianças de 7 anos de idade, identificando uma prevalência de $20,1 \%$, com predominância de casos de fluorose moderada. Os autores não encontraram diferenças estatisticamente significativas entre escolas públicas ou privadas.

MALTZ e SILVA (2001), analisando a fluorose dentária, utilizando o índice TF, em mil escolares da rede pública e particular de Porto Alegre, encontraram uma 
prevalência de $49,9 \%$ e $60,8 \%$ respectivamente, diferença esta atribuída ao maior acesso aos produtos fluorados nos estudantes de maior renda.

Nos estudos nacionais que discutem as desigualdades na distribuição do processo saúde-doença bucal, os autores frisam a necessidade de determinar grupos epidemiologicamente mais susceptíveis como uma etapa fundamental para a definição de estratégias de ação de promoção de saúde e prevenção (NARVAI et al. 2000, PATUSSI 2000). Dessa forma, seria possível obter maior sucesso no controle das doenças e minimizar problemas funcionais e sociais, visto que já é possível detectar redução das iniqüidades a partir da implementação de ações como a fluoretação das águas de abastecimento público, programas específicos de educação em saúde bucal e uso extensivo do flúor.

Observa-se que, de modo geral, os estudos que trabalham com abordagens ecológicas têm maior poder preditivo em identificar os diferenciais no estado de saúde da população em relação às doenças bucais, por estas serem patologias de alta prevalência em todos os níveis sócio-econômicos, embora seja cada vez mais freqüente a concentração da cárie dentária em grupos de risco ou de polarização.

A lógica da análise espacial das doenças também resgata a idéia de que além de variáveis biológicas, existem fatores físicos do meio, fatores sociais, econômicos e culturais, agindo sobre um determinado grupo de forma a definir a ocorrência de variações nas doenças, num nível de determinação simples ou complexa, sugerindo ou confirmando hipóteses explicativas (MAYER 1996, ESTÉVE et al. 1994). São modelos de base para a discussão política das desigualdades entre regiões e um instrumento para os planejadores, já que através de mapas de risco e de ocorrência 
dos fenômenos torna- se possivel definir as zonas mais homogêneas da exposição de interesse (ESTÉVE et al. 1994).

Nessa perspectiva, este estudo visa contribuir para a programação em saúde bucal em Salvador, Bahia, na medida em que a morbidade das doenças bucais foi obtida utilizando o distrito sanitário, área administrativa mínima responsável pelas decisões locais no setor saúde, além do tipo de estabelecimento de ensino, como discriminador do nível sócio-econômico. Assim, coloca-se a possibilidade de a partir do perfil epidemiológico de cada área, e conseqüentemente de suas diferenças, estabelecer práticas individuais e coletivas mais adequadas às necessidades da população e, também, de maior impacto epidemiológico, em conjunto com outras práticas coletivas desenvolvidas no município, buscando assim a eqüidade em saúde bucal. 


\section{OBJETIVOS}

\subsection{Objetivo Geral}

Analisar a ocorrência de cárie e fluorose dentária na população escolar de 12 e 15 anos de idade em Salvador, Bahia, Brasil, de modo a identificar os diferenciais na condição de saúde e as áreas prioritárias de risco e de intervenção.

\subsection{Objetivos Especificos}

a) Determinar a prevalência e severidade da cárie dentária no município de Salvador, Bahia, aos 12 e 15 anos de idade;

b) Mensurar a prevalência e a severidade da fluorose dentária;

c) Analisar a distribuição da prevalência da cárie e fluorose dentária por distrito sanitário, utilizando como covariáveis: cobertura assistencial no último ano; tipo de financiamento da assistência, participação em programas preventivos, exposição à água fluoretada dos 0 aos 5 anos de vida e inserção em escola pública ou particular;

d) Analisar a prevalência de cárie e fluorose dentária, segundo tipo de estabelecimento de ensino. 


\section{HIPÓTESES DE TRABALHO}

Partindo do pressuposto da importância da epidemiologia como instrumento no campo do planejamento em saúde, este trabalho propõe-se a, com base em informações epidemiológicas obtidas no nível municipal, identificar áreas ou populações de risco para o municipio de Salvador/BA segundo as seguintes hipóteses:

\subsection{Cárie dentária}

\section{$1^{\mathrm{a}}$. Hipótese}

Existem diferenças entre a prevalência de cárie dentária segundo distrito sanitário em Salvador-BA.

\section{$2^{2}$. Hipótese}

Os escolares da rede pública de ensino tem maior prevalência de cárie dentária do que as crianças da rede particular em Salvador-BA. 


\subsection{Fluorose dentária}

$1^{\text {a }}$. Hipótese

Existem diferenças entre a prevalência de fluorose dentária segundo distrito sanitário em Salvador-BA.

$2^{\mathbf{a}}$. Hipótese

Existem diferenças entre a prevalência de fluorose dentária entre crianças de escolas da rede pública e particular Salvador-BA. 


\section{METODOLOGIA}

\subsection{Local do Estudo}

Salvador é a capital do Estado da Bahia, situada na região Nordeste do Brasil, aos 13 graus de latitude Sul e 38 graus de longitude Oeste, numa península do Oceano Atlântico. Foi fundada em 1549, por Tomé de Souza, e manteve-se como capital do país até 1763 , quando esta foi transferida para o Rio de Janeiro.

Durante todo o periodo colonial, foi o epicentro do pais, sede da administração colonial e pólo comercial exportador da cultura de cana de açúcar. Quando a sede administrativa foi transferida para a região Centro-Sul, áreas como a mineração no século XVIII, a produção têxtil, de alimentos e bebidas no século XIX e posteriormente a industrialização, vivida após 1960 com a descoberta do petróleo na região, consolidaram o município como um pólo comercial, turístico e de serviços (SOUZA e FARIA 1980). Predominam, hoje, o setor terciário e a construção civil, com atividades de baixa produtividade e alta instabilidade ocupacional, embora seja crescente o investimento no turismo como um elemento fundamental para a manutenção do fluxo econômico no município (BRASIL. IBGE 1997).

Observa-se que o processo de industrialização não trouxe melhorias para as grandes desigualdades existentes na cidade. A transferência de oligopólios, a alta proporção de migração da zona rural para a urbana e um histórico de exploração de mão de obra, inicialmente escrava, depois operária e por fim o subemprego, pelo contrário, cultivaram e refletiram uma política nacional de manutenção das iniqüidades sociais (SOUZA e FARIA 1980). Os autores acrescentam ainda que é marcante a pobreza que se vê em toda a cidade, e, de certo modo, esta imagem está 
associada em todo o país a um imaginário de beleza, de folclore, de místico, e de festa. Enfatizam a dualidade que se criou "de uma pobreza fácil (grifo dos autores), que mascara o duro trabalho diário, o desemprego e subemprego e as grandes desigualdades decorrentes do processo de construção do município, de crises e períodos de estagnação econômica."

A cidade, em 2000, possuía uma população de 2.440 .886 habitantes, $99,96 \%$ localizados na zona urbana, distribuídos em 17 regiões administrativas pela Companhia de Desenvolvimento da Região Metropolitana de Salvador (CONDER), de acordo com critérios físicos e urbanísticos e de planejamento e 76 zonas de informação (BRASIL.IBGE 2000). Já a Secretaria Municipal de Saúde agrega algumas das regiões administrativas, e utiliza no seu planejamento e programação das ações de saúde, 12 Distritos Sanitários (Anexo 1), sendo eles: Barra-Rio Vermelho; Centro Histórico; Itapagipe; Brotas; Boca do Rio; Itapoã; Cajazeiras; Cabula-Beiru; Liberdade; Pau da Lima; Subúrbio Ferroviário e São Caetano-Valéria (PREFEITURA MUNICIPAL DO SALVADOR 1994).

No setor saúde, o município foi habilitado a gestão plena da atenção básica em 1997, com um processo de municipalização tardio, desestruturação parcial dos serviços e uma política não definida de recursos humanos e físicos adequados ao processo (CABRAL et al. 2000).

A maior parte dos serviços em odontologia, nos setores público e privado, ainda está voltada para o modelo restaurador de atendimento, com algumas iniciativas locais de implantação de práticas preventivas com oferta organizada de serviços, sendo que o principal problema é a garantia da continuidade destas ações. Destaca-se 
que, após a implantação do SUS, expandiu-se significativamente no município a oferta de serviços em saúde bucal no setor público e, no setor privado, isto se deu em decorrência do surgimento de convênios e credenciamentos de baixo custo (CANGUSSU 1998, CABRAL et al. 2000). A fluoretação foi introduzida em 1975 e interrompida em 1989, embora não existam, para o período, registros de controle do nível ótimo de flúor, a não ser o fornecido pela empresa pública de abastecimento de água, estabelecido em $0,7 \mathrm{ppm}$. O retorno ao processo de fluoretação ocorreu em novembro de 1996 , com dosagens de 0,7 ppm e, concomitantemente, a estruturação de um sistema de vigilância sanitária, com a participação do Conselho Regional de Odontologia da Bahia e Vigilância Sanitária Municipal (SECRETARIA ESTADUAL DE SAÚDE-BAHIA 1996). O percentual da população com acesso à água tratada correspondia a $85,40 \%$ no início da década de 80 e 93,87\% em 1991 (BRASIL.IBGE 2000).

Isto significa que, da população incluída neste estudo, aqueles com 12 anos de idade não foram beneficiados por este método preventivo até a idade de 8 anos, enquanto aqueles com 15 anos de idade tiveram beneficio parcial, com exposição ao método somente até os 3 anos de idade, no máximo, e novamente com 11 anos de idade.

Poucos estudos epidemiológicos em saúde bucal foram desenvolvidos no município. A maior parte sobre grupos específicos para subsidiar a avaliação de programas em unidades básicas de saúde, envolvendo população escolar (SECRETARIA ESTADUAL DE SAÚDE-BAHIA 1996); os levantamentos realizados pelo Ministério da Saúde em 1986 e 1996 (BRASIL.MS 1988, 
BRASIL.MS 1996) e alguns trabalhos acadêmicos, envolvendo populações de préescolares (VASCONCELOS et al. 2000), adolescentes de 12 a 19 anos de idade (CANGUSSU 1998) e gestantes (SCAVUZZI 1995), desenvolvidos no distrito sanitário Barra Rio-Vermelho, visto que este constitui-se um espaço docente assistencial (CABRAL et al. 2000).

Observa-se que na maior parte dos trabalhos em Salvador-BA, em relação à cárie dentária, encontram-se condições de saúde bucal satisfatórias segundo a meta estabelecida pela OMS/FDI para o ano 2000 aos 12 anos de idade, com a presença do fenômeno da polarização. Neste sentido, ressalta-se a importância de, num panorama epidemiológico de baixa prevalência da doença, identificar-se grupos ou áreas geográficas de alto risco para subsidiar futuras intervenções em saúde bucal.

\subsection{Tipo de estudo}

O desenho epidemiológico proposto para este estudo é o transversal, de prevalência para a análise do município e por tipo de estabelecimento de ensino, indicado para doenças de ocorrência freqüente e crônicas. A escolha deste tipo de estudo foi orientada por sua facilidade de execução, curta duração, possibilidade de reprodução e por permitir a análise de vários fatores intervenientes num mesmo momento histórico, além do seu potencial em gerar hipóteses epidemiológicas (ALMEIDA FILHO e ROUQUAYROL 1996).

Para a análise de agregados, utilizou-se como unidade de análise um grupo de indivíduos, que podem ser selecionados por critérios sociais, econômicos ou administrativos, envolvendo dados de prevalência de uma ou mais doenças (KLEINBAUM et al. 1982, BORRELL 1989), caracteristica dos estudos do tipo 
ecológico. Neste caso, a opção foi o uso de áreas definidas geográfica e administrativamente pelos distritos sanitários, unidade operacional e gerencial utilizada pela Secretaria Municipal de Saúde de Salvador para o planejamento e desenvolvimento das ações de saúde.

ROTHMAN (1987) e LAWSON et al. (1999) afirmam que se pode dispôr ou não de informações prévias para estes grupos, sendo mais comuns os estudos que utilizam grandes fontes de dados secundários, pela agilidade e facilidade de acesso. KELSEY et al. (1986) reforçam que através deste tipo de desenho é possível uma aproximação do contexto macro-social e cultural, visto que os dados coletados dizem respeito a grupos socialmente definidos.

Dentre as principais limitações descritas na literatura para este tipo de desenho têm-se (KLEINBAUM et al. 1982, KELSEY et al. 1986, ROTHMAN 1987, BORREL 1989, LAWSON et al. 1999):

- a falácia ecológica, resultado de uma inferência causal individual com base nos dados de observação de grupos;

- as dificuldades no teste de hipóteses etiológicas, visto que existe um potencial de variáveis de confusão individuais e coletivas que, geralmente, não são abordadas, bem como o grande risco de colinearidade das variáveis sócioeconômicas;

- a não homogeneidade interna em cada grupo de comparação, já que as áreas geográficas costumam ser definidas não só por critérios sociais, econômicos ou demográficos, mas também administrativos. 


\subsection{População de Estudo}

A população de referência constituiu-se de escolares de 12 anos $(\mathrm{N}=51.560)$ e 15 anos $(\mathrm{N}=52.420)$, de ambos os sexos, regularmente matriculados em escolas de $1^{\circ}$. e $2^{\circ}$. graus (ensino fundamental e médio), públicas e privadas, de Salvador, Bahia, no ano de 2001 (BRASL.MEC 2000). Este número representava 97\% das crianças da idade de 12 anos residentes no município e $95 \%$ aos 15 anos.

Estas idades foram selecionadas porque a Organização Mundial da Saúde considera os 12 anos como idade de comparação e vigilância internacional das doenças bucais, e os 15 anos, como a idade na qual a prevalência de cárie é mais significativa que a dos 12 anos de idade, visto que os dentes permanentes estão expostos de 3 a 9 anos no ambiente bucal (WHO 1997).

$\mathrm{Na}$ impossibilidade de se estudar toda a população, optou-se pela obtenção de uma amostra probabilística em múltiplo estágio (COCHRAN 1965), cujas unidades amostrais primárias representavam o cadastro de escolas públicas e particulares da cidade, fornecida pelo Ministério da Educação-MEC (BRASIL.MEC 2000); Secretaria Estadual de Educação do Estado da Bahia e Secretaria Municipal de Educação de Salvador. Foram sorteados 72 estabelecimentos de ensino, do total de 778 escolas (535 públicas e 243 particulares), pré-estratificados por Distrito Sanitário, obedecendo a proporcionalidade entre escolas públicas e privadas, de ensino fundamental e de ensino médio, bem como a ponderação da amostra de acordo com a densidade populacional de cada distrito.

Para o cálculo da amostra foram usados os dados populacionais mais recentes disponiveis da média e variabilidade de cárie dentária da população adolescente aos 12 anos de idade (CPO-D=1,53; $\mathrm{DP}=2,35)$ para o município de Salvador 
(BRASIL.MS 1996), e as informações contidas no manual "Oral Health Surveys. Basic Methods” (WHO 1997), que preconiza o mínimo de 25 crianças em regiões com baixa prevalência de cárie dental. Optou-se por dobrar este número, com o objetivo de estabelecer uma margem de segurança em relação a perdas e recusas de participação.

Foram considerados 12 estratos de análise, o número de distritos sanitários da cidade, e'a unidade como número mínimo capaz de detectar-se a diferença entre os estratos. O nível de significância adotado foi de $5 \%$ e o poder do teste foi de $80 \%$. A distribuição $\mathrm{t}$ de Student foi considerada a mais pertinente para o cálculo da amostra, utilizando o método proposto por ZAR (1996), conforme descrito:

$$
\mathrm{n} \geq \frac{2 \mathrm{~s}_{\mathrm{p}}^{2}}{\delta^{2}}\left(\mathrm{t}_{\alpha, v}+\mathrm{t}_{1-\beta, v}\right)^{2}, \text { sendo: }
$$

$\mathrm{n}=$ amostra mínima requerida

$v=$ variabilidade entre os grupos $=\mathrm{gn}_{\mathrm{o}}-\mathrm{g}($ sendo no $=50$ e $\mathrm{g}=12)=588$

$\alpha=$ nível de significância $=5 \%$

$\beta=$ erro aceitável na hipótese alternativa $=20 \%$

$\delta=$ diferença mínima detectável na unidade do estudo $=1$

$\mathrm{Sp}=$ desvio padrão $=2,35$

$t_{\alpha, v}=1,96 \quad t_{1-\beta, v}=1,282$ 
Obteve-se uma amostra mínima de 117 adolescentes por idade e por distrito sanitário. De posse das listagens de alunos em cada escola foram selecionadas aleatoriamente as crianças em cada idade, com reposição única em casos de evasão escolar. Assim a amostra mínima total prevista foi de 2.808 adolescentes, 1.404 aos 12 anos e 1.404 aos 15 anos de idade. Para a inclusão de alunos na idade de 12 anos considerou-se aqueles nascidos após o mês 06/1987, e aos 15 anos, após 06/1984.

Nos distritos com maior densidade populacional (São Caetano-Valéria e Subúrbio Ferroviário) e que se esperava maior migração entre local de residência e local de localização da escola (Barra-Rio Vermelho e Centro Histórico) aumentou-se em até 70\% o número mínimo estabelecido no cálculo da amostra. Também optou-se por superestimar a amostra em $10 \%$ a $20 \%$ nos distritos em que eram registrados maiores índices de evasão escolar: Barra-Rio Vermelho, Centro Histórico, Brotas, Cabula-Beiru e Subúrbio Ferroviário. 
Tabela 1- Probabilidade de sorteio das escolas segundo categoria de ensino e distrito sanitário em Salvador, Bahia, 2001.

\begin{tabular}{|c|c|c|c|c|c|c|}
\hline \multirow[b]{2}{*}{ Distrito } & \multicolumn{5}{|c|}{ Categoria de Ensino } & \multirow[b]{2}{*}{ Total } \\
\hline & 1 & 2 & 3 & $4^{*}$ & 5 & \\
\hline Barra- Rio Vermelho & 0,05 & 0,06 & 0,13 & 0,03 & 0,09 & 0,06 \\
\hline Centro histórico & 0,10 & 0,05 & 0,08 & 0.03 & 0,06 & 0,06 \\
\hline Itapagipe & 0,11 & 1,00 & 0,10 & 0,03 & 0,08 & 0,08 \\
\hline Brotas & 0,09 & 0,20 & 0,30 & 0,06 & 0,06 & 0,09 \\
\hline Boca do Rio & 0,14 & 1,00 & 0,33 & 0,17 & 0,17 & 0,22 \\
\hline Itapuã & 0,12 & 0,14 & 0,16 & 0,04 & 0,10 & 0,10 \\
\hline Cajazeiras & 0,25 & 0,25 & 0,33 & 0,03 & 0,67 & 0,08 \\
\hline Cabula- Beiru & 0,08 & 0,22 & 0,17 & 0,05 & 0,13 & 0,09 \\
\hline Liberdade & 0,25 & 0,20 & 1,00 & 0,07 & 0,25 & 0,17 \\
\hline Pau da Lima & 0,14 & 1,00 & 1,00 & 0,05 & 0,11 & 0,10 \\
\hline Subúrbio Ferroviário & 0,25 & 0,33 & 0,25 & 0,05 & 0,18 & 0,11 \\
\hline São Caetano- Valéria & 0,20 & - & 0,67 & 0,08 & 0,20 & 0,16 \\
\hline $\begin{array}{l}\text { 1- Escolas de } 5^{\mathrm{a}} \text {. a } 8^{\mathrm{a}} \text {. } \\
\text { 3- Escolas de ensino } \mathrm{n} \\
5 \text { - Escolas de } 5^{\mathrm{a}} \text { a a } 8^{\mathrm{a}} \text {. } \\
\text { * não foram encontrad } \\
\text { privada. }\end{array}$ & $\begin{array}{l}\text { e priv } \\
\text { o púb } \\
\text { e púb } \\
\text { rianca }\end{array}$ & & $\begin{array}{l}\text { 2-Esco } \\
4-\text { Escol }\end{array}$ & $\begin{array}{l}\text { ensi } \\
1^{\mathrm{a}} \cdot \mathrm{a}\end{array}$ & édio 1 & rede \\
\hline
\end{tabular}

\subsection{Calibração da equipe}

A calibração da equipe ( 7 examinadores e 7 anotadores) foi dividida em três etapas: a primeira teórica, com duração de 12 horas, em que se discutiu os índices utilizados, seus critérios, a ficha clínica da coleta de dados, utilizando como materiais didáticos apostilas, livros e fotos das condições possíveis de serem encontradas durante a 
coleta. A segunda e a terceira etapas foram realizadas em uma escola pública do município, não incluída no estudo. Realizou-se, na segunda etapa, com duração de 8 horas, o exame de 40 alunos de 12 a 14 anos com a discussão ampliada dos critérios dos índices e das condições encontradas, com o objetivo de construir o consenso para o grupo. $\mathrm{Na}$ terceira fase, os exames em 80 alunos foram realizados duas vezes por examinadores diferentes, sem consulta entre eles, de forma a mensurar os erros interexaminadores, e a cada 10 exames era realizado o reexame do primeiro adolescente, para a mensuração do erro intra-examinador. Esta etapa teve duração de 16 horas.

Para a cárie dentária (condição da coroa) o percentual de concordância geral foi de $98,16 \%$ e o kappa ${ }^{1}=0,89$, considerado por EKLUND et al. (1996) como excelente, sendo a pior concordância entre os examinadores de $85,30 \%$. Ambos os indicadores foram calculados a partir da média de concordância para cada dois examinadores. Quando considerada a fluorose dentária, a concordância entre os examinadores foi de $89,72 \%$, com um kappa $=0,69$ (classificada como boa ou substancial), e a menor concordância intra-examinador foi de $92,00 \%$. Em relação à etnia o percentual de concordância geral foi de $85,58 \%$. Observa-se que, nas diversas condições em que os índices foram utilizados, obteve-se uma concordância considerada satisfatória pela Organização Mundial da Saúde para os levantamentos epidemiológicos em saúde bucal (WHO 1997).

\footnotetext{
${ }^{1} \mathrm{O}$ kappa é um índice de concordância ajustado, que leva em consideração as concordâncias esperadas e a chance de que as mesmas ocorram devido ao acaso.
} 


\subsection{Aspectos Éticos}

O desenvolvimento deste estudo seguiu os requisitos da Resolução 196/96 do Conselho Nacional de Saúde/ Ministério da Saúde do Brasil (BRASIL.MS 1997), e as normas internas da Faculdade de Saúde Públicá dả USP, quie regüulamentam pesquisass envolvendo seres humanos, nos quais os adolescentes só foram examinados após a obtenção da autorização, por meio da assinatura dos pais ou responsáveis dos alunos do termo de consentimento, utilizando como modelo aquele aplicado no levantamento do Estado de São Paulo, em 1998 (SÃo PAULO 1999) (Anexo 4).

\subsection{Coleta de dados}

A coleta de dados foi realizada em dois momentos. O primeiro em ambiente escolar, utilizando-se uma ficha desenvolvida para este estudo (Anexo 2), após terem sido obtidos os termos de consentimento; e o segundo na Secretaria Municipal de Saúde, onde foram obtidas as informações sobre a assistência odontológica desenvolvida no municipio, recursos fisicos e humanos em cada distrito sanitário, como a existência de alguma política/prática distrital específica em relação à saúde bucal; número de dentistas e pessoal auxiliar por distrito sanitário e número de consultórios odontológicos públicos em cada local (Anexo 3).

Os exames clínicos foram realizados no próprio ambiente escolar, durante o periodo letivo, obtendo-se as seguintes informações:

- Dados gerais: nome, data de nascimento, endereço de residência, nome da escola, tipo de financiamento da escola (pública, privada), série em curso, localização geográfica da escola, local de moradia nos primeiros cinco anos de vida, acesso a atenção à saúde bucal, caracterizada pela participação em outros programas com uso de flúor 
tópico e acesso à assistência odontológica no último ano e tipo de financiamento da mesma (se público, particular ou convênio).

- Exame: foram inspecionadas as condições da coroa em relação à cárie e a fluorose dentária, segundo os critérios estabelecidos pela Organização Mundial da Saúde (WHO 1997).

\section{Cárie dentária: condição da coroa}

O exame da cárie dentária foi basicamente visual, com a utilização do espelho bucal plano e da sonda periodontal específica proposta pela Organização Mundial da Saúde (sonda CPI). Todos os dentes foram examinados assim que qualquer superficie ou parte da mesma estivesse presente no arco dentário, sendo anotado um código para cada unidade dentária. Como tratou-se de uma população nas idades de 12 e 15 anos, em que os terceiros molares ainda não estavam presentes na cavidade oral, a ficha preparada incluiu apenas 28 espaços para o cálculo do índice CPO-D. Foram utilizadas, como critérios de decisão complementar, as recomendações do Caderno de Instruções utilizado no levantamento realizado em 1998, no estado de São Paulo, elaborado pelos professores Paulo Capel Narvai e Roberto Augusto Castellanos Fernandez, da Faculdade de Saúde Pública da Universidade de São Paulo (SÃO PAULO 1999). Os critérios para diagnóstico e codificação foram:

- 0: sadios- não há evidência de cárie. Estágios iniciais da doença não são levados em consideração. Todas as lesões questionáveis devem ser codificadas como dente hígido. Os seguintes sinais também devem ser codificados como higidos:

- manchas esbranquiçadas; 
- descolorações ou manchas rugosas resistentes à pressão da sonda CPI;

- sulcos e fissuras de esmalte manchados, mas que não apresentam sinais visuais de base amolecida, esmalte socavado, ou amolecimento das paredes, detectáveis com a sonda CPI;

- áreas escuras, brilhantes, duras e fissuradas do esmalte de um dente com fluorose moderada ou severa;

- lesões que, com base na sua distribuição ou história, ou exame táctil/visual, resultem de abrasão.

- 1: cariado- sulco, fissura ou superficie lisa apresenta cavidade evidente, ou tecido amolecido na base ou descoloração do esmalte ou de parede ou há uma restauração temporária. A sonda CPI deve ser empregada para confirmar evidências visuais de cárie nas superficies oclusal, vestibular e lingual. Na dúvida, considerar o dente hígido

- 2: restaurado com cárie- há uma ou mais restaurações e ao mesmo tempo uma ou mais áreas estão cariadas. Não há distinção entre cáries primárias e secundárias, ou seja, se as lesões estão ou não em associação fisica com a(s) restauração(ões).

- 3: restaurado sem a presença de cárie- há uma ou mais restaurações definitivas e inexiste cárie primária ou recorrente. Um dente com coroa colocada devido à cárie é incluído nesta categoria. Se a coroa resulta de outras causas, como suporte de prótese, é codificada como 7.

- 4: dente permanente extraido por motivo de cárie e não por outras razões. 
- 5: dentes permanentes ausentes por outras razões. Registrado quando existirem ausências congênitas de unidades dentárias ou extração por motivos ortodônticos ou periodontais;

- 6: presença de selantes de fóssulas e fissuras. Este código é utilizado quando for detectada com a sonda a presença de selante ou compósito na superficie oclusal, sem a presença de cárie. No caso de existir indícios de cavitação por cárie deverá ser anotado o código 1.

- 7: presença de coroa metálica ou estética substituindo a presença natural da coroa dentária por motivos estéticos, de trauma ou apoio de prótese fixa;

- 8: dente não erupcionado. Esta categoria não inclui os dentes ausentes por motivos congênitos (anodontias) ou por motivo de avulsão por trauma;

- 9: trauma- presença de dente com fratura sem lesão evidente de cárie;

- X: dente excluído do exame por não ter sido examinado. Codificação modificada do manual a fim de uniformizar a anotação dos exames nas diversas condições.

Para o cálculo do índice CPO-D, o componente $\mathrm{C}$ incluiu todos os dentes classificados com os códigos 1 e 2 , o componente $P$ compreendeu os dentes com o código 4 e o componente $\mathrm{O}$ os dentes com o código 3 (WHO 1997) para as idades de 12 e 15 anos.

Fluorose dentária: Índice de Dean

As lesões fluoróticas geralmente são bilaterais, simétricas e tendem a apresentar estrias horizontais na superficie dentária. Os pré-molares e segundos molares são os dentes mais afetados, seguidos pelos incisivos superiores. $O$ examinador deve inspecionar 
todos os dentes no arco dentário, registrando um único código para o individuo. Os códigos utilizados para a anotação da prevalência e severidade da doença são:

- 0: normal: a coloração do esmalte é branco-leitosa, brilhante e translúcida;

- 1: questionável: o esmalte apresenta leves alterações da sua translucidez natural, geralmente pequenas nuvens ou manchas esbranquiçadas;

- 2: muito leve: presença de áreas esbranquiçadas pequenas e opacas, com bordas irregularmente definidas que não representam mais de $25 \%$ da superficie dentária;

- 3: leve: presença de áreas esbranquiçadas pequenas e opacas, com bordas irregularmente definidas que não representam mais de 50\% da superficie dentária;

- 4: moderada: A superficie do esmalte tem manchas esbranquiçadas ou marrons bem nítidas, e pequenas regiões com perda de estrutura;

- 5: severa: a estrutura do esmalte é bastante comprometida e a hipoplasia é marcada, podendo inclusive alterar a anatomia do dente pela grande perda mineral. As manchas brancas ou castanhas estão disseminadas por toda a superficie dentária que apresenta um aspecto de corrosão;

- X- exclusão: registrada nos casos em que for impossível o exame dentário, como apinhamento excessivo e uso de bandas ortodônticas ${ }^{2}$.

Os dados foram coletados por sete examinadores previamente calibrados, tendo sido mensurados, no momento do treinamento, os erros inter e intra-examinador, e sete anotadores treinados para este fim, em ambiente escolar, com iluminação natural; com o adolescente deitado em decúbito dorsal e o examinador posicionado atrás da cabeça do mesmo, utilizando espelhos bucais planos e sondas periodontais estéreis, recipientes de

\footnotetext{
${ }^{2}$ Codificação modificada do manual original para homogeneizar a anotação e digitação dos dados em relação à cárie dentária.
} 
armazenamento de instrumental contaminado e recipientes para desinfecção, gaze, toalhas descartáveis e sabão para lavagem das mãos, segundo especificações da Organização Mundial da Saúde (WHO 1997).

\subsection{Processo de análise}

Os dados foram digitados e armazenados num banco de dados criado no programa Epi Info, (DEAN et al. 1990). Os cálculos dos erros de digitação foram feitos a partir da dupla entrada de dados e percentual de concordância das mesmas, bem como a revisão do banco após a identificação de erros na análise descritiva de cada variável. A análise foi realizada no Epi Info e no pacote estatístico STATA, versão 6.0®.

De forma a possibilitar a compreensão da ocorrência da cárie e fluorose dentária em Salvador, as peculiaridades de cada distrito sanitário e as possíveis variáveis, de acesso e cobertura dos serviços de saúde que interagem nestas alterações, procedeu-se a análise descritiva das seguintes condições:

- Distribuição da amostra por sexo, idade, grupo étnico e localização geográfica (distrito sanitário da escola); número de recusas e perdas de exame por distrito sanitário;

- Caracterização da rede assistencial pública segundo recursos fisicos, recursos humanos e programas específicos desenvolvidos;

- Concordância entre distrito sanitário da escola e distrito sanitário de residência; 
- CPO-D e medidas de variabilidade, composição percentual do índice e percentual de indivíduos sadios por idade; Índice de Cárie Significativa aos 12 anos de idade;

- Prevalência e severidade da fluorose dentária;

- Distribuição das covariáveis por tipo de estabelecimento de ensino (público/ particular), sexo, etnia, local de moradia nos primeiros 5 anos de vida, exposição a programas com uso do flúor, acesso ao dentista no último ano e tipo de financiamento da consulta;

- Distribuição da cárie dentária por tipo de estabelecimento de ensino e identificação de diferenças a partir do teste $t$ de Student para médias e Qui-quadrado para proporções, com n-1 graus de liberdade, ambos com nivel de significância de 5\%;

- Distribuição da fluorose dentária por tipo de estabelecimento de ensino e identificação das diferenças a partir do teste do Qui-quadrado, com n-1 graus de liberdade e um nível de significância de 5\%.

\section{Cárie e fluorose dentária segundo estabelecimento de ensino}

Com o objetivo de testar a hipótese das diferenças de prevalência da cárie e fluorose dentária entre escolas públicas e privadas, como discriminadoras do nível sócioeconômico, procedeu-se a análise confirmatória para a associação entre tipo de estabelecimento de ensino e ocorrência de cárie e de fluorose dentária.

Utilizou-se a regressão logística não-condicional como um instrumento complementar à análise descritiva e bivariada, por esta proporcionar maior poder, na medida em que permite a obtenção da medida de associação do efeito sob estudo, 
ajustada para o efeito simultâneo das covariáveis utilizadas, sendo estas necessariamente dicotômicas ou categoriais (KLEINBAUM 1994).

O processo de análise dos dados com o uso da regressão logística, em todas as associações em que este método foi utilizado, compôs-se das seguintes etapas de modelagem, aos 12 e 15 anos de idade, separadamente:

- Construção do modelo teórico das possíveis variáveis de confusão, isto é, potenciais fatores associados à exposição e ao efeito abordados neste estudo;

- análise da associação entre distrito sanitário de localização da escola e prevalência de cárie dentária. Utilizou-se a técnica backward, partindo-se de um modelo saturado, sendo que a modelagem seguiu a proposta descrita por KLEINBAUM (1994):

1. Re-categorização das variáveis para os códigos 0- referente; 1 - risco; construção das variáveis de desenho $\left(\right.$ dummy $\left.{ }^{3}\right)$;

2. Composição do modelo saturado com a variável dependente: prevalência de cárie dentária/prevalência de fluorose dentária; a variável independente principal (distrito sanitário da escola) e as covariáveis, possíveis termos de confusão;

3. Análise da confusão através da comparação da medida bruta da associação principal obtida após o ajuste segundo cada variável de confusão, bem como a precisão dos intervalos de confiança. Para a inclusão das variáveis de confusão no modelo saturado considerou-se o nível de significância de $20 \%$. Observa-se que esta é uma etapa subjetiva, dependente dos critérios do investigador;

\footnotetext{
${ }^{3}$ As variáveis dummy são utilizadas no modelo de regressão logística quando na presença de três ou mais categorias, utilizando sempre o código zero para a melhor condição e analisando o restante dos estratos em relação a mesma.
} 
4. Obtenção do modelo final; diagnóstico e teste do ajustamento do modelo para a associação principal utilizando a análise dos resíduos e a razão de máxima verossimilhança.

Para a análise por tipo de estabelecimento de ensino, as seguintes variáveis foram utilizadas na equação saturada:

\section{Variáveis dependentes:}

- Prevalência de cárie dental (CPO-D=0 e CPO-D>=1) por idade ou

- Prevalência de fluorose dentária (Índice de Dean $<=1$ e Índice de Dean $>1$ ) por idade;

\section{Variável independente principal:}

- tipo de estabelecimento de ensino: privado(0) e público(1);

\section{Covariáveis:}

- sexo: masculino (0) e feminino (1);

- etnia: negra (0); parda (1); branca (2) e amarela, que foi excluída da análise por representar apenas 1 indivíduo em toda amostra. Os critérios utilizados foram os estabelecidos pela Fundação IBGE na amostragem por domicílio realizada no Brasil, no ano 2000, descritos no Anexo 5 (BRASIL.IBGE 2000);

- participação em atividade de promoção de saúde/prevenção nos últimos 2 anos com uso do flúor tópico: $\operatorname{sim}(0)$; não/não sabe informar (1);

- local de residência nos primeiros 5 anos de vida: Salvador (0); outros municípios e residiu somente parte do tempo em Salvador (1);

- acesso ao consultório odontológico no último ano: $\operatorname{sim}(0)$, não/não sabe informar (1); 
- tipo de financiamento da assistência odontológica: (0)público, (1)particular; (2) convênio/credenciamento, (3) nunca teve acesso.

\section{Cárie e fluorose dentária segundo distritos sanitários}

Procurou-se identificar as especificidades dos distritos sanitários e relação da prevalência e severidade das alterações estudadas utilizando as seguintes análises:

- Classificação dos CPO-D aos 12 anos segundo distritos sanitários de acordo com os critérios de severidade estabelecidos pela Organização Mundial da Saúde segundo MOLLER (1980-83), citado por PINTO (1992):

- CPO-D 0,1 a 1,1- prevalência muito baixa;

- CPO-D 1,2 a 2,6- prevalência baixa;

- CPO-D 2,7 a 4,4-prevalência moderada;

- CPO-D 4,5 a 6,5- prevalência alta;

- CPO-D acima de 6,5- prevalência muito alta;

- Distribuição da prevalência de severidade da fluorose segundo distrito sanitário;

- Análise Multivariada - Regressão Logística.

Utilizou-se a regressão logística não- condicional, com o modelo saturado composto das seguintes variáveis

\section{Variảveis dependentes:}

- Prevalência de cárie dental (CPO-D=0 e CPO-D>=1) por distrito sanitário, por idade;

- Prevalência de fluorose dentária (índice de Dean $>=1$ e Índice de Dean $>1$ ) por distrito sanitário, por idade; 


\section{Variável independente principal:}

- distrito sanitário em que está localizada a escola ( 0 a 11$)$ : optou-se pelo uso desta variável já que houve uma concordância satisfatória em relação ao distrito sanitário de residência, bem como o desenvolvimento de práticas de promoção de saúde bucal se efetivarem, no município, em sua maior parte, no ambiente escolar. O distrito com menor prevalência de cárie dentária (maior percentual de $\mathrm{CPO}-\mathrm{D}=0$ ) foi utilizado como o referente;

\section{Covariáveis:}

Foram utilizadas as mesmas covariáveis da associação por tipo de estabelecimento de ensino. 


\section{RESULTADOS}

\subsection{Caracterização da população de estudo}

Examinou-se 3.318 adolescentes de escolas públicas e privadas de SalvadorBA, e após a revisão e digitação das fichas, 5 foram excluidas por falta de preenchimento do campo "idade". Assim, procedeu-se a análise dos dados com a população de 3.313 escolares, 1.750 aos 12 anos de idade e 1.563 aos 15 anos de idade, segundo a distribuição apresentada na Tabela 2. O erro de digitação foi de $0,20 \%$ dos campos, sendo que, após a identificação destes, retornou-se às fichas originais e foram realizadas as correções necessárias no banco de dados.

Tabela 2- Distribuição da população de estudo, aos 12 e 15 anos de idade, segundo distrito sanitário em Salvador, Bahia, 2001.

\begin{tabular}{lccc}
\hline \multirow{2}{*}{ Distrito' sanitário } & \multicolumn{3}{c}{ População de estudo } \\
\hline Barra- Rio Vermelho (BRV) & 202 & 174 & 376 \\
Centro histórico (CH) & 134 & 137 & 271 \\
Itapagipe (ITG) & 150 & 109 & 259 \\
Brotas (BRT) & 141 & 140 & 281 \\
Boca do Rio (BR) & 146 & 111 & 257 \\
Itapoã (ITA) & 127 & 139 & 266 \\
Cajazeiras (CAJ) & 140 & 148 & 288 \\
Cabula- Beiru (CB) & 144 & 140 & 284 \\
Liberdade (LIB) & 112 & 117 & 229 \\
Pau da Lima (PL) & 137 & 110 & 247 \\
Subúrbio Ferroviário (SF) & 164 & 131 & 295 \\
São Caetano- Valéria (SCV) & 153 & 107 & 260 \\
\hline TOTAL & 1.750 & 1.563 & 3.313 \\
\hline
\end{tabular}


As perdas amostrais, tanto aos 12 quanto aos 15 anos de idade, foram pequenas, representando $1,1 \%$ da amostra sorteada (Tabela 3). Quando somados os dados excluídos e as perdas de participação, o percentual obtido totalizou 1,49\%.

Tabela 3- Distribuição percentual das perdas amostrais de participação, aos 12 e 15 anos de idade, segundo distrito sanitário em Salvador, Bahia, 2001.

\begin{tabular}{lcccccc}
\hline & \multicolumn{5}{c}{ Idade } & \\
\cline { 2 - 7 } Distrito sanitário & \multicolumn{2}{c}{12 anos } & \multicolumn{1}{c}{15 anos } & \multicolumn{2}{c}{ TOTAL } \\
\hline Barra-Rio Vermelho (BRV) & n & $\%$ & $\mathrm{n}$ & $\%$ & $\mathrm{n}$ & $\%$ \\
Centro histórico (CH) & - & - & - & - & - & - \\
Itapagipe (ITG) & - & - & - & - & - & - \\
Brotas (BRT) & - & - & 8 & 7,0 & 8 & 3,1 \\
Boca do Rio (BR) & - & - & - & - & - & - \\
Itapoã (ITA) & - & - & 6 & 5,4 & 6 & 2,3 \\
Cajazeiras (CAJ) & - & - & - & - & - & - \\
Cabula-Beiru (CB) & - & - & - & - & - & - \\
Liberdade (LIB) & - & - & - & - & - & - \\
Pau da Lima (PL) & 5 & 4,0 & - & - & 5 & 2,2 \\
Subúrbio Ferroviário (SF) & - & - & 7 & 6,4 & 7 & 2,8 \\
São Caetano-Valéria (SCV) & - & - & - & - & - & - \\
\hline TOTAL & - & - & 10 & 9,3 & 10 & 3,8 \\
\hline
\end{tabular}

De modo geral, foi alta a concordância entre o distrito sanitário onde está localizada a escola e o distrito sanitário de residência (Figura 1), chegando a 100\% nos distritos de Cajazeiras, Pau da Lima e Subúrbio Ferroviário. Somente nas regiões centrais da cidade (Barra-Rio Vermelho e Centro Histórico) houve maior dispersão geográfica dos alunos, sendo esta mais elevada aos 15 anos de idade. 
Figura 1

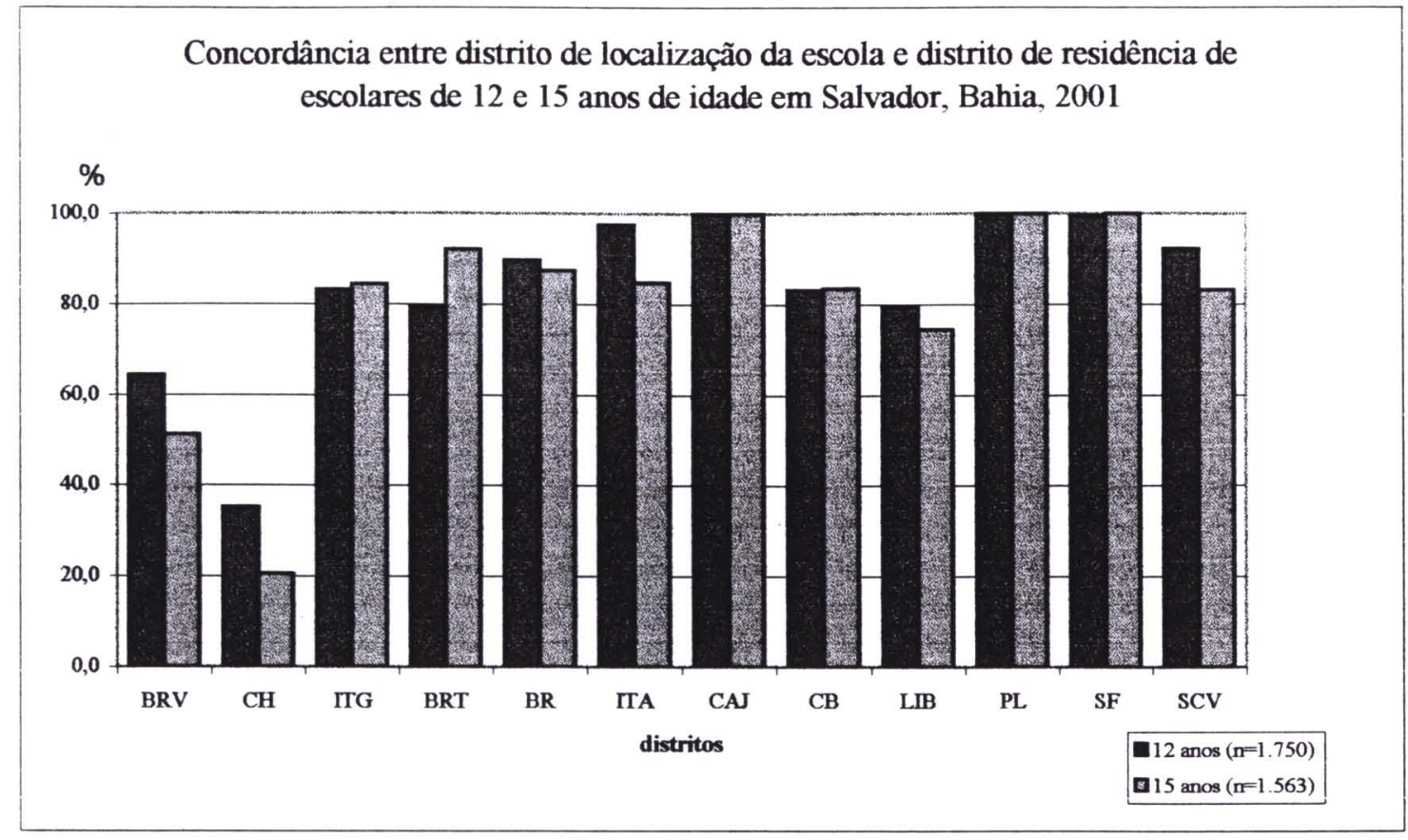

O número de estudantes do sexo feminino examinado foi maior do que aqueles do sexo masculino. Houve a predominância, na amostra, da etnia parda, $71,2 \%$ aos 12 anos e $73,2 \%$ aos 15 anos, respectivamente (Tabela 4). $\mathrm{O}$ acesso ao dentista no último ano aproximou-se dos 50\% da população de estudo (Figura 2), com uma distribuição semelhante em relação ao tipo de financiamento: público, particular e convênio. A participação em programas preventivos com o uso do flúor em escolas nos últimos 2 anos foi maior aos 12 anos (39,7\%) do que aos 15 anos de idade $(27,6 \%)$ (Figura 3). A maior proporção da amostra constituiu-se de estudantes que nasceram e residiram no próprio município de Salvador, $84,7 \%$ aos 12 anos, caracterizando neste grupo a não ingestão de flúor sistêmico decorrente da fluoretação das águas de abastecimento público até os oito anos de idade, enquanto 
aos 15 anos estes alunos estiveram apenas parcialmente (dos 0 aos 3 anos de idade e dos 11 aos 15 anos de idade) submetidos a este método preventivo (Tabela 4).

Figura 2

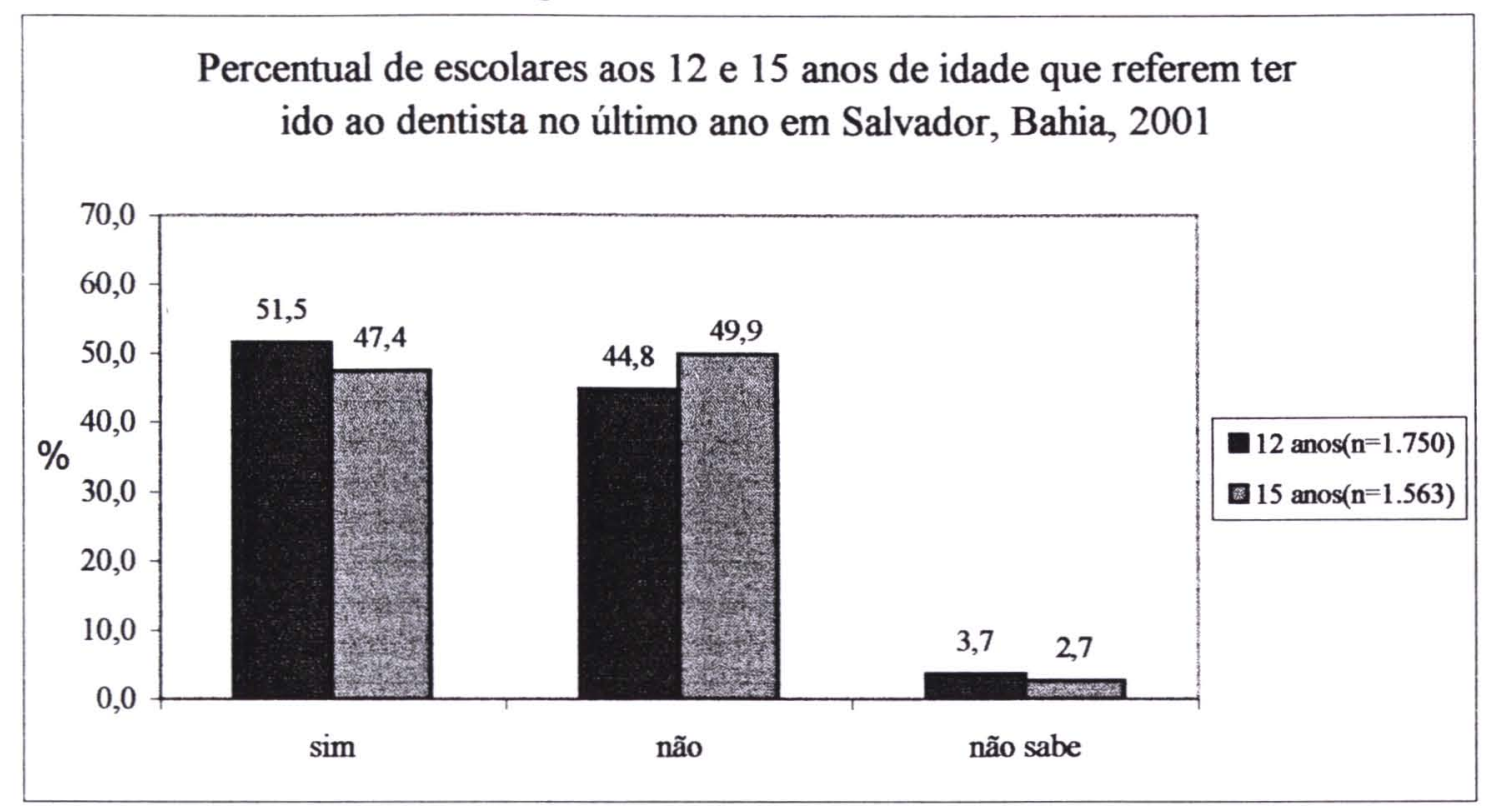

Figura 3

Percentual de escolares aos 12 e 15 anos de idade que relatam ter participado de programas coletivos nos últimos 2 anos em Salvador, Bahia, 2001.

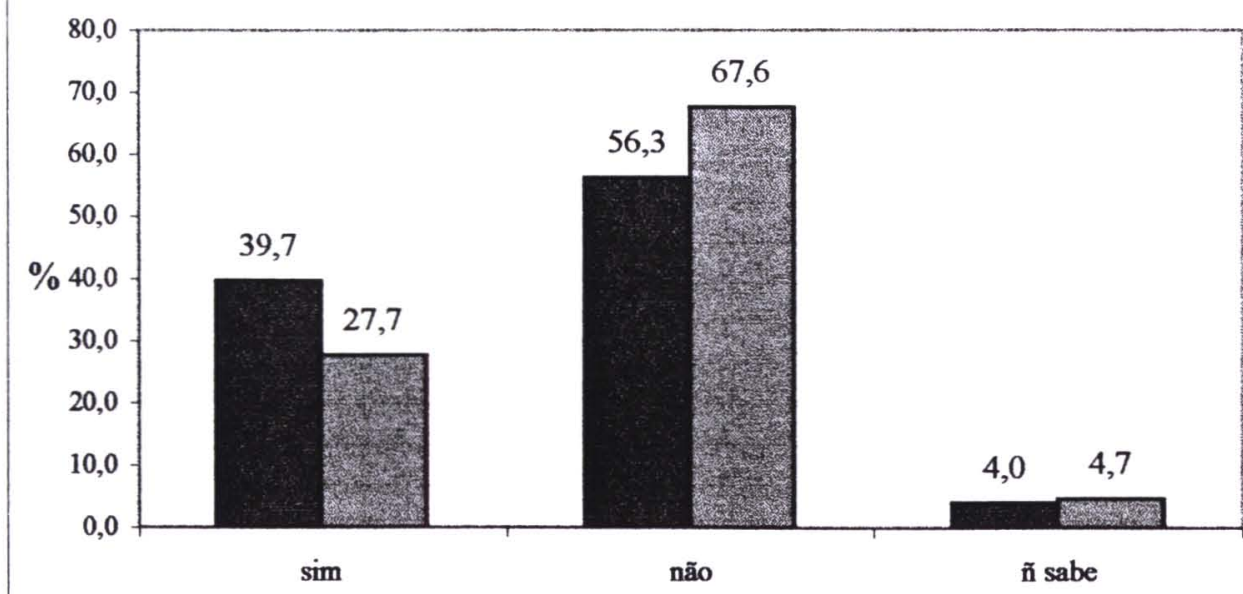


Tabela 4- Caracterização da população de estudo aos 12 e 15 anos de idade segundo tipo de escola, sexo, etnia, visita ao dentista no último ano, tipo de financiamento da mesma, participação em programas com uso do flúor e local de moradia nos primeiros 5 anos de vida em Salvador, Bahia, 2001.

\begin{tabular}{|c|c|c|c|c|}
\hline \multirow{2}{*}{ Variáveis } & \multicolumn{2}{|c|}{12 anos $(n=1.750)$} & \multicolumn{2}{|c|}{15 anos $(n=1.563)$} \\
\hline & $\mathrm{n}$ & $\%$ & $\mathrm{n}$ & $\%$ \\
\hline \multicolumn{5}{|c|}{ Tipo de Escola } \\
\hline pública & 1315 & 75,1 & 1139 & 72,9 \\
\hline particular & 435 & 24,9 & 424 & 27,1 \\
\hline \multicolumn{5}{|l|}{ Sexo } \\
\hline masculino & 797 & 45,5 & 661 & 42,3 \\
\hline feminino & 953 & 54,5 & 902 & 57,7 \\
\hline \multicolumn{5}{|l|}{ Etnia } \\
\hline branco & 88 & 5,0 & 73 & 4,7 \\
\hline negro & 414 & 23,7 & 345 & 22,1 \\
\hline pardo & 1247 & 71,2 & 1145 & 73,2 \\
\hline amarelo & 1 & 0,1 & - & - \\
\hline \multicolumn{5}{|c|}{$\begin{array}{l}\text { Visita ao dentista último } \\
\text { ano }\end{array}$} \\
\hline $\operatorname{sim}$ & 902 & 51,5 & 741 & 47,4 \\
\hline não & 784 & 44,8 & 780 & 49,9 \\
\hline não sabe & 64 & 3,7 & 42 & 2,7 \\
\hline \multicolumn{5}{|c|}{ Financiamento } \\
\hline público & 303 & 17,3 & 206 & 13,2 \\
\hline particular & 279 & 15,9 & 268 & 17,1 \\
\hline convênio & 250 & 14,3 & 242 & 15,5 \\
\hline não sabe & 86 & 4,9 & 33 & 2,1 \\
\hline não se aplica & 832 & 47,6 & 814 & 52,1 \\
\hline \multicolumn{5}{|c|}{$\begin{array}{l}\text { Participação programas } \\
\text { coletivos últimos } 2 \text { anos }\end{array}$} \\
\hline $\operatorname{sim}$ & 695 & 39,7 & 432 & 27,7 \\
\hline não & 985 & 56,3 & 1057 & 67,6 \\
\hline não sabe & 70 & 4,0 & 74 & 4,7 \\
\hline \multicolumn{5}{|c|}{$\begin{array}{l}\text { Local de moradia dos } \\
0 \text { aos } 5 \text { anos de idade }\end{array}$} \\
\hline Salvador & 1481 & 84,7 & 1278 & 81,8 \\
\hline Outros & 269 & 15,3 & 285 & 18,2 \\
\hline
\end{tabular}




\subsection{A cárie dentária no município de Salvador}

Encontrou-se, para o município, um CPO-D, aos 12 anos de idade, de 1,44 e de 2,66 aos 15 anos de idade, com a predominância do componente cariado e do restaurado, respectivamente (Tabela 5). Quanto as crianças livres da doença, observou-se o percentual de $49 \%(46,7-51,3) 95 \%$ IC, aos 12 anos, e, aos 15 anos, esta proporção correspondeu a 34,9\% (32,5- 37,3) 95\%IC. Analisando o Índice de Cárie Significante, o valor da média obtida foi de 3,85 aos 12 anos de idade.

Tabela 5- Condição dentária: CPO-D, intervalo de confiança a 95\%, Índice de Cárie Significante e composição percentual do índice em escolares de 12 e 15 anos de idade em Salvador, Bahia, 2001.

\begin{tabular}{|c|c|c|c|c|c|c|c|c|c|c|c|}
\hline \multirow[b]{2}{*}{ Idade } & \multirow[b]{2}{*}{$\mathrm{n}$} & \multirow[b]{2}{*}{ CPO-D } & \multicolumn{2}{|c|}{ IC $95 \%$} & & \multicolumn{2}{|c|}{ C } & \multicolumn{2}{|c|}{$\mathbf{P}$} & \multicolumn{2}{|c|}{ O } \\
\hline & & & $\mathrm{LI}^{1}$ & $\mathrm{LS}^{2}$ & $\mathrm{SiC}^{3}$ & $\bar{x}$ & $\%$ & $\bar{x}$ & $\%$ & $\bar{x}$ & $\%$ \\
\hline 12 anos & 1.750 & 1,44 & 1,35 & 1,52 & 3,85 & 0,72 & 50,00 & 0,07 & 4,86 & 0,65 & 45,14 \\
\hline 15 anos & 1.563 & 2,66 & 2,52 & 2,80 & 6,09 & 1,11 & 41,73 & 0,15 & 5,64 & 1,20 & 52,63 \\
\hline 7 & 31 & 1,9 & 84 & 2,00 & 4,97 & 0,90 & 46 & 0,10 & 5,2 & 0,91 & 47,92 \\
\hline
\end{tabular}

LI- Limite Inferior

${ }^{2}$ LS- Limite Superior

${ }^{3} \mathrm{SiC}$ - Índice de Cárie Significativa segundo proposta de BRATTHALL (2000).

A figura 4 descreve os resultados dos levantamentos populacionais utilizando o índice CPOD no municipio de Salvador, Bahia, aos 12 anos de idade. Entre os anos de 1986 e 1996, ocorreu um decréscimo de $460 \%$ da ocorrência de cárie dentária. Embora esta redução tenha se mantido entre 1996 e 2001, com um percentual menor de 5,9\%, identificou-se uma tendência de estabilização do indicador. 
Figura 4

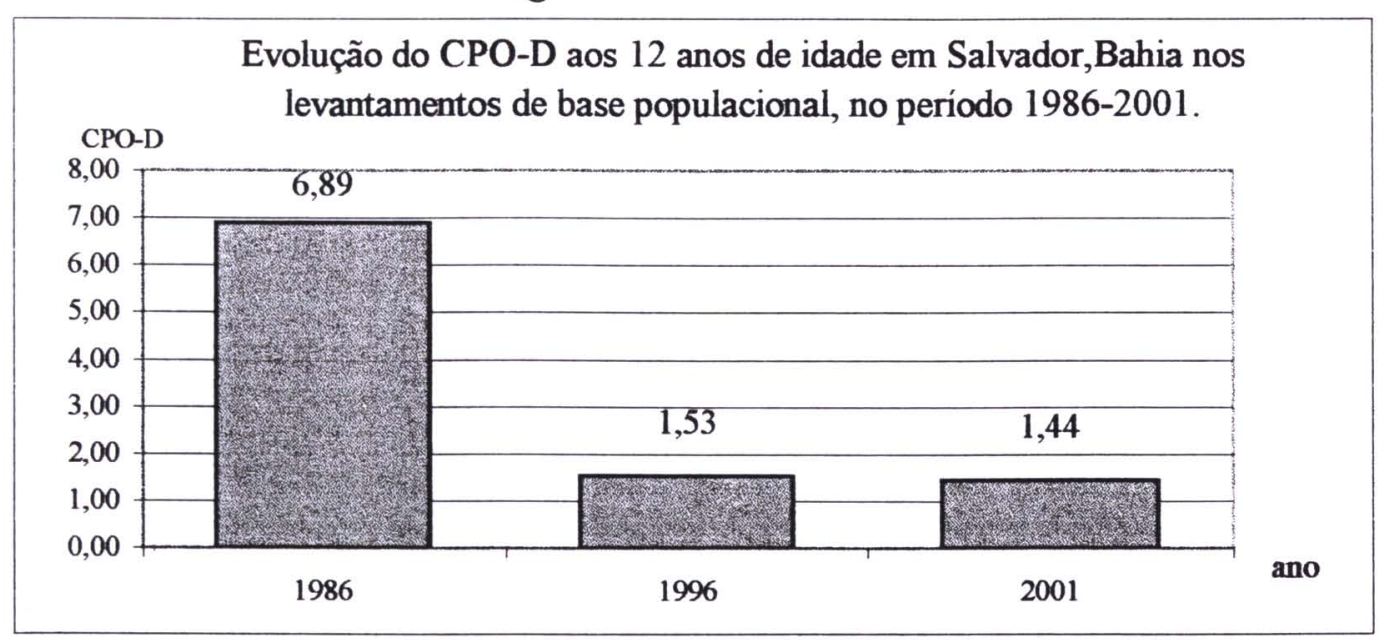

Houve uma concentração da população nos baixos níveis de cárie dental, sendo que praticamente $80 \%$ das crianças aos 12 anos de idade apresentaram-se com valores do CPO-D com até 3 dentes acometidos pela doença (Figura 5). Esta distribuição foi similar aos 15 anos de idade, embora com uma pequena redução do percentual de crianças com valores do CPO-D iguais ou menores que 3 (Figura 6).

Figura 5

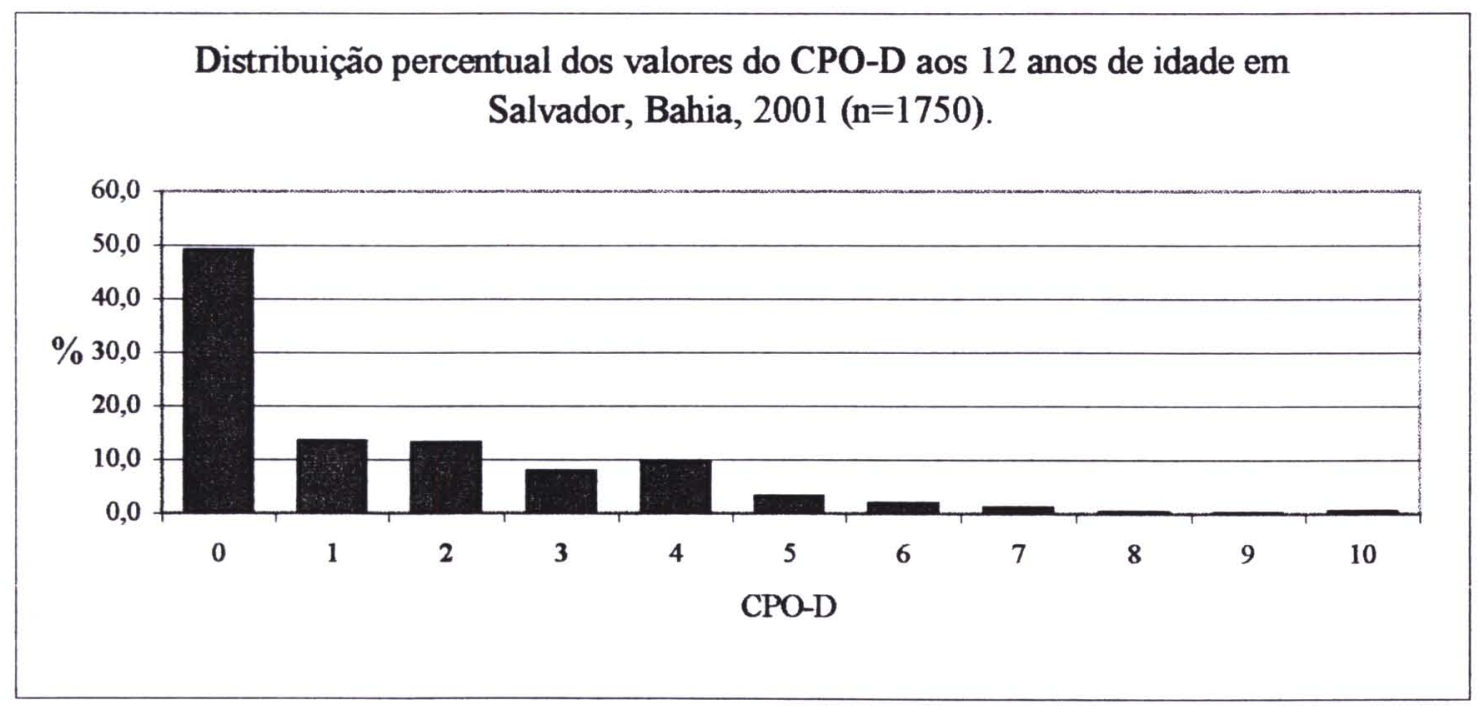


Figura 6

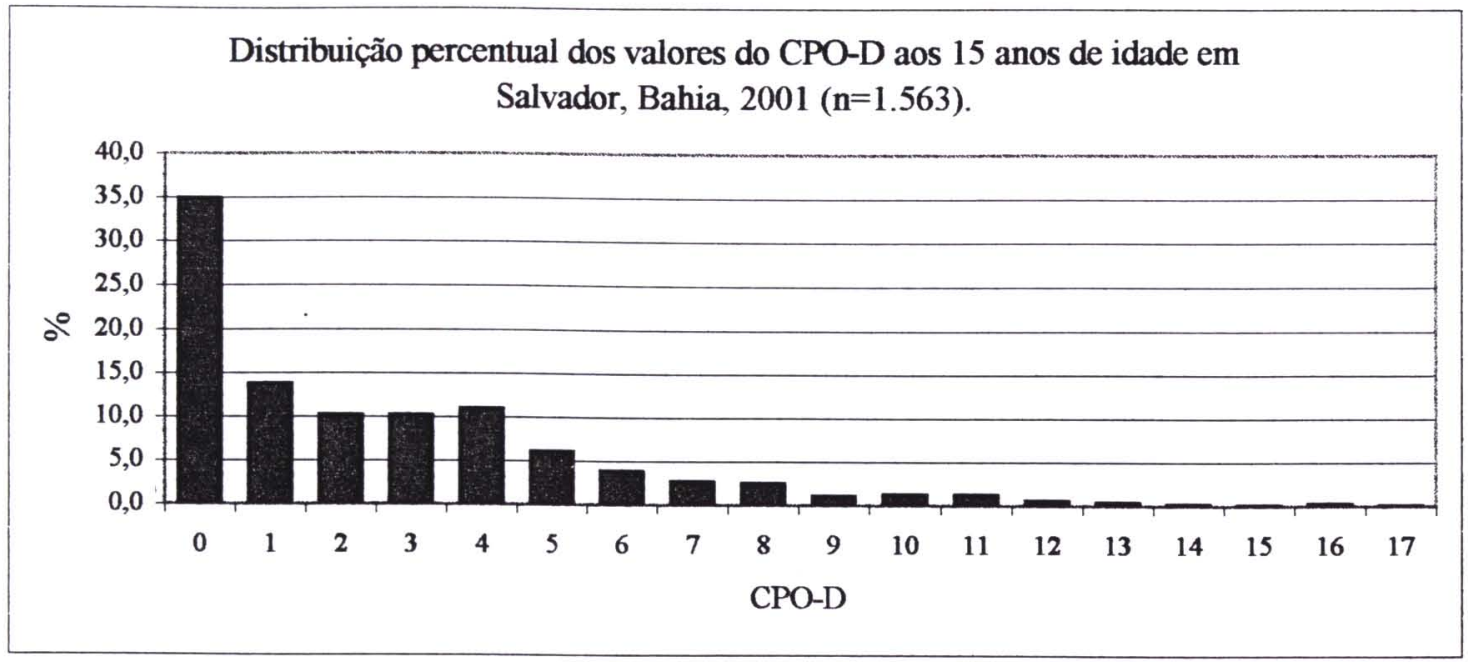

As unidades dentárias mais atingidas pela cárie aos 12 anos de idade foram os primeiros molares permanentes, correspondendo a $75,1 \%$ do total de dentes acometidos, seguidos dos segundos molares, incisivos e pré-molares (Figura 7). Já aos 15 anos, apesar dos primeiros molares continuarem representando os dentes mais afetados houve uma maior participação de outros elementos, especialmente os segundos molares e pré-molares (Figura 8).

Figura 7

Distribuição percentual do CPO-D por grupo dentário aos 12 anos de idade em Salvador, Bahia, 2001.

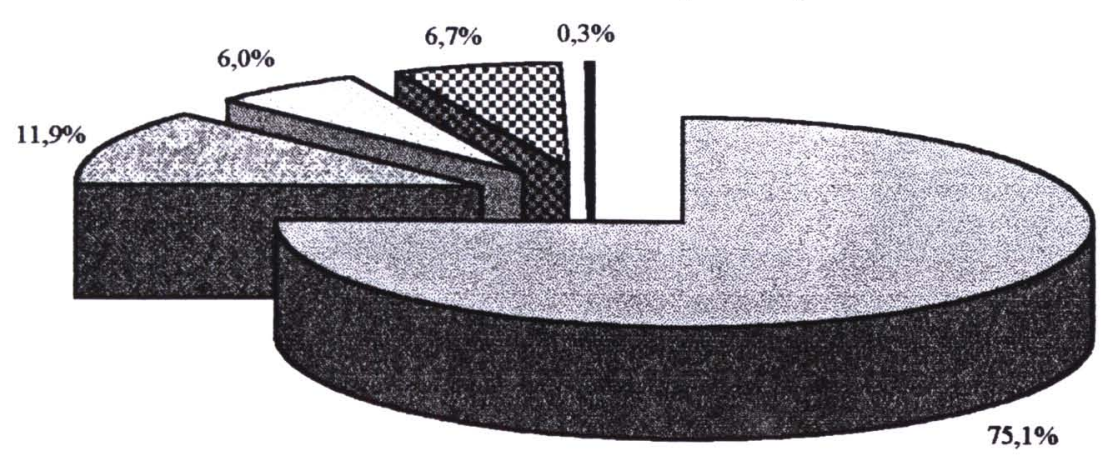

[ los. Ms

圆20.Ms

口PMs

QIncisivos

- Caninos 
Figura 8

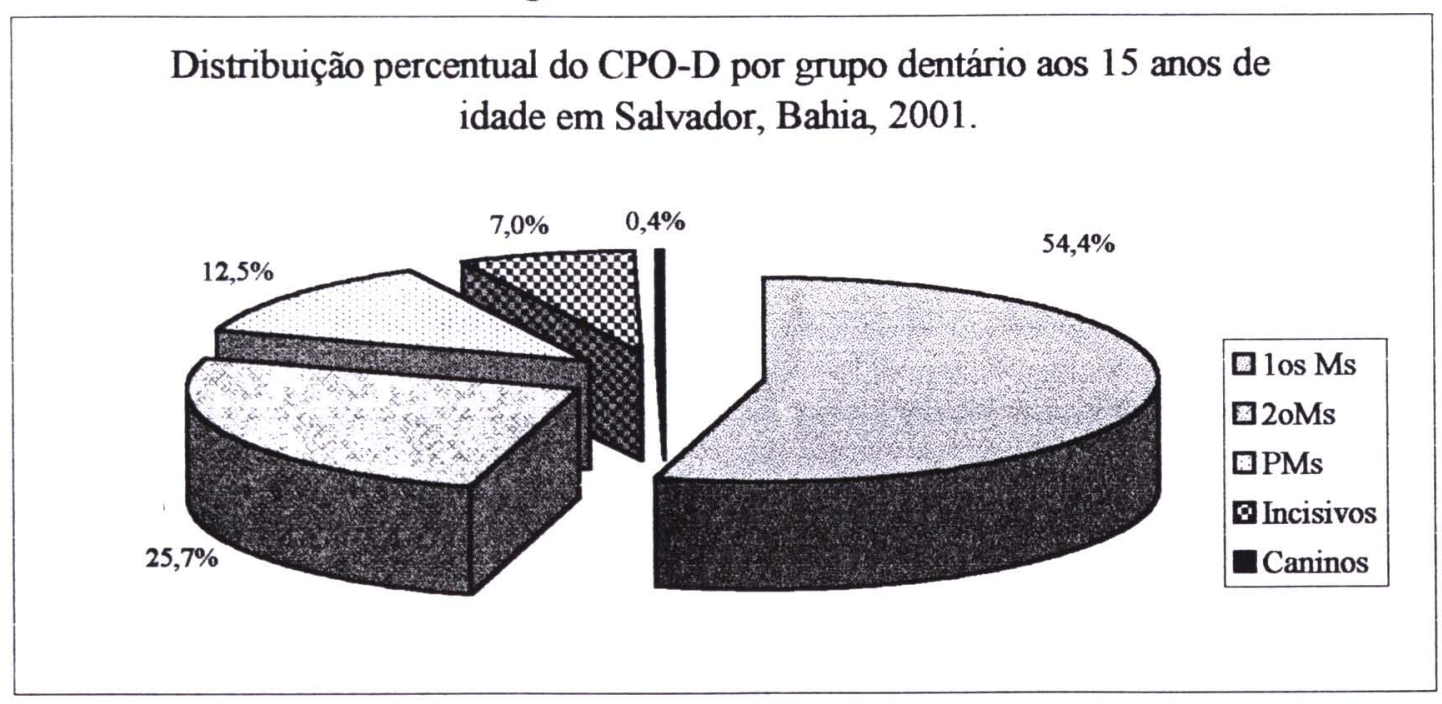

Do total de dentes erupcionados, $6 \%$ apresentaram cárie dentária aos 12 anos e $9 \%$ aos 15 anos de idade, como pode ser observado na figura 9 , indicando um incremento da doença na adolescência.

Figura 9

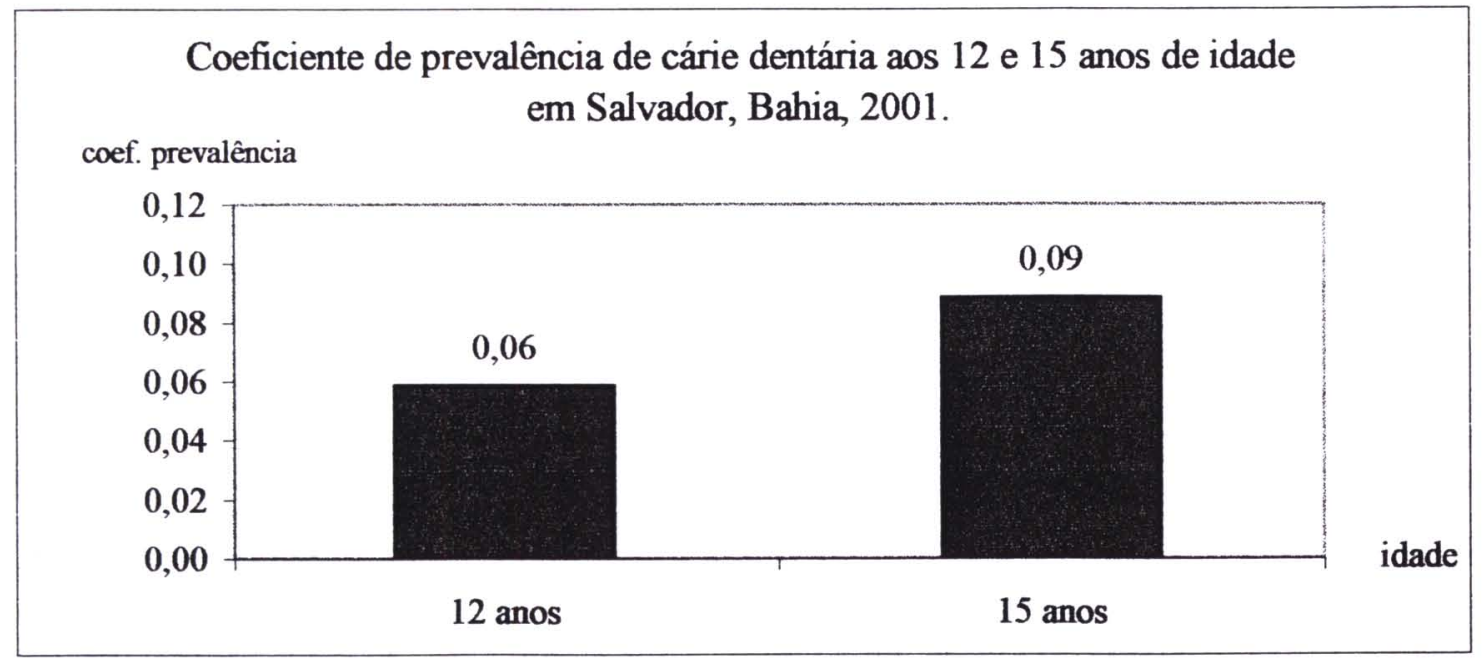




\subsection{Cárie dentária segundo distrito sanitário}

Quando se analisa a distribuição da cárie dentária por distrito sanitário, destacam-se as menores médias do CPO-D e a maior proporção de indivíduos livres de cárie nos distritos de Cajazeiras, Pau da Lima e Subúrbio Ferroviário, aos 12 anos, com uma severidade classificada como muito baixa segundo os critérios da OMS, de um CPO-D $<1,2$. Os outros distritos colocam-se na categoria de prevalência baixa, isto é, um CPO-D entre 1,2 e 2,6 (Tabela 6, Figuras 10 e 11). As regiões com as maiores médias do CPO-D também apresentam os maiores valores do Índice de Cárie Significante, sendo estes os distritos do Centro Histórico, Itapoã e Liberdade.

Tabela 6- Condição dentária: CPO-D e intervalo de confiança a 95\%, Índice de Cárie Significante, percentagem de indivíduos livres de cárie e intervalo de confiança a $95 \%$ em escolares de 12 anos de idade segundo distrito sanitário em Salvador, Bahia, 2001.

\begin{tabular}{|c|c|c|c|c|c|c|c|c|}
\hline \multirow[b]{2}{*}{ Distrito Sanitário } & \multirow[b]{2}{*}{$\mathbf{n}$} & \multirow[b]{2}{*}{ CPO-D } & \multicolumn{2}{|c|}{$95 \%$ IC } & \multirow[b]{2}{*}{$\mathrm{SiC}^{3}$} & \multirow[b]{2}{*}{$\begin{array}{c}\text { \%livres } \\
\text { cárie }\end{array}$} & \multicolumn{2}{|c|}{$95 \% \mathrm{IC}$} \\
\hline & & & $\mathrm{LI}^{1}$ & $\mathrm{LS}^{2}$ & & & $\mathrm{LI}^{1}$ & $\mathrm{LS}^{2}$ \\
\hline Barra-Rio Vermelho (BRV) & 202 & 1,44 & 1,20 & 1,68 & 3,69 & 46,50 & 39,62 & 53,38 \\
\hline Centro histórico $(\mathrm{CH})$ & 134 & 1,60 & 1,26 & 1,94 & 4,22 & 46,30 & 37,77 & 54,83 \\
\hline Itapagipe (ITG) & 150 & 1,51 & 1,22 & 1,80 & 3,71 & 43,30 & 35,29 & 51,31 \\
\hline Brotas (BRT) & 141 & 1,48 & 1,15 & 1,81 & 4,00 & 50,40 & 42,06 & 58,74 \\
\hline Boca do Rio (BR) & 146 & 1,53 & 1,22 & 1,84 & 4,00 & 48,60 & 40,41 & 56,79 \\
\hline Itapoã (ITA) & 127 & 1,82 & 1,47 & 2,17 & 4,83 & 37,80 & 29,28 & 46,32 \\
\hline Cajazeiras (CAJ) & 140 & 1,14 & 0,80 & 1,48 & 3,50 & 60,70 & 52,53 & 68,87 \\
\hline Cabula-Beiru (CB) & 144 & 1,40 & 1,11 & 1,69 & 3,57 & 49,30 & 41,05 & 57,55 \\
\hline Liberdade (LIB) & 112 & 1,91 & 1,48 & 2,34 & 4,53 & 35,70 & 26,74 & 44,66 \\
\hline Pau da Lima (PL) & 137 & 1,13 & 0,84 & 1,42 & 3,56 & 63,50 & 55,36 & 71,64 \\
\hline Subúrbio Ferroviário (SF) & 164 & 1,13 & 0,87 & 1,39 & 3,50 & 55,50 & 47,89 & 63,11 \\
\hline São Caetano-Valéria (SCV) & 153 & 1,39 & 1,11 & 1,67 & 3,59 & 47,70 & 39,79 & 55,61 \\
\hline TOTAL & 1.750 & 1,44 & 1,35 & 1,52 & 3,85 & 49,00 & 46,66 & 51,34 \\
\hline
\end{tabular}

LI- Limite Inferior

${ }^{2}$ LS- Limite Superior

${ }^{3}$ SiC- Índice de Cárie Significativa segundo proposta de BRATTHALL (2000). 
Figura 10

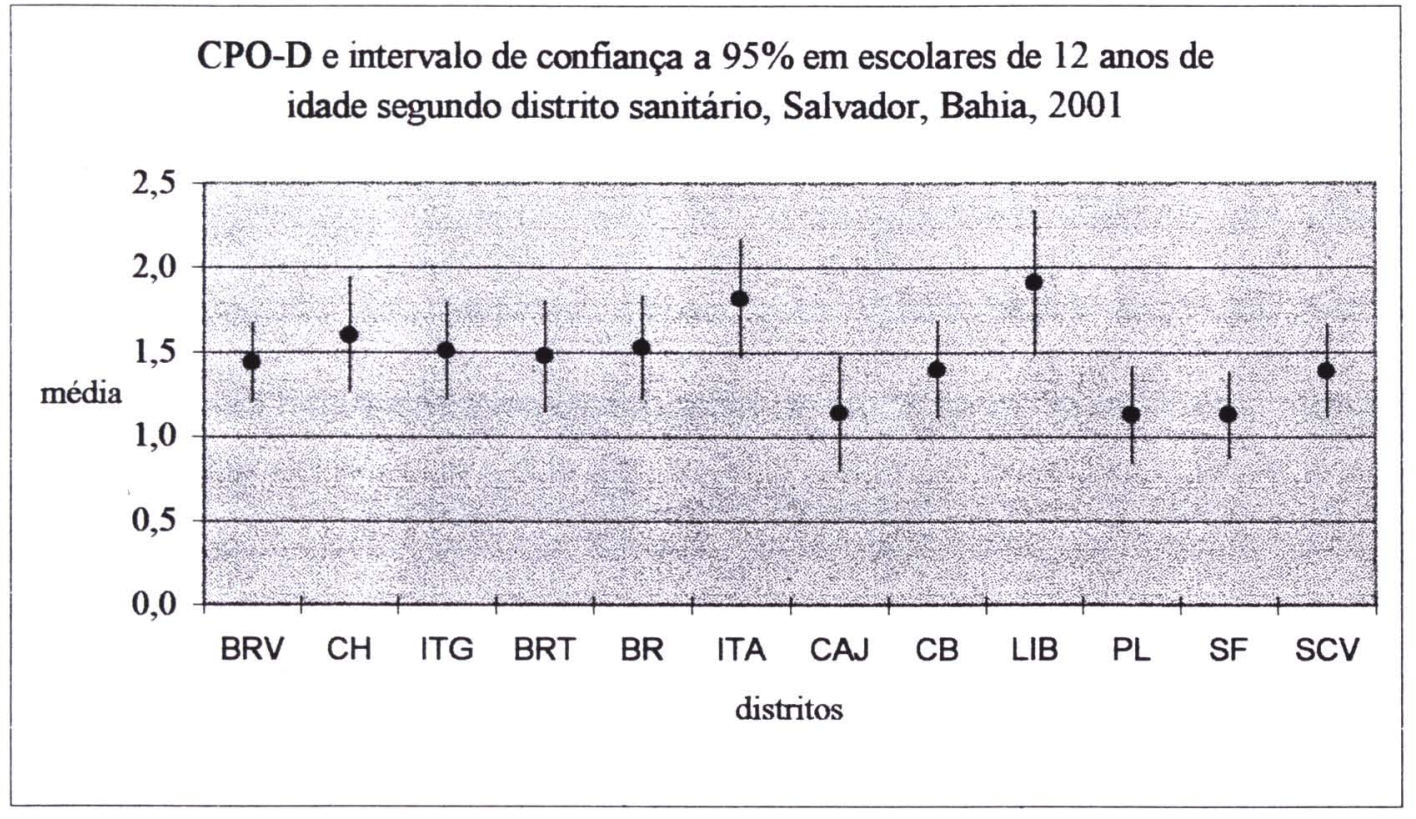

Figura 11

Percentual de escolares livres de cárie e intervalo de confiança a $95 \%$ aos

12 anos de idade segundo distrito sanitário em Salvador, Bahia, 2001

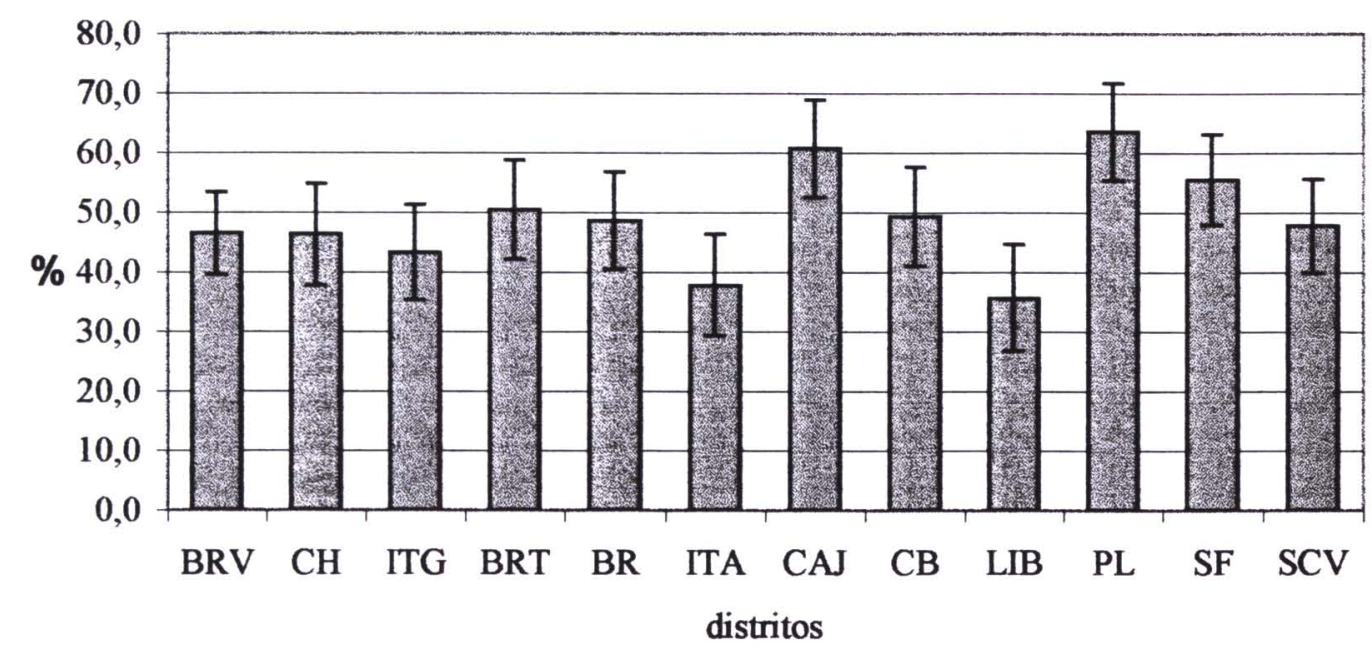


Dentre as covariáveis consideradas relevantes para as diferenças dos indices de cárie nesta idade, testou-se a etnia, o acesso ao dentista no último ano e tipo de financiamento, participação em programas coletivos nos últimos dois anos e local de moradia nos primeiros 5 anos de vida. Na Tabela 7 , pode-se observar que todas as variáveis propostas apresentavam distribuições diferenciadas entre os distritos sanitários, sendo relevante serem investigadas na modelagem, na análise de regressão logística. 


\begin{tabular}{|c|c|c|c|c|c|c|c|}
\hline 品 & $\frac{\mathrm{a}}{5}$ & $0_{0}$ & 8 & 8 & 8 & 8 & 구 \\
\hline & $\begin{array}{c}z \\
\frac{n}{3}\end{array}$ & $\tilde{n}^{n} 0^{\infty}$ & 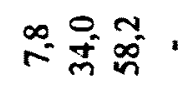 & 宩安的 & 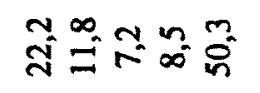 & $\begin{array}{l}0.00 \\
\text { से }\end{array}$ & $\tilde{z}$ \\
\hline & 出营 & $\begin{array}{l}0 \\
i= \\
i\end{array}$ & チ & 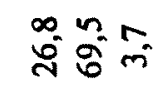 & 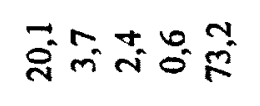 & 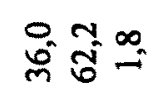 & $\vec{\infty}$ \\
\hline ถุำ & $2 \frac{5}{\frac{9}{n}}$ & $\begin{array}{l} \pm 0 \\
\dot{m} \\
\tilde{m}^{\circ}\end{array}$ & ․ & $\vec{\gamma}$ के & $\begin{array}{l}0 \\
\dot{I}\end{array}$ & 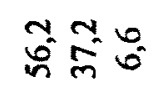 & $\begin{array}{l}\infty \\
\infty \\
\infty\end{array}$ \\
\hline & 思弯 & $\hat{n} \frac{2}{4}$ & 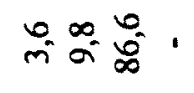 & $\vec{n}=\stackrel{\infty}{=}$ & 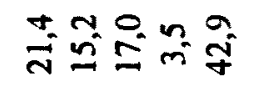 & लि: & ڤ̊ \\
\hline के & 思竎 & $\vec{a}$ & $\vec{\infty} \vec{\infty} \cdot$ & 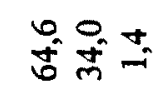 & $\begin{array}{l}n \\
\vec{i} \\
\vec{i}\end{array}$ & 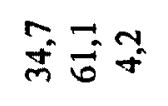 & हू \\
\hline 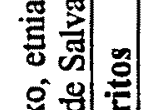 & 己월 & $\hat{9} \hat{n}^{2}$ & $\vec{\varrho} \overrightarrow{\tilde{N}} \tilde{\delta}$. & लें̂ें & 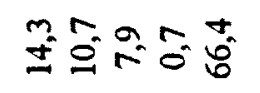 & $\begin{array}{l}0 \\
=0 \\
0\end{array}$ & $\hat{\infty}^{\circ}$ \\
\hline & $\varangle \Xi$ & $\begin{array}{l}n= \\
n=y \\
n=y\end{array}$ & के ते $\overrightarrow{\hat{n}}$. & $\vec{\sigma}+\vec{m}$ & 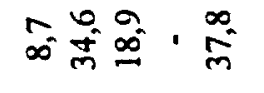 & 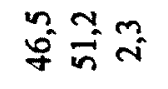 & $\stackrel{t}{0}$ \\
\hline & & $\hat{\tilde{y}}$ & $\underset{*}{*} \frac{m}{\sim} \underset{*}{*}$ & 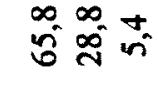 & 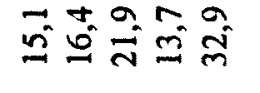 & $\begin{array}{l}m \\
f^{*} \\
f^{\circ}\end{array}$ & \\
\hline 5 & & $\begin{array}{l}\infty \\
\rightarrow \infty \\
\dot{q}\end{array}$ & ' & $\begin{array}{l}\infty \\
\dot{n} \\
n\end{array}$ & 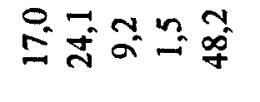 & 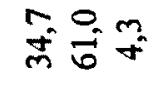 & \\
\hline & $\stackrel{0}{\pi}$ & $\frac{n}{a}=\frac{m}{n}$ & $\stackrel{2}{=} 0 \overline{0}$. & $\frac{m}{n}=$ & 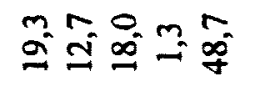 & $\sin 0$ & $\infty_{\infty}^{*}$ \\
\hline 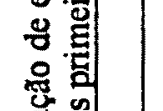 & 둰 & 﨎 & 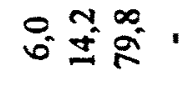 & 乱㐫. & 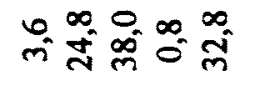 & $\overrightarrow{\infty^{0}} \frac{-}{0}$ & \\
\hline 2 & 畐 웝 & $\frac{0}{n}:$ & 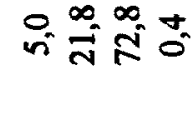 & 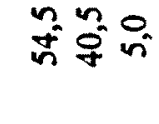 & 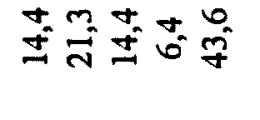 & $\hat{n}^{m} \tilde{y}$ & \\
\hline 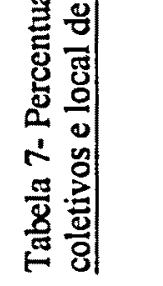 & & 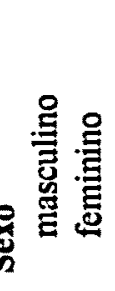 & 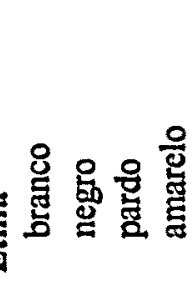 & & 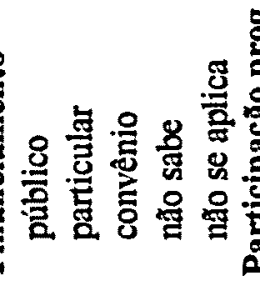 & & \\
\hline
\end{tabular}


Na regressão logística considerou-se como variável dependente a prevalência de cárie dentária, utilizando como referência o distrito de melhor condição de saúde bucal (Pau da Lima), detectou-se diferenças estatisticamente significativas entre os distritos, ajustadas pelas variáveis sexo e acesso ao dentista no último ano. Nenhuma das outras covariáveis propostas no modelo saturado foram importantes na associação principal. Destacam-se os distritos do Centro Histórico, Brotas, Itapoã, Subúrbio Ferroviário com cerca de 1,5 vezes mais ocorrência de cárie do que o referente; Barra-Rio Vermelho, Itapagipe e São Caetano-Valéria com 2 vezes maior prevalência e a Liberdade, com a pior condição de saúde, aproximadamente 3 vezes (Tabela 8).

Tabela 8- Modelo reduzido da regressão logística para a associação entre prevalência de cárie dentária (CPO-D=0) aos 12 anos de idade segundo distrito sanitário ajustado por sexo e acesso ao dentista no último ano, Salvador, Bahia, 2001. ${ }^{1}$

\begin{tabular}{lccc}
\hline Variáveis & Odds Ratio (OR) & \multicolumn{3}{c}{ Intervalo de confiança 95\% } \\
& & $\mathrm{LI}^{2}$ & $\mathrm{LS}^{3}$ \\
\hline Distrito Pau da Lima & 1,00 & \multicolumn{2}{c}{-} \\
Distrito Barra-Rio Vermelho & $1,93^{*}$ & 1,23 & 3,03 \\
Distrito Centro Histórico & $1,72^{*}$ & 1,05 & 2,83 \\
Distrito Itapagipe & $2,24^{*}$ & 1,39 & 3,64 \\
Distrito Brotas & 1,65 & 1,01 & 2,68 \\
Distrito Boca do Rio & 1,61 & 0,99 & 2,62 \\
Distrito Itapoã & $2,69^{*}$ & 1,62 & 4,48 \\
Distrito Cajazeiras & 1,22 & 0,75 & 2,00 \\
Distrito Cabula- Beiru & 1,57 & 0,97 & 2,56 \\
Distrito Liberdade & $3,02^{*}$ & 1,78 & 5,13 \\
Distrito Subúrbio Ferroviário & 1,62 & 1,01 & 2,16 \\
Distrito São Caetano-Valéria & $1,88^{*}$ & 1,17 & 3,04 \\
\hline
\end{tabular}

\footnotetext{
${ }^{\top} \mathrm{R}^{2}=0,14 \quad \mathrm{p}=0,000 \quad$ Máxima verossimilhança- $\mathrm{p}=0,15$

${ }^{2} \mathrm{LI}$ : Limite Inferior

${ }^{3}$ LS: Limite Superior

* diferenças estatisticamente significativas num nível de $5 \%$.
} 
Aos 15 anos de idade, quando se analisa o CPO-D e seu respectivo intervalo de confiança, destaca-se que apenas os distritos de Pau da Lima, Cajazeiras e São Caetano-Valéria mantêm-se com valores inferiores a um $\mathrm{CPO}-\mathrm{D}=2,00$. Os distritos Barra-Rio Vermelho, Itapagipe, Boca do Rio, Cabula-Beiru, Subúrbio Ferroviário e Liberdade apresentaram níveis intermediários da doença e os distritos do Centro Histórico,' Brotas, Itapoã foram identificados com um CPO-D acima do valor 3. (Tabela 9, Figuras 12 e 13).

Tabela 9- Condição dentária: CPO-D e intervalo de confiança a 95\%, percentagem de indivíduos livres de cárie e intervalo de confiança a 95\% em escolares de 15 anos de idade segundo distrito sanitário em Salvador, Bahia, 2001.

\begin{tabular}{lccccccc}
\hline & & & \multicolumn{2}{c}{$95 \% \mathrm{IC}$} & \%livres & \multicolumn{2}{c}{$95 \% \mathrm{IC}$} \\
\cline { 8 - 9 } Distrito Sanitário & $\mathrm{n}$ & CPO-D & $\mathrm{LI}^{\mathbf{1}}$ & $\mathrm{LS}^{2}$ & cárie & LI $^{1}$ & $\mathrm{LS}^{2}$ \\
\hline Barra-Rio Vermelho (BRV) & 174 & 2,56 & 2,18 & 2,94 & 35,60 & 28,49 & 42,71 \\
Centro Histórico (CH) & 137 & 3,10 & 2,52 & 3,68 & 27,00 & 19,49 & 34,51 \\
Itapagipe (ITG) & 109 & 2,29 & 1,77 & 2,81 & 37,60 & 28,41 & 46,79 \\
Brotas (BRT) & 140 & 3,35 & 2,79 & 3,91 & 22,10 & 15,16 & 29,04 \\
Boca do Rio (BR) & 111 & 2,27 & 1,72 & 2,82 & 42,30 & 33,02 & 51,58 \\
Itapoã (TTA) & 139 & 3,10 & 2,53 & 3,67 & 26,60 & 19,18 & 34,02 \\
Cajazeiras (CAJ) & 148 & 1,82 & 1,47 & 2,17 & 45,30 & 37,20 & 53,40 \\
Cabula-Beiru (CB) & 140 & 2,40 & 1,91 & 2,89 & 32,10 & 24,29 & 39,91 \\
Liberdade (LIB) & 117 & 2,87 & 2,35 & 3,39 & 24,80 & 16,90 & 32,70 \\
Pau da Lima (PL) & 110 & 1,40 & 1,04 & 1,76 & 51,80 & 42,37 & 61,23 \\
Subúrbio Ferroviário (SF) & 131 & 2,10 & 1,67 & 2,53 & 37,40 & 29,03 & 45,77 \\
São Caetano-Valéria (SCV) & 107 & 1,95 & 1,47 & 2,43 & 40,20 & 30,82 & 49,58 \\
\hline TOTAL & 1.563 & 2,46 & 2,52 & 2,80 & 34,90 & 32,53 & 37,27 \\
\hline
\end{tabular}

LI: Limite Inferior

${ }^{2}$ LS: Limite Superior 
Figura 12

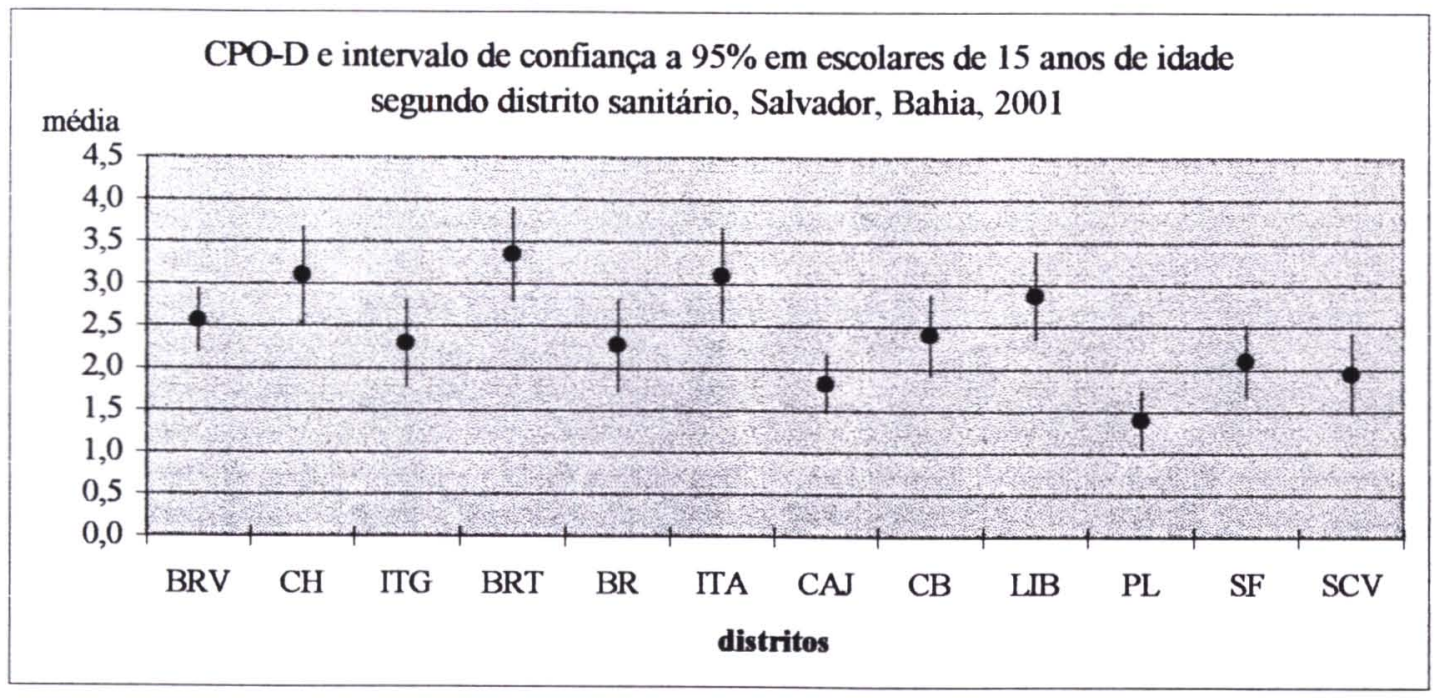

Figura 13

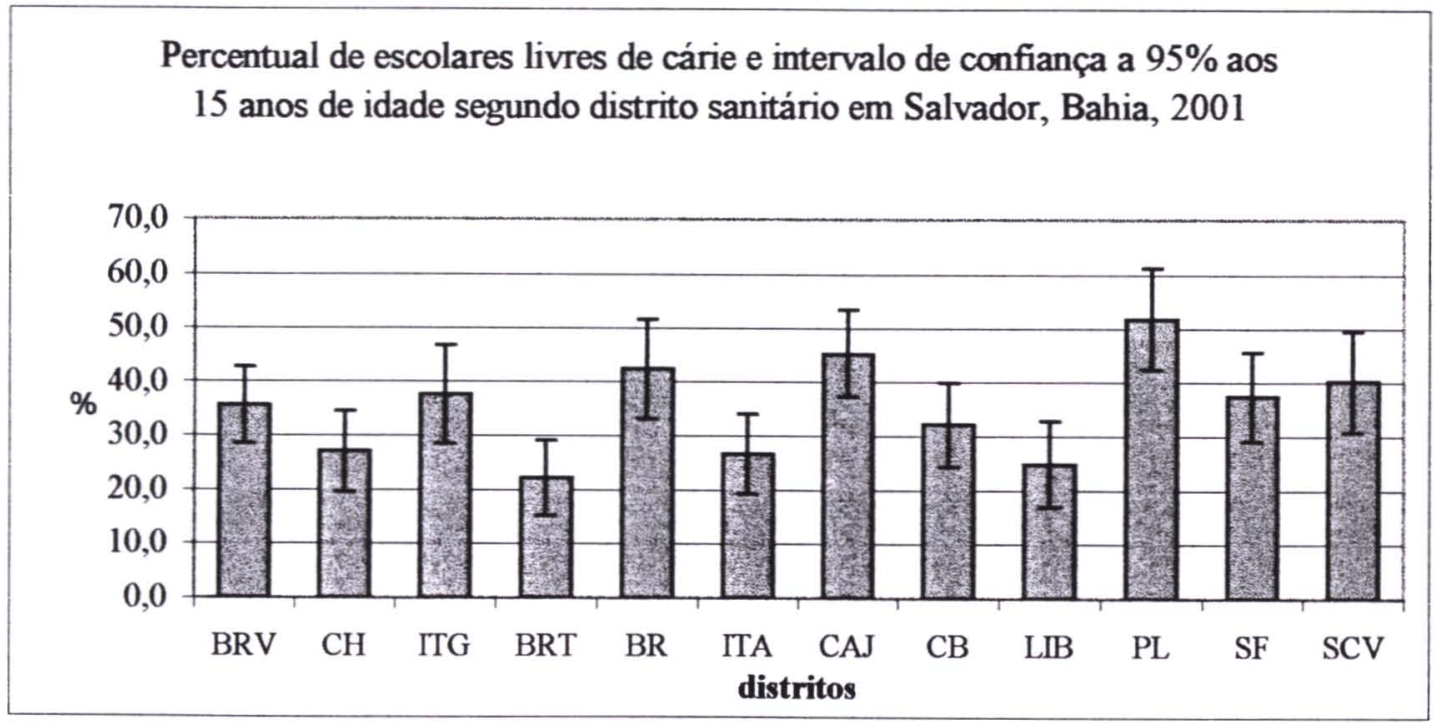

Ao testar-se, na análise descritiva, as possiveis variáveis de confusão e sua distribuição segundo distrito sanitário na idade de 15 anos, as variáveis etnia, acesso ao dentista no último ano e tipo de financiamento e participação em programas coletivos nos últimos dois anos, se apresentaram significantes no teste do quiquadrado (Tabela 10). 


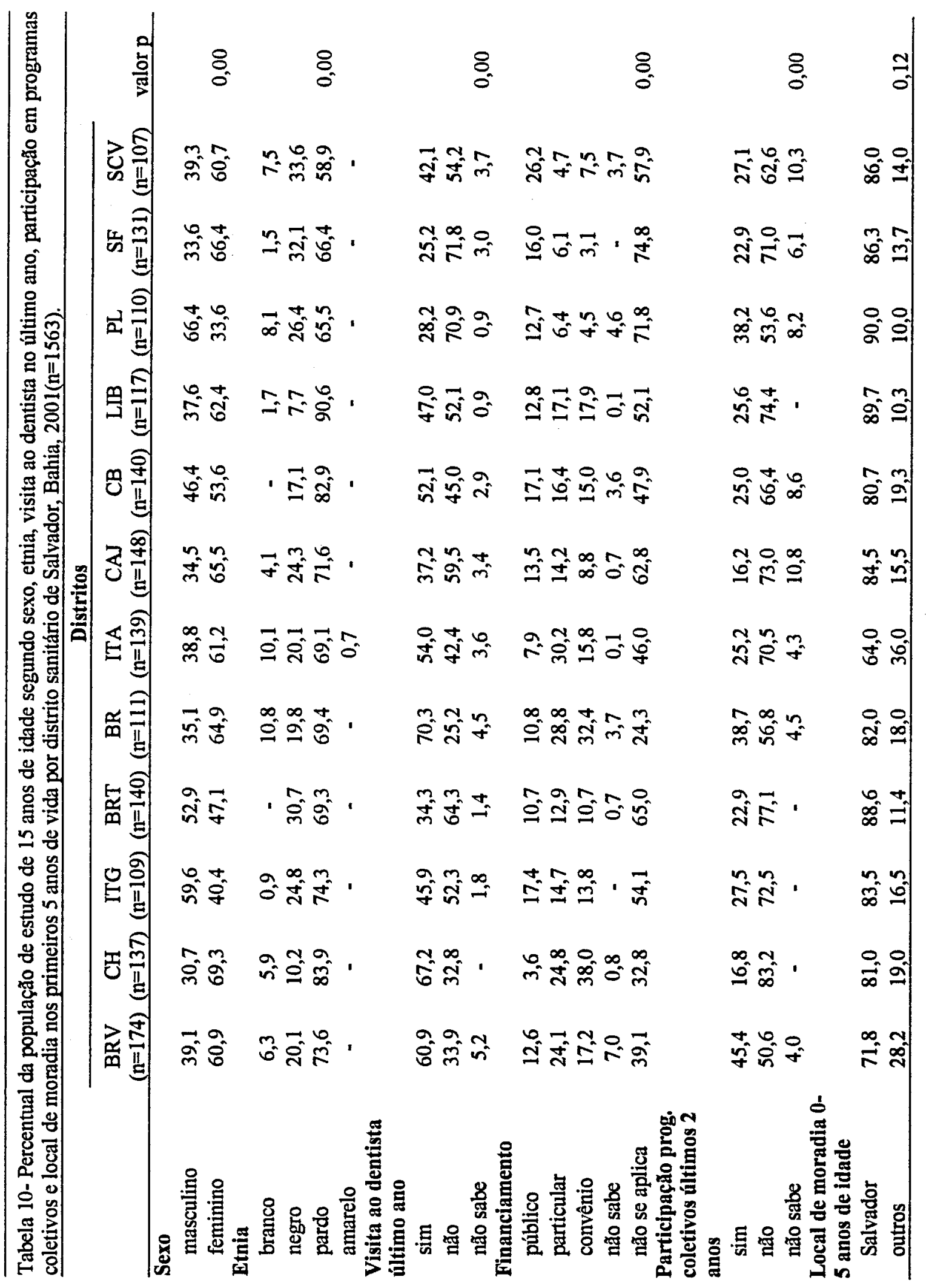


$\mathrm{Na}$ modelagem da regressão logística aos 15 anos, utilizando como referência o distrito de Pau da Lima, também foram detectadas diferenças estatisticamente significativas entre os distritos do Centro Histórico, Brotas, Itapoã, Cabula- Beiru e Liberdade, ajustadas pelo sexo, participação em programas de promoção de saúde bucal com uso do flúor e acesso ao dentista no último ano segundo tipo de financiamento. No restante das áreas não houve associação estatisticamente significativa (Tabela 11).

Tabela 11- Modelo reduzido da regressão logística para a associação entre prevalência de cárie dentária $(\mathrm{CPO}-\mathrm{D}=0)$ aos 15 anos de idade segundo distrito sanitário ajustado por sexo, participação em programas nos últimos dois anos e tipo de financiamento no acesso ao dentista, Salvador, Bahia, 2001. ${ }^{1}$

\begin{tabular}{lccc}
\hline Variáveis & Odds Ratio (OR) & \multicolumn{2}{c}{ Intervalo de confiança- 95\% } \\
& & LI $^{2}$ & LS $^{3}$ \\
\hline Distrito Pau da Lima & 1,00 & \multicolumn{2}{c}{} \\
Distrito Barra-Rio Vermelho & 1,50 & 0,91 & 2,48 \\
Distrito Centro Histórico & $1,92^{*}$ & 1,09 & 3,36 \\
Distrito Itapagipe & 1,48 & 0,86 & 2,57 \\
Distrito Brotas & $3,38^{*}$ & 1,93 & 5,89 \\
Distrito Boca do Rio & 0,97 & 0,56 & 1,70 \\
Distrito Itapoã & $2,20^{*}$ & 1,27 & 3,81 \\
Distrito Cajazeiras & 1,00 & 0,60 & 1,67 \\
Distrito Cabula-Beiru & $1,77^{*}$ & 1,04 & 3,00 \\
Distrito Liberdade & $2,51^{*}$ & 1,41 & 4,47 \\
Distrito Subúrbio Ferroviário & 1,53 & 0,90 & 2,60 \\
Distrito São Caetano-Valéria & 1,28 & 0,73 & 2,23
\end{tabular}

${ }^{T} R^{2}=0,14 \quad p=0,0000 \quad$ Máxima verossimilhança- $p=0,19$

${ }^{2}$ LI: Limite Inferior

${ }^{3}$ LS: Limite Superior

*diferenças estatisticamente significativas ao nível de 5\%. 
Observa-se, na Figura 14, que além das diferenças significativas entre os distritos sanitários aos 12 anos de idade, a composição percentual deste índice é desigual entre os mesmos. Aos 12 anos predominam nos distritos Barra-Rio Vermelho, Centro Histórico e Liberdade o componente restaurado, enquanto que nos distritos de Itapoã, Brotas, Subúrbio Ferroviário e São Caetano-Valéria é maior a proporção de dentes cariados.

Figura 14

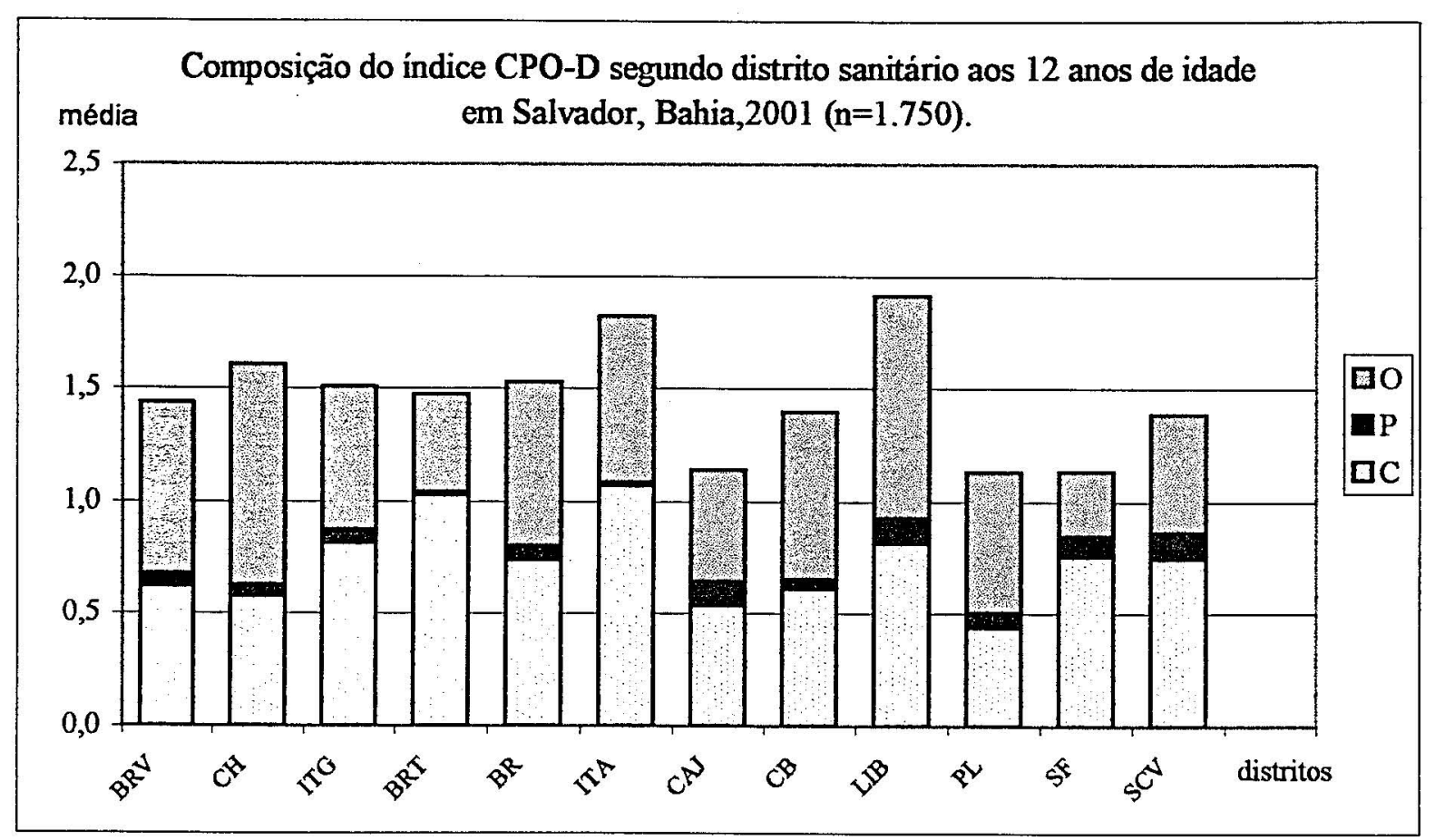

Já aos 15 anos de idade destaca-se a predominância do componente restaurado nos distritos Barra-Rio Vermelho, Centro Histórico, Boca do Rio, Itapoã, CabulaBeiru e Liberdade. Nas outras regiões, observa-se a maior proporção de dentes cariados (Figura 15). 
Figura 15

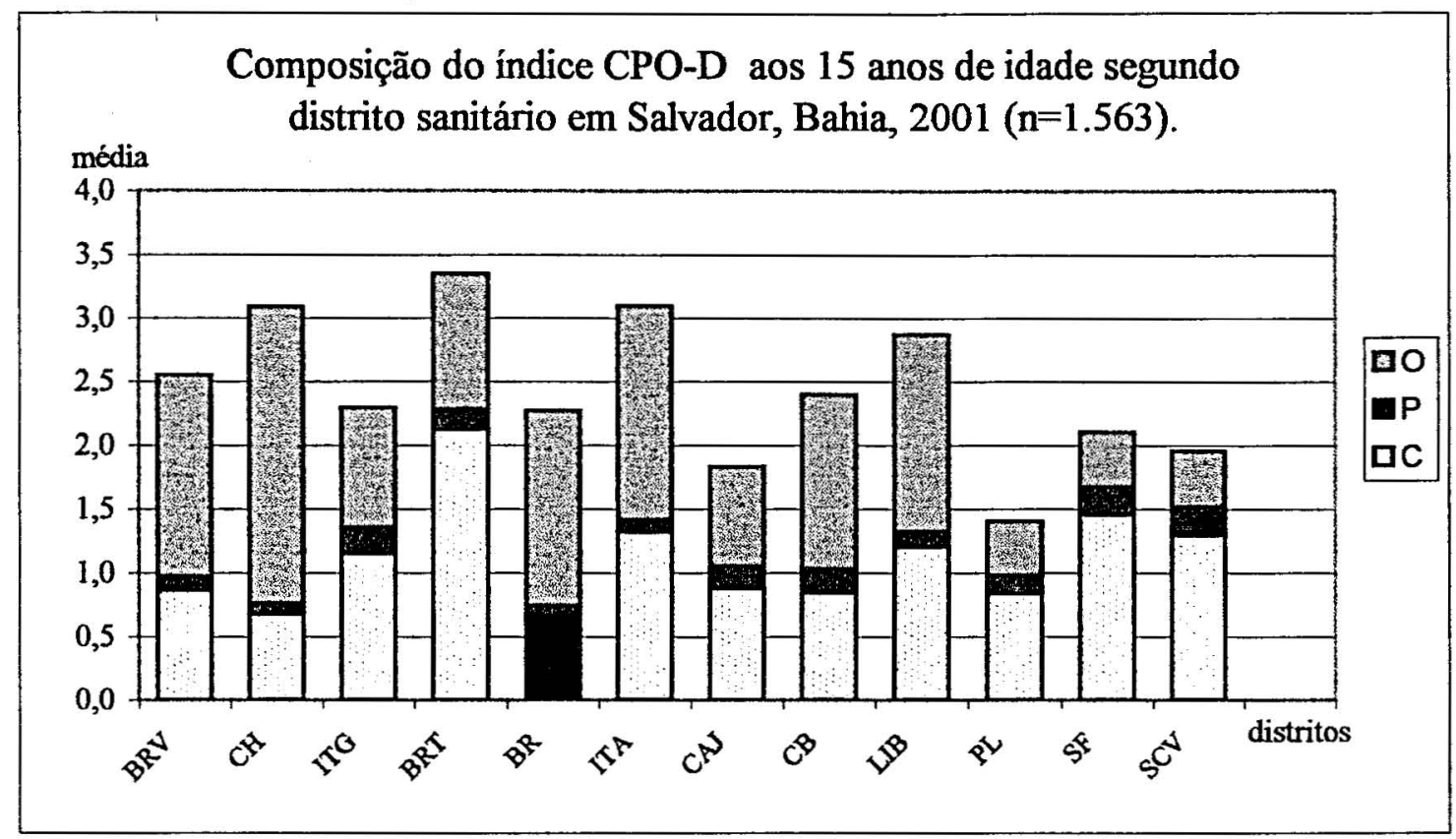

Em relação à distribuição da assistência odontológica no setor público no município, observa-se a concentração de cirurgiões dentistas e pessoal auxiliar nos distritos centrais da cidade (Barra-Rio Vermelho, Centro Histórico, Brotas) e registro de ações de promoção de saúde bucal em apenas poucas regiões: Barra-Rio Vermelho, Boca do Rio, Cajazeiras, Cabula-Beiru, Pau da Lima e Subúrbio Ferroviário. 
Tabela 12- Caracterização da rede assistencial e práticas desenvolvidas pela Secretaria Municipal de Saúde de Salvador, Bahia, 2001

\begin{tabular}{lccccc}
\hline Distrito & CD $^{*}$ & THD* & ACD* & $\begin{array}{l}\text { Consul } \\
\text { tórios* }\end{array}$ & Programas específicos \\
\hline $\begin{array}{l}\text { Barra- Rio } \\
\text { Vermelho }\end{array}$ & 40 & 5 & 11 & 11 & $\begin{array}{l}\text { - programas vinculados às práticas } \\
\text { coletivas UFBA (desde 1992) } \\
\text { - PACS desenvolvendo ações de } \\
\text { educação em saúde bucal }\end{array}$ \\
\hline $\begin{array}{l}\text { Centro } \\
\text { Histórico }\end{array}$ & 27 & 5 & 8 & 11 & - \\
\hline Itapagipe & 9 & 1 & 3 & 4 & \\
\hline Brotas & 28 & 6 & 6 & 6 & - \\
\hline Boca do Rio & 9 & 1 & 4 & 3 & $\begin{array}{l}\text { - programas de fluorterapia mensal } \\
\text { desde 1994 }\end{array}$ \\
\hline Itapoã & 20 & 6 & 3 & 5 & - \\
\hline Cajazeiras & 10 & 1 & 3 & 4 & \\
\hline $\begin{array}{l}\text { Cabula- } \\
\text { Beiru }\end{array}$ & 30 & 3 & 9 & 13 & $\begin{array}{l}\text { - convênio docente assistencial FDC/ } \\
\text { Odontologia agosto/2001 } \\
\text { - programas coletivos desde 1995 }\end{array}$ \\
\hline Liberdade & 17 & 3 & 6 & 6 & \\
\hline Pau da Lima & 20 & 2 & 6 & 8 & $\begin{array}{l}\text { - programa preventivo com } \\
\text { fluorterapia intensiva/manutenção em } \\
\text { todas as unidades de saúde desde } \\
\text { 1994; } \\
\text { - campo de prática para o Pólo de } \\
\text { Capacitação em saúde da família } \\
\text { ISC/UFBA 1998-2000 }\end{array}$ \\
\hline
\end{tabular}

\begin{tabular}{|c|c|c|c|c|c|}
\hline $\begin{array}{l}\text { Subúrbio } \\
\text { Ferroviário }\end{array}$ & 26 & 4 & 8 & 13 & $\begin{array}{l}\text { - programas preventivos pontuais } \\
-3 \text { equipes PSF com dentista }\end{array}$ \\
\hline $\begin{array}{l}\text { São Caetano- } \\
\text { Valéria }\end{array}$ & 10 & 1 & 4 & 5 & $\begin{array}{l}\text { - programa saúde na escola } \\
\text { (julho/2001) }\end{array}$ \\
\hline \multicolumn{6}{|c|}{$\begin{array}{l}\text { * não foram incluidos os dados referentes a rede assistencial do Serviço Social da Indústria, } \\
\text { Serviço Social do Comércio e Serviço Nacional de transporte, além dos equipamentos da } \\
\text { Faculdade de Odontologia/ FDC (Fundação para o Desenvolvimento da Ciência) localizados } \\
\text { no distrito Cabula-Beinu e da Faculdade de Odontologia da Universidade Federal da Bahia, } \\
\text { localizados no distrito Barra-Rio Vermelho. } \\
\text { Fonte: Secretaria Municipal de Saúde, Coordenação de Odontologia }\end{array}$} \\
\hline
\end{tabular}




\subsection{Cárie dentária segundo tipo de escola}

$\mathrm{Na}$ análise por tipo de escola-pública ou privada, não foram encontradas diferenças estatisticamente significativas nos indicadores de cárie dentária (CPO-D e percentual de indivíduos livres de cárie) entre os dois grupos na análise bivariada (Tabela 13).

Tabela 13- Condição dentária: CPO-D, desvio padrão, percentagem de individuos livres de cárie e medidas de dispersão em escolares da rede pública e privada aos $12 \mathrm{e}$ 15 anos de idade, Salvador, Bahia, 2001.

\begin{tabular}{|c|c|c|c|c|c|c|}
\hline & \multicolumn{2}{|c|}{ Escolas públicas } & \multicolumn{2}{|c|}{ Escolas privadas } & \multicolumn{2}{|c|}{ TOTAL } \\
\hline & 12 anos & 15 anos & 12 anos & 15 anos & 12 anos & 15 anos \\
\hline $\mathbf{n}$ & 1315 & 1129 & 435 & 434 & 1750 & 1563 \\
\hline CPO-D (dp)* & $1,46(1,90)$ & $2,38(2,76)$ & $1,37(1,85)$ & $9(3,24)$ & $1,44(1,88) 2$ & $6(2,91)$ \\
\hline \%livres cárie* & 48,70 & 34,70 & 50,10 & 35,30 & 49,00 & 34,90 \\
\hline Quartil superior & 3,00 & 4,00 & 2,00 & 4,00 & 2,00 & 4,00 \\
\hline Mediana & 1,00 & 2,00 & 0,00 & 2,00 & 1,00 & 2,00 \\
\hline Quartil inferior & 0,00 & 0,00 & 0,00 & 0,00 & 0,00 & 0,00 \\
\hline
\end{tabular}

* diferenças não estatisticamente significativas aos 12 e 15 anos de idade nos testes $t$ de Student e Qui-quadrado respectivamente.

Observa-se nas figuras 16 e 17 que, nos estudantes de escolas privadas, predominam os dentes restaurados, enquanto que naqueles de escolas públicas, os dentes cariados, tanto aos 12 quanto aos 15 anos de idade. Em relação aos dentes perdidos, praticamente não existe diferença entre os grupos aos 12 anos de idade, enquanto aos 15 anos os alunos de escolas públicas têm uma maior proporção de perda dentária (Figura 16 e 17). 
Figura 16

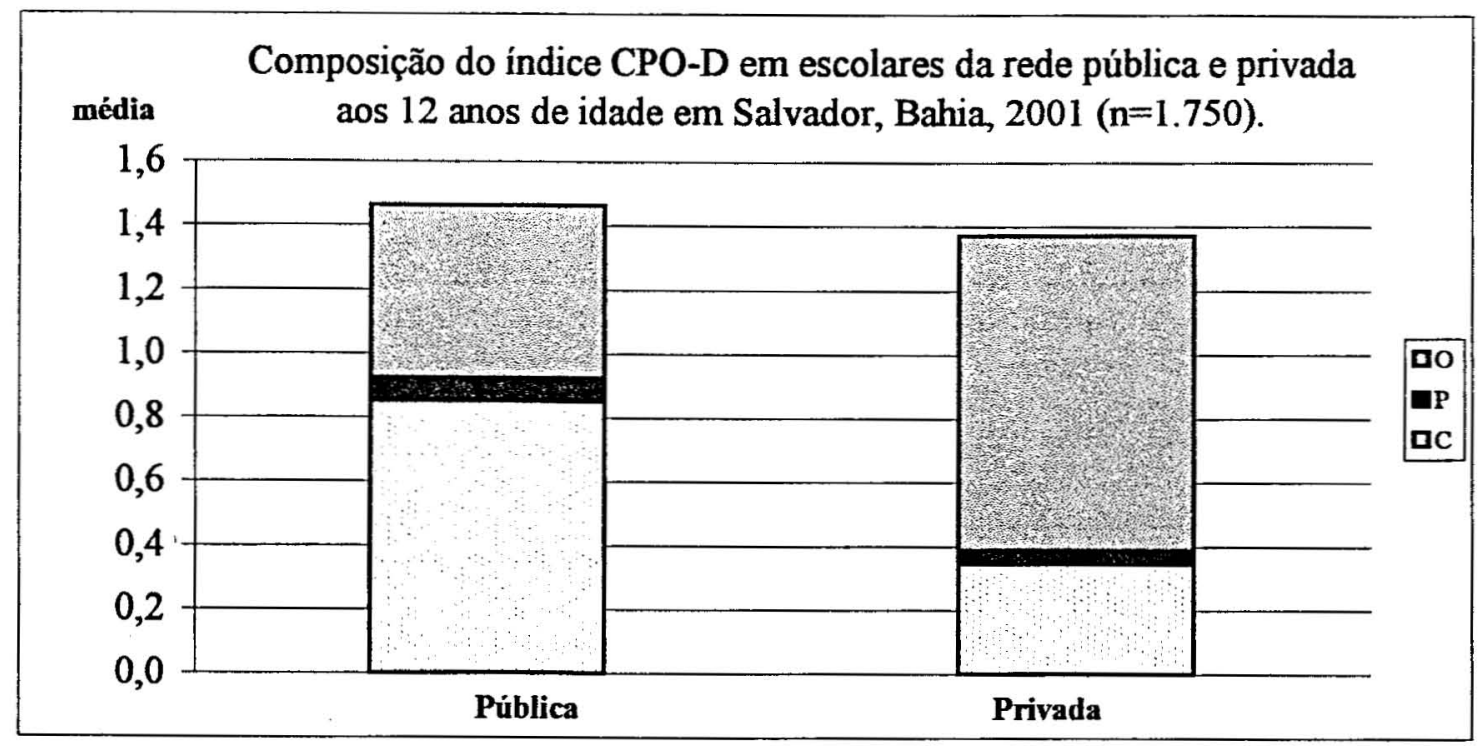

Figura 17

Composição do índice CPO-D em escolares da rede pública e privada aos 15 anos de idade em Salvador, Bahia, 2001 ( $\mathrm{n}=1.563)$.

média

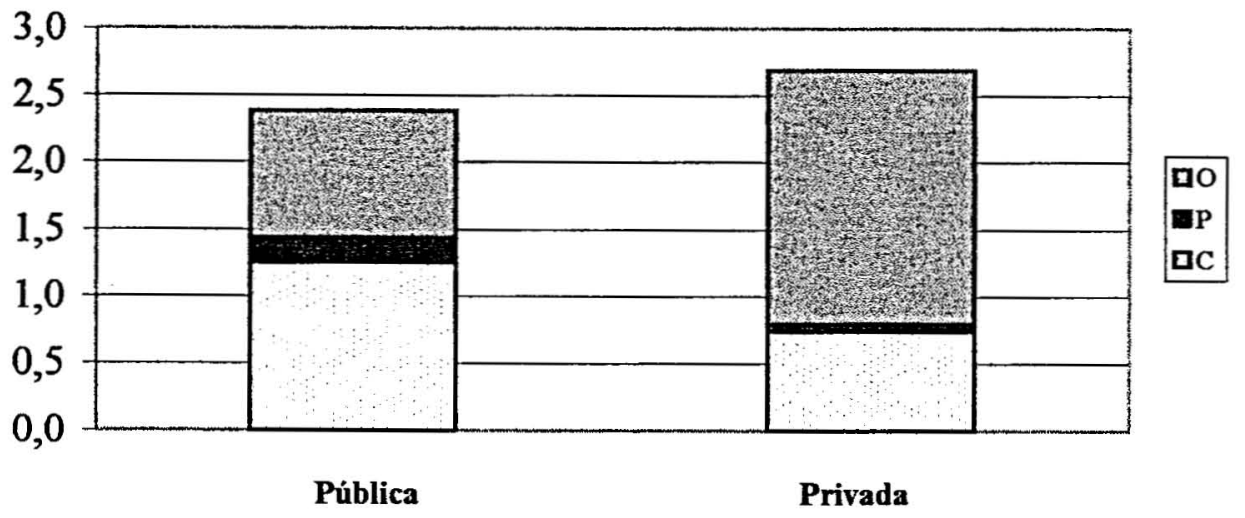

Entretanto, na análise de regressão logística, considerando como variável dependente a prevalência de cárie dentária (CPO- $\mathrm{D}=0$ e CPO-D>=1), se encontrou uma maior probabilidade de ocorrência de cárie nos estudantes de 12 anos de idade de escolas públicas $(\mathrm{OR}=1,30 \quad 1,02-1,6495 \% \mathrm{IC})$, quando se ajustou para acesso ao 
consultório odontológico segundo tipo de financiamento (Tabela 14). Aos 15 anos, embora esta mesma variável tenha se apresentado como de confusão em relação a associação principal, observou-se uma maior ocorrência de cárie em alunos de escolas públicas não estatisticamente significativa (Tabela 14).

Tabela 14- Modelo reduzido da regressão logística para a associação entre prevalência de cárie dentária $(\mathrm{CPO}-\mathrm{D}=0)$ aos 12 e 15 anos de idade segundo tipo de escola ajustado por tipo de financiamento no acesso ao dentista ${ }^{3}$, Salvador, Bahia, 2001.

Variáveis

Odds Ratio (OR) Intervalo de confiança- $95 \%$

$\mathrm{LI}^{4} \quad \mathrm{LS}^{5}$

$12 \operatorname{anos}^{1}$

Escola privada

1,00

Escola pública

1,30

$1,02 \quad 1,64$

$15 \operatorname{anos}^{2}$

Escola privada

1,00

Escola pública

1,21

$0,94 \quad 1,56$

T12 anos: $R^{2}=0,28 \quad p=0,000 \quad$ Máxima verossimilhança- $p=0,07$

${ }^{2} 15$ anos: $R^{2}=0,18 \quad p=0,000 \quad$ Máxima verossimilhança- $p=0,15$

${ }^{3}$ Tipo de financiamento no acesso ao dentista: público, particular e convênio

${ }^{4}$ LI: Limite Inferior

${ }^{5}$ LS: Limite Superior 


\subsection{Fluorose dentária}

A prevalência de fluorose encontrada no município de Salvador foi de $31,40 \%$ aos 12 anos de idade e $27,60 \%$ aos 15 anos de idade, com uma predominância dos casos nos graus muito leve e leve, conforme se observa na Tabela 15.

Tabela 15- Distribuição da fluorose dentária (índice de Dean) aos 12 e 15 anos de idade em Salvador, Bahia, 2001.

\begin{tabular}{|c|c|c|c|c|c|c|}
\hline \multirow[b]{2}{*}{ Grau } & \multicolumn{3}{|c|}{12 anos } & \multicolumn{3}{|c|}{15 anos } \\
\hline & $\mathbf{n}$ & $\%$ & $\mathrm{IC}^{1} \quad 95 \%$ & $\mathbf{n}$ & $\%$ & IC $^{1} 95 \%$ \\
\hline SEM FLUOROSE & 1.200 & 68,60 & $65,97-71,23$ & 1.132 & $\mathbf{7 2 , 4 0}$ & $69,8-75,00$ \\
\hline normal & 996 & 56,90 & $53,82-59,98$ & 935 & 59,80 & $56,66-62,94$ \\
\hline questionável & 204 & 11,70 & $7,29-16,11$ & 197 & 12,60 & $7,97-17,23$ \\
\hline COM FLUOROSE & $\mathbf{5 5 0}$ & $\mathbf{3 1 , 4 0}$ & $27,52-35,28$ & 431 & 27,60 & $23,38-31,82$ \\
\hline muito leve & 478 & 27,30 & $23,31-31,29$ & 365 & 23,40 & $19,06-27,7$ \\
\hline leve & 69 & 3,90 & $0,00-8,47$ & 63 & 4,00 & $0,00-8,84$ \\
\hline moderada & 3 & 0,20 & $0,00-5,25$ & 3 & 0,20 & $0,00-5,25$ \\
\hline severa & - & - & - & - & - & - \\
\hline TOTAL & 1.750 & 100,00 & - & 1.563 & 100,00 & \\
\hline
\end{tabular}

Intervalo de Confiança

Foram encontradas diferenças estatisticamente significativas (teste do quiquadrado; nível de significância de 5\%) na análise descritiva na distribuição da fluorose dentária segundo distrito sanitário, com menores prevalências, aos 12 anos de idade, para as regiões: Barra-Rio Vermelho, Brotas, Itapoã, Cabula-Beiru e Pau da Lima, com percentuais abaixo dos $30 \%$. Já aos 15 anos de idade, os distritos de 
Brotas, Boca do Rio, Cajazeiras, Cabula-Beiru, Pau da Lima, Subúrbio Ferroviário e São Caetano-Valéria apresentaram prevalências abaixo dos $30 \%$.

Uma alta prevalência desta alteração foi descrita no distrito da Liberdade, com um percentual de $72,4 \%$ ao 12 anos e, aos 15 anos de idade, esta tendência repete-se com um percentual de $57,3 \%$ de indivíduos com algum grau de fluorose dentária. O Centro Histórico e Itapagipe tiveram como resultado percentuais entre $30,0 \%$ e $40,0 \%$ tanto aos 12 como aos 15 anos de idade, Esta mesma faixa de prevalência repetiu-se nas regiões do Barra-Rio Vermelho e Itapoã aos 15 anos de idade. Os distritos com menores proporções desta alteração foram aos 12 anos- Pau da Lima $(18,2 \%)$, Brotas $(18,4 \%)$ e Cabula-Beiru $(19,4 \%)$, e aos 15 anos- Subúrbio Ferroviário (13,0\%), Cajazeiras (13,5\%) e Pau da Lima (14,6\%) (Tabelas 16 e 17). 


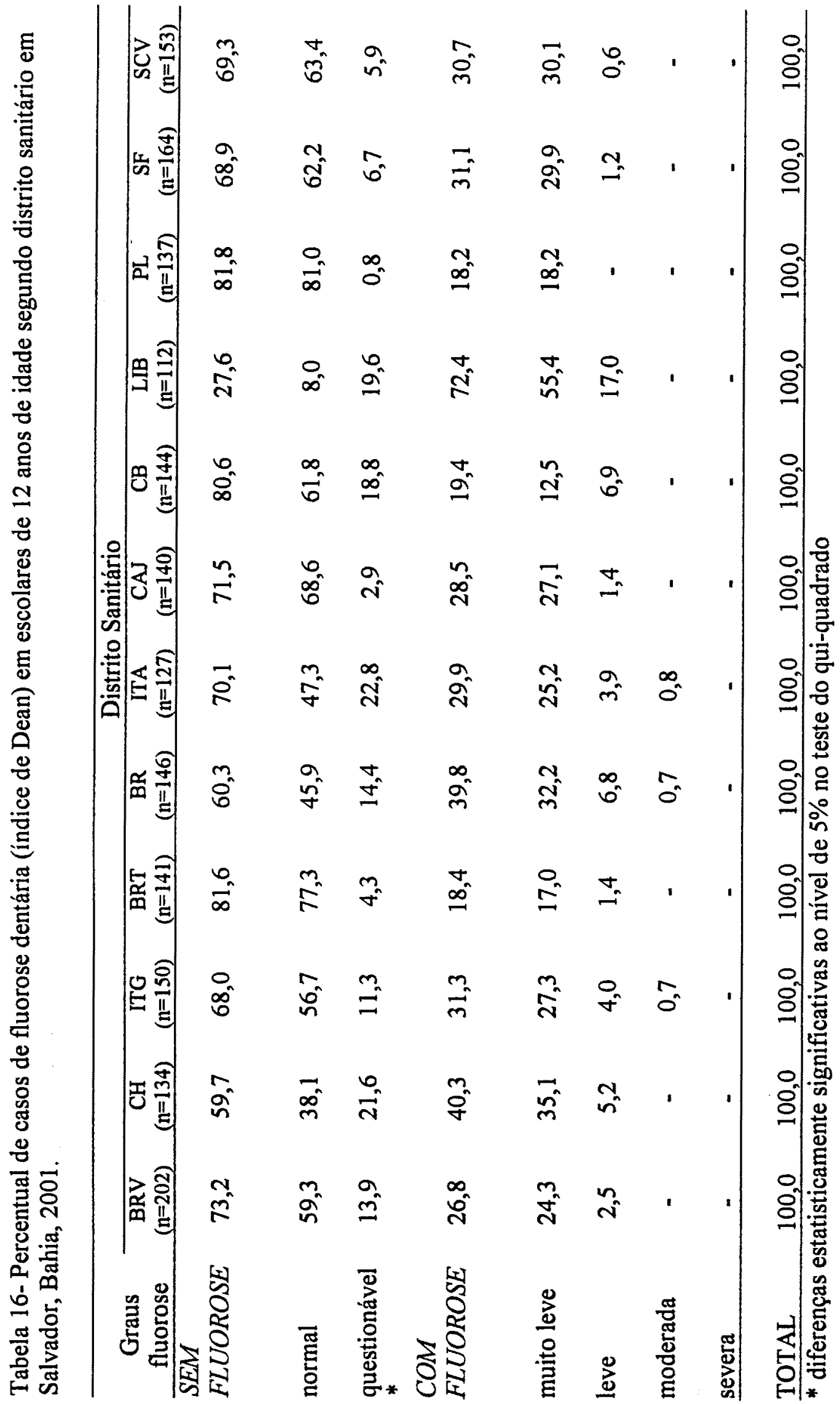




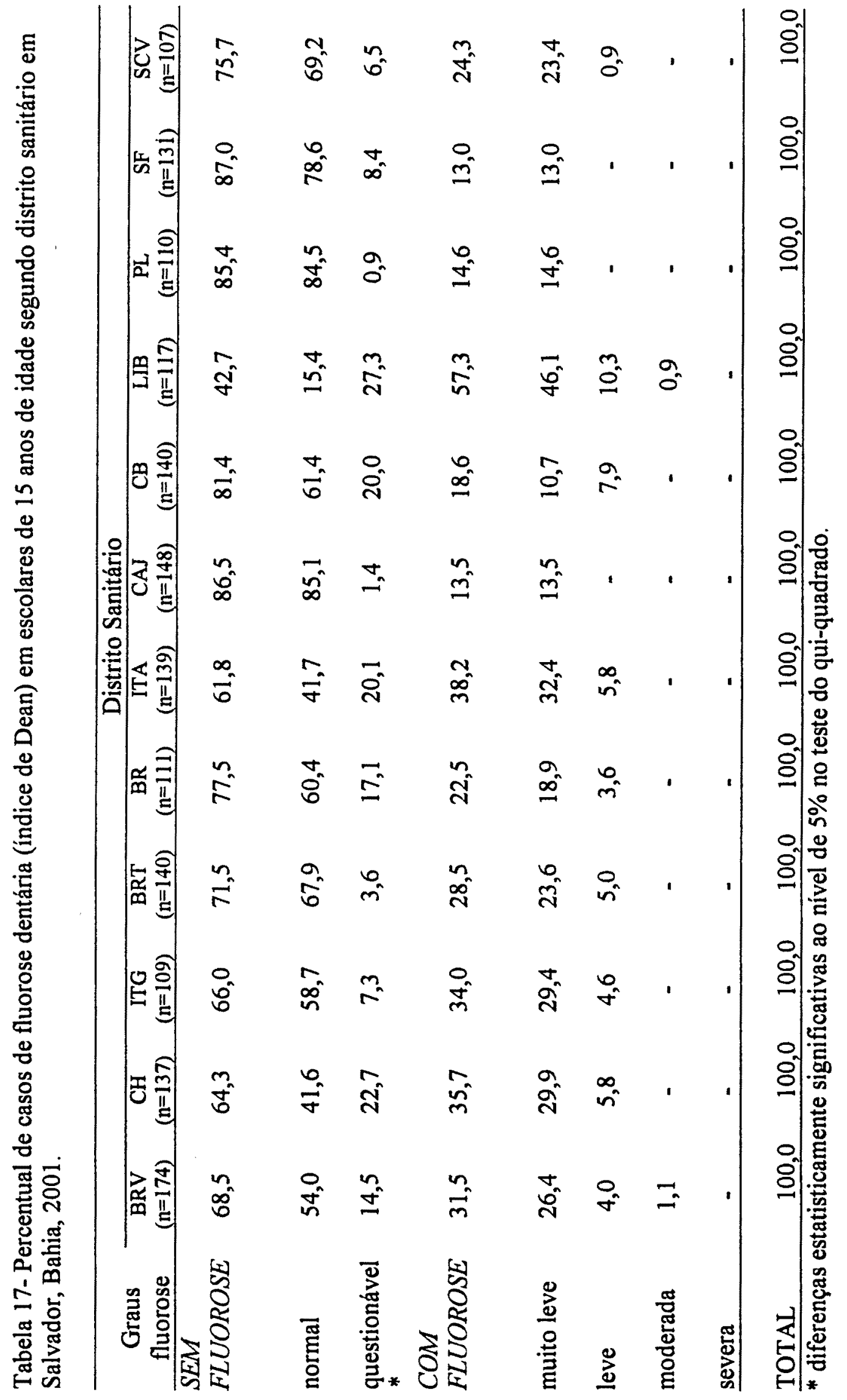


$\mathrm{Na}$ análise de regressão logistica, se mantêm estatisticamente significativas as diferenças na ocorrência de fluorose dentária, segundo distrito sanitário aos 12 anos de idade, ajustadas pelo acesso ao dentista no último ano segundo tipo de financiamento. Não houve diferença somente entre os distritos de Pau da Lima e Brotas, conforme se observa na Tabela 18.

Tabela 18- Modelo reduzido da regressão logística para associação entre prevalência de fluorose dentária (Índice de Dean<=1) aos 12 anos de idade segundo distrito sanitário ajustado por tipo de financiamento do acesso ao dentista, Salvador, Bahia, 2001.

Variáveis Odds Ratio (OR) Intervalo de confiança $95 \%$

\begin{tabular}{lrrr} 
& & LI $^{2}$ & LS $^{3}$ \\
\hline Distrito Pau da Lima & 1,00 & \multicolumn{2}{c}{-} \\
Distrito Barra-Rio Vermelho & 2,95 & 1,76 & 4,93 \\
Distrito Centro Histórico & 6,97 & 3,99 & 12,17 \\
Distrito Itapagipe & 3,28 & 1,92 & 5,62 \\
Distrito Brotas & $1,28 *$ & 0,72 & 2,30 \\
Distrito Boca do Rio & 5,04 & 2,94 & 8,64 \\
Distrito Itapoã & 4,85 & 2,78 & 8,48 \\
Distrito Cajazeiras & 1,95 & 1,12 & 3,41 \\
Distrito Cabula- Beiru & 2,67 & 1,55 & 4,62 \\
Distrito Liberdade & 49,90 & 22,29 & 111,72 \\
Distrito Subúrbio Ferroviário & 2,61 & 1,53 & 4,45 \\
Distrito São Caetano-Valéria & 2,51 & 1,46 & 4,31
\end{tabular}

${ }^{1} R^{2}=0,06 \quad p=0,000 \quad$ Máxima verossimilhança- $p=0,066$

${ }^{2}$ LI: Limite Inferior

${ }^{3}$ LS: Limite Superior

* diferença não estatisticamente significativa em relação ao referente ao nível de $5 \%$.

Já aos 15 anos de idade, não existiu diferença estatisticamente significativa na prevalência de fluorose dentária entre os distritos de Cajazeiras e Subúrbio 
Ferroviário, em relação ao referente, ajustadas pelo sexo, mantendo-se em ambas as idades a maior severidade para o distrito da Liberdade (Tabela 19).

Tabela 19- Modelo reduzido da regressão logística para associação entre prevalência de fluorose dentária (Índice de Dean<=1) aos 15 anos de idade segundo distrito sanitário ajustado por sexo, Salvador, Bahia, 2001. ${ }^{1}$

\begin{tabular}{lrrr}
\hline Variáveis & Odds Ratio (OR) & \multicolumn{3}{r}{ Intervalo de confiança- 95\% } \\
& & LI $^{2}$ & LS $^{3}$ \\
\hline Distrito Pau da Lima & 1,00 & 2,79 & 9,31 \\
Distrito Barra-Rio Vermelho & 5,10 & 4,62 & 16,19 \\
Distrito Centro Histórico & 8,65 & 2,07 & 7,52 \\
Distrito Itapagipe & 3,95 & 1,44 & 5,08 \\
Distrito Brotas & 2,71 & 2,08 & 7,60 \\
Distrito Boca do Rio & 3,98 & 4,50 & 15,65 \\
Distrito Itapoã & 8,39 & 0,52 & 2,10 \\
Distrito Cajazeiras & $1,05^{*}$ & 1,97 & 6,84 \\
Distrito Cabula- Beiru & 3,67 & 16,13 & 69,05 \\
Distrito Liberdade & 33,38 & 0,84 & 3,22 \\
Distrito Subúrbio Ferroviário & $1,65^{*}$ & 1,37 & 5,17 \\
Distrito São Caetano-Valéria & 2,66 & & \\
\hline
\end{tabular}

${ }^{1} R^{2}=0,07 \quad p=0,000 \quad$ Máxima verossimilhança- $p=0,082$

${ }^{2}$ LI: Limite Inferior

${ }^{3}$ LS: Limite Superior

* diferença não estatisticamente significativa em relação ao referente ao nivel de $5 \%$.

Quando se analisa a distribuição da fluorose dentária por tipo de estabelecimento de ensino, observa-se uma maior proporção de indivíduos livres desta alteração nas escolas públicas-70,0\% aos 12 anos de idade e $74,0 \%$ aos 15 anosem relação às particulares- $64,1 \%$ e $68,4 \%$ respectivamente, diferença esta estatisticamente significante em ambas as idades (Tabela 20). 
Tabela 20 - Distribuição da fluorose dentária em escolas públicas e privadas aos $12 \mathrm{e}$ 15 anos de idade em Salvador, Bahia, 2001.

\begin{tabular}{|c|c|c|c|c|c|c|c|c|c|c|c|c|}
\hline \multirow{3}{*}{ Fluorose } & \multicolumn{4}{|c|}{ Escolas públicas } & \multicolumn{4}{|c|}{ Escolas privadas } & \multicolumn{4}{|c|}{ TOTAL } \\
\hline & \multicolumn{2}{|c|}{12 anos } & \multicolumn{2}{|c|}{15 anos } & \multicolumn{2}{|c|}{12 anos } & \multicolumn{2}{|c|}{15 anos } & \multicolumn{2}{|c|}{12 anos } & \multicolumn{2}{|c|}{15 anos } \\
\hline & & $\%$ & $\mathrm{n}$ & $\%$ & $\mathbf{n}$ & $\%$ & $\mathrm{n}$ & $\%$ & $\mathrm{n}$ & $\%$ & $\mathrm{n}$ & $\%$ \\
\hline \multicolumn{13}{|c|}{ SEM } \\
\hline FLUOROSE & 921 & $70,0^{*}$ & 835 & $74,0^{*}$ & 279 & $64,1^{*}$ & 297 & $68,4^{*}$ & 1200 & 68,6 & 1132 & 72,4 \\
\hline Sadio & 775 & 58,9 & 706 & 62,6 & 221 & 50,8 & 229 & 52,7 & 996 & 56,9 & 935 & 59,8 \\
\hline questionável & 146 & 11,1 & 129 & 11,4 & 58 & 13,3 & 68 & 15,7 & 204 & 11,7 & 197 & 12,6 \\
\hline \multicolumn{13}{|l|}{${ }^{\star} \mathrm{COM}$} \\
\hline FLUOROSE & 394 & 30,0 & 294 & 26,0 & 156 & 35,9 & 137 & 31,6 & 550 & 31,4 & 431 & 27,6 \\
\hline muito leve & 348 & 26,5 & 251 & 22,2 & 130 & 29,9 & 114 & 26,3 & 478 & 27,3 & 365 & 23,4 \\
\hline leve & 43 & 3,3 & 41 & 3,6 & 26 & 6,0 & 22 & 5,1 & 69 & 3,9 & 63 & 4,0 \\
\hline moderada & 3 & 0,2 & 2 & 0,2 & & - & 1 & 0,2 & 3 & 0,2 & 3 & 0,2 \\
\hline severa & & - & - & - & & - & - & - & - & - & - & \\
\hline TOTAL & 1315 & 100,0 & 129 & 100,0 & 435 & 100,0 & 434 & 100,0 & 1750 & 100,01 & 1563 & 100,0 \\
\hline
\end{tabular}

* diferença estatisticamente significativa $(p<0,05)$ no teste do qui-quadrado

$\mathrm{Na}$ análise de regressão logística confirmou-se a menor ocorrência de fluorose dentária em alunos de escolas públicas aos 12 anos de idade (OR=0,72; 0,57-0,89 95\% IC), sendo que nenhuma das covariáveis investigadas se mostraram relevantes para esta associação. Aos 15 anos de idade, encontrou-se uma associação praticamente idêntica $(\mathrm{OR}=0,71 ; 0,55-0,9195 \% \mathrm{IC})$, sendo que as variáveis etnia $\mathrm{e}$ acesso ao dentista, no último ano, segundo tipo de financiamento, foram variáveis de confusão para esta associação. 


\section{DISCUSSÃO}

Neste estudo, diversas eram as possibilidade de investigação das iniqüidades em saúde bucal em Salvador, em virtude da complexidade inerente aos fenômenos relacionados ao desenvolvimento humano e ao processo saúde/doença estudados. Dada a escassez de dados epidemiológicos populacionais existentes no município, a primeira opção de análise foi explorar as condições da cárie e fluorose dentária no âmbito municipal. Posteriormente, de forma a privilegiar o planejamento local em saúde, optou-se pela análise segundo distrito sanitário, unidade operacional mínima instituída pela Secretaria Municipal de Saúde para a definição de práticas de saúde e de diretrizes operacionais. Por fim, a análise segundo tipo de estabelecimento de ensino tenta resgatar o nível sócio-econômico como elemento relevante na determinação das doenças bucais, conforme pode-se observar no texto a seguir.

Na população de estudo, de escolares de 12 e 15 anos de Salvador, Bahia, houve a predominância do sexo feminino e da etnia parda, coerente com a caracterização da população realizada pelo IBGE no censo populacional do ano 2000 para o município (BRASIL.IBGE 2000).

$\mathrm{O}$ acesso ao dentista, incluindo o setor público, privado e conveniado e a participação em programas preventivos com o uso do flúor, foram maiores do que os descritos em trabalhos realizados em outras regiōes do pais (CÉSAR et al. 1999) ou, mesmo, no próprio município, em anos anteriores (CANGUSSU 1998, CABRAL et al. 2000). A expansão da rede assistencial do SUS e a possibilidade de novos modelos de atenção após o processo de municipalização, a multiplicação de convênios de menor custo e as mudanças progressivas da odontologia na forma de abordar o 
processo saúde/doença bucal, incorporando a proposta de promoção da saúde em sua prática são alguns dos fatores descritos para o aumento da cobertura e melhoria das condições de saúde bucal em Salvador, embora ainda persista a baixa cobertura e pouca efetividade do setor público (CABRAL et al 2000).

\subsection{A cárie dentária no município de Salvador}

Confirma-se aos 12 anos de idade, para todo o município, a redução significativa do CPO-D em relação aos dados descritos pelo Ministério da Saúde em 1986 para a região Nordeste (BRASIL.MS 1988), com um valor de 1,44 (1,35-1,52) 95\%IC. Este indice foi muito semelhante ao valor encontrado pelo Ministério da Saúde em 1996, de 1,53 (BRASIL.MS 1996), embora sejam inúmeras as diferenças metodológicas entre os estudos, desde o processo amostral até os critérios utilizados no indicador. $\mathrm{O}$ resultado também foi menor do que aqueles encontrados em estudos desenvolvidos em outras regiões do país (FREIRE et al. 1999, NARVAI et al. 2000, PATUSSI 2000) e muito abaixo da meta estabelecida pela Organização Mundial da Saúde para o ano 2000, de no máximo três dentes atingidos pela doença.

Quando calculou-se o SiC, índice proposto por BRATHALL (2000), encontrou-se o valor de 3,85 para os 12 anos de idade, acima do valor de no máximo 3, proposto pela OMS como meta para os países em desenvolvimento no ano de 2015 , embora o indice tenha sido menor do que os descritos pelo mesmo autor para os Estados Unidos, de 5,21; França, de 4,63; Alemanha, de 4,11 e África do Sul, 4,30. Este indice, coerente com a argumentação do autor, permitiria em populações com baixos níveis de cárie dentária, em que o controle já se estabeleceu a partir do uso de 
dentifrícios fluorados, água fluoretada e outras ações de saúde pública, identificar os subgrupos de alta atividade da doença e estabelecer medidas mais efetivas abrangendo estratégias de risco, de forma a reduzir neste grupo necessidades mais complexas no futuro.

Nesta mesma idade houve a predominância dos dentes cariados (50\%) em relação aos restaurados $(45,14 \%)$ e perdidos $(4,86 \%)$, coerente com outros estudos desenvolvidos no país, que destacam as dificuldades da população no acesso aos serviços públicos de saúde e resolutividade das necessidades restauradoras. Na população com menor renda, o alto custo da assistência no setor privado, é também um fator limitador no acesso (BRASIL.MS 1993, KNUPP 1997, NARVAI et al. 2000).

Aos 15 anos de idade o CPO-D foi de 2,66 (2,52- 2,80) 95\%IC, indicando um incremento da cárie dentária com a idade, como já foi descrito por PINTO (1992), embora esta ainda se mantenha com um grau baixo de severidade quando comparado a outros estudos nacionais (BRASIL.MS 1986, PINTO 1992). Em relação à composição percentual do índice, identificou-se uma maior proporção do componente restaurado.

Embora tenha-se encontrado neste estudo, tanto aos 12 como aos 15 anos de idade, a presença do componente extraído, evidenciando a existência de uma assistência ainda mutiladora, bem como da exclusão de parcelas da população do acesso e integralidade da atenção à saúde bucal (BRASIL.MS 1993), destaca-se a redução significativa do número de dentes cariados e perdidos quando comparados a estudos anteriores realizados no município como o de SILVA et al. (1984), que 
relatavam no ano de 1982 para a idade de 14 anos cerca de $85 \%$ dos primeiros molares permanentes cariados e, no arco inferior, quase $15 \%$ dos mesmos perdidos.

Estes resultados ratificam a melhoria da condição de saúde bucal na população jovem no município. Considerando que esta foi uma população com acesso a programas com o uso de fluoretos no âmbito escolar, tem acesso a água fluoretada com niveis de flúor adequados e de forma contínua desde 1996, residem em zona urbana e relatam ter acesso a dentifrícios fluorados, e, como em outros munícipios, houve um aumento da cobertura assistencial proporcionada pela implantação do SUS e a implantação de modelos assistências de maior impacto epidemiológico (CABRAL et al 2000), pode-se suscitar a hipótese de que como em outras regiões do país, como coloca NARVAI (1996), estes podem ser os fatores que mais contribuiram no controle da cárie dentária neste grupo.

Em ambas as idades houve uma maior concentração de crianças com até quatro dentes acometidos por cárie, e menos de $20 \%$ das mesmas concentrando os altos valores do CPO-D. Este grupo foi identificado em muitos estudos epidemiológicos envolvendo populações com baixos índices da doença, mobilizando a necessidade de estratégias de intervenção a partir do conceito de risco, na perspectiva de garantir a eqüidade em saúde (BARMES 1999, FREIRE et al. 1999, NARVAI et al. 2000).

O grupo dentário mais atingido foi o dos molares permanentes, coerente com os resultados de SILVA et al. (1984) em um estudo anterior desenvolvido em Salvador, que também encontrou um maior acometimento dos molares permanentes, analisando escolares de 7 a 14 anos, embora no período deste estudo prevalecesse um 
perfil epidemiológico de maior prevalência de cárie. Este resultado enfatiza a necessidade do controle precoce da doença através de estratégias de promoção da saúde bucal (PINTO 1992).

Por se tratar de um estudo transversal, um dos possíveis limites deste estudo é a sua incapacidade de identificar fatores etiológicos que possam ter contribuído para a melhoria da condição de saúde bucal neste grupo. Além disso, diversos outros fatores de proteção não foram incluídos na investigação como por exemplo a dieta, uso de substâncias químicas como a clorexidina ou outras potenciais fontes de flúor, além de variáveis sociais e demográficas.

Entretanto, este trabalho conseguiu, com precisão, gerar medidas de prevalência e severidade para a cárie dentária, em ambas as idades. Observa-se que, embora tenham sido perdidos elementos amostrais aos 15 anos de idade nos distritos de Itapagipe, Boca do Rio, Pau da Lima e São Caetano- Valéria, a super-estimação inicial no cálculo amostral parece ter compensado satisfatoriamente a pequena discrepância em relação a amostra minima requerida.

Também os resultados expressivos conseguidos na calibração da equipe de examinadores para a cárie dentária, constituem elementos importantes na garantia de qualidade e confiabilidade das estimativas produzidas tanto aos 12 como aos 15 anos de idade.

\subsection{Cárie dentária segundo distrito sanitário}

Na tentativa de detectar as desiguais distribuições da cárie dentária no municipio, de forma a identificar grupos ou áreas epidemiologicamente susceptíveis, 
procedeu-se a análise das condições da cárie dentária, segundo distrito sanitário de localização da escola. Optou-se pela unidade escolar, e não o distrito de residência por ambos apresentarem uma boa concordância em quase todos os distritos e em função das estratégias de promoção e prevenção à saúde bucal serem desenvolvidas, prioritariamente, no ambiente escolar (CABRAL et al. 2000).

O distrito sanitário que apresentou melhor condição em relação à cárie dentária foi o de Pau da Lima, tanto aos 12 (CPO-D=1,13; 63,5\% livres de cárie) como aos 15 anos de idade (CPO-D=1,4;51,8\% livres de cárie). Este distrito foi o primeiro a ser constituído no município, a partir de um convênio de cooperação técnica entre Brasil e Itália e vem, desde então, tentando desenvolver ações de vigilância à saúde, incluindo a saúde bucal, se constituindo também em campo de prática para o programa de residência multiprofissional em saúde da família do Instituto de Saúde Coletiva/UFBA de 1998 a 2001 (PREFEITURA MUNICIPAL DO SALVADOR 1994). Por isto ele foi utilizado como referência para todos os procedimentos analiticos desenvolvidos neste trabalho, considerando que maior severidade encontrada em outras áreas poderiam ser consideradas injustas ou evitáveis, isto é, passíveis de serem minimizadas.

Os distritos de Cajazeiras e Subúrbio Ferroviário também apresentaram severidade de cárie muito baixa aos 12 anos de idade, com um CPO-D<1,2. O restante das regiões foi classificado na categoria de baixa prevalência, segundo os critérios da Organização Mundial da Saúde, como descreve MOLLER (1980-83) citado por PINTO (1992). 
De modo geral, foi alta a proporção de indivíduos livres da doença aos 12 anos de idade, com piores condições nos distritos de Itapoã e Liberdade, que apresentaram também os CPO-D's mais elevados- 1,82 e 1,91 respectivamente. A análise de regressão logística também mostrou maior ocorrência de cárie nestas áreas, após o ajuste para as variáveis sexo e acesso ao dentista no último ano.

Ao calcular o Índice de Cárie Significante- SiC, aos 12 anos de idade (BRATTHALL 2000), por distrito sanitário, tentou-se identificar, numa população de baixa severidade de cárie como a do município, as possíveis áreas que apresentavam subgrupos de maior ocorrência da doença.

Neste sentido, coerente com os resultados apresentados pelo índice CPO-D, o $\mathrm{SiC}$ apresentou seus maiores valores em Itapoã, na Liberdade e no distrito do Centro Histórico, 4,83; 4,53 e 4,22 respectivamente. As regiões com melhores condições em relação à cárie dentária foram Cajazeiras, Pau da Lima e o Subúrbio Ferroviário, com um $\mathrm{SiC}$ de 3,50, valor próximo da meta proposta de 3 pela OMS para o ano de 2015 .

Dentre as possíveis hipóteses para estas diferenças, têm-se que o distrito de Itapoã, embora tenha apresentado um alto percentual de crianças que referiram participar de atividades de promoção da saúde bucal nos últimos dois anos, não possui nenhum registro dos mesmos na Secretaria Municipal de Saúde. Considera-se, também, que este possui uma rede assistencial pequena em relação ao porte do distrito, especialmente por ter sua área de abrangência ampliada ao atender municípios vizinhos, como Lauro de Freitas, Candeias e Camaçari (PREFEITURA MUNICIPAL SALVADOR 1994). 
A região da Liberdade tem uma das menores coberturas de programas com uso de fluoretos, aos 12 anos de idade, e também nenhum registro na Secretaria Municipal de Saúde do desenvolvimento dos mesmos, embora a sua rede assistencial seja considerada satisfatória. Embora não seja possível identificar através dos dados empíricos, observa-se que, naqueles distritos em que existe uma preocupação da gestão em saúde na tentativa de implantação de modelos de atenção à saúde de maior impacto 'epidemiológico, bem como redes sociais (Igreja, Organizações não governamentais, Escola) preocupados com o bem estar social, parecem também estar presentes melhores condições de saúde bucal.

Aos 15 anos de idade, Brotas, Centro Histórico, Itapoã e Liberdade são aqueles que se encontram com piores condições em relação à cárie dentária. Entretanto são menores as diferenças em relação a outras regiões de nivel intermediário da doença, com melhores condições para os distritos da Boca do Rio, Pau da Lima e Cajazeiras.

As regiões de Pau da Lima e Boca do Rio apresentam as maiores coberturas dos programas de promoção da saúde bucal, tanto aos 12 como aos 15 anos, coerente com os dados apresentados pela Coordenação de Odontologia da Secretaria Municipal de Saúde, embora a mesma correlação não possa ser feita com o acesso ao dentista no último ano.

Assim, destaca-se a relevância de medidas preventivas como o acesso a aguá fluoretada e aos programas com uso de fluoretos extensivos a toda a população, bem como as estratégias de educação em saúde bucal no controle da cárie dentária, embora neste estudo o impacto destas ações não tenha sido mensurado individualmente. 
Quando se analisa a assistência, observou-se que naqueles distritos onde o acesso ao dentista no último ano foi maior, eleva-se também o componente restaurado do indice CPO-D, sendo necessário investigações posteriores sobre o impacto epidemiológico que esta representa na condição de saúde bucal deste grupo, visto que outros trabalhos como os de PINTO (1989), TREASURE e DEVER (1994), NADANOVSKY e SHEIHAM (1995), SLADE et al. (1996) e GELBIER (1998) têm identificado a pouca participação da mesma para a melhoria das condições de saúde bucal, destacando inclusive o potencial iatrogênico que esta tem representado, quando associada a um modelo intervencionista e estritamente curativo-restaurador.

Em relação à distribuição da rede assistencial municipal por distrito sanitário, existe uma concentração de recursos fisicos e humanos nas áreas mais centrais da cidade, como o Barra-Rio Vermelho, Cabula-Beiru, Centro Histórico e Brotas, sendo que, nos dois primeiros também estão localizadas as duas faculdades de odontologia existentes no município, não incluídas neste estudo já que estas se constituem referência para todo o estado da Bahia. Não existem estudo anteriores que associação a distribuição da rede assistencial e seu impacto na condição de saúde, embora se suspeite que a alocação de consultórios e pessoal não se dá em função de critérios epidemiológicos, mas sim geográficos e políticos.

Embora tenha sido informada nas respostas dos questionários individuais uma cobertura significativa dos programas com o uso do flúor, este resultado não é coerente com os registros oficiais identificados na Secretaria Municipal de Saúdę e não existindo também avaliações de impacto das medidas ou qualquer tipo de 
protocolo oficial no desenvolvimento das mesmas, sendo assim importante investimentos em um sistema de informação mais efetivo para o município.

Deve-se enfatizar que, setor saúde tem sido considerado relevante na mediação das desigualdades sociais, reduzindo o impacto das mudanças políticas e econômicas na saúde da população, como coloca MENDES (1996), mas de modo geral, discute-se que os serviços e práticas tendem a se distribuir de forma inadequada (WHITEHEAD 2000), não privilegiando as necessidades de saúde identificadas na população, como sugerido neste estudo.

Além disso, ainda predomina nos serviços de saúde bucal um modelo cirúrgico-restaurador, de baixo impacto e cobertura, insuficiente para atender a demanda espontânea reprimida, com práticas de vigilância à saúde bucal ainda pontuais e periféricas (CABRAL et al. 2000), reflexo das dificuldades de implantação do Sistema Único de Saúde (DALLARI 1995, MENDES 1996), e sem garantia de continuidade da descentralização das ações de saúde e compromisso na mudança do modelo assistencial.

Como limites do estudo da cárie dentária por distritos sanitários, cita-se aqueles inerentes as características do desenho e ao tipo de dados coletados (de prevalência e informações referidas), já colocados por diversos autores (KLEINBAUM et al. 1982, KELSEY et al. 1986, ROTHMAN 1987, BORRELL 1987, LAWSON et al. 1999). Embora de baixo poder analítico no teste de hipóteses, a comparação de indicadores, permitiram a identificação de grupos mais susceptíveis e indicam a possibilidade de outros estudos etiológicos para detectar variáveis ou fatores associados aos agravos, bem como implementar medidas mais efetivas no 
controle da doença. Isto é, naqueles distritos em que foram identificadas piores condições em relação a cárie dentária, são necessárias intervenções mais expressivas no controle da doença, bem como a continuidade de ações populacionais, como a fluoretação das águas de abastecimento público e garantia de acesso a dentifrícios fluorados.

Além disso, inúmeras variáveis individuais e coletivas podem estar associadas ao agravo ou a área geográfica estudada, inclusive às discriminadoras do nível sócioeconômico, como descrevem os trabalhos de BRAGAMIAN e RUSSEL (1971), ELLEY e LANGFORD (1992), NADANOVSKY e SHEIHAM (1995), AMSTUTZ e ROZIER (1995), PETRIDOU et al. (1996), JONES et al. (1997), MOYSÉS (2000), PATUSSI (2000) e MALTZ e SILVA (2001), e não foram abordadas neste estudo.

Destaca-se também, como um aspecto muito relevante ao estudo, a não homogeneidade interna dentro de cada distrito sanitário, já que esta é uma área definida por critérios administrativos pelo setor saúde, e não sociais, convivendo de forma próxima áreas de níveis de renda extremos, ou de necessidades de saúde, visto que não são muito escassos os dados populacionais em saúde bucal disponiveis no município.

\subsection{Cárie dentária segundo tipo de escola}

Em relação à prevalência de cárie dentária segundo o tipo de estabelecimento de ensino, aos 12 anos de idade observou-se uma maior ocorrência da doença em estudantes de escolas públicas na análise de regressão logística $(\mathrm{OR}=1,3 ; 1,02-1,64)$ 95\%IC, diferença estatisticamente significativa quando ajustada para a variável 
acesso ao dentista no último ano por tipo de financiamento. Este resultado foi semelhante aos estudos de FREIRE et al. (1999), no estado de Goiás e MALTZ e SILVA (2001), em Porto Alegre.

Os autores que relatam a maior ocorrência de cárie em crianças de escolas públicas, atribuem-na às dificuldades no acesso a produtos fluorados e serviços de saúde bucal, considerados como de fundamental relevância para o controle da cárie na população, e a maior ingestão de alimentos açucarados pelo seu menor custo (SOUZA et al. 1998).

Já aos 15 anos de idade, esta diferença não foi estatisticamente significativa, com apenas uma maior proporção de dentes obturados nos alunos de escolas privadas, coerente com os resultados dos trabalhos de WITT (1992), KNUPP (1997) e NARVAI et al. (2000). Estes destacam o baixo poder preditivo desta classificação do nível sócio-econômico para determinar iniqüidades em saúde bucal, reforçando que, a única diferença detectada entre estes grupos, foi uma maior proporção de dentes restaurados em crianças de escolas privadas, em função do acesso facilitado aos serviços.

Pode-se destacar também que, como em outras regiões do apesar da assistência odontológica ser mais disponivel aos escolares da rede privada em função da renda país (CÉSAR et al. 1999), de modo geral os programas coletivos com uso do flúor ocorrem com maior freqüência em escolares da rede pública de ensino, o que pode ter contribuído para a redução das diferenças entre os dois grupos. 


\subsection{Fluorose dentária}

As prevalências de fluorose dentária encontradas aos $12(31,4 \%)$ e aos 15 anos de idade $(27,6 \%)$ foram próximas às descritas para esta alteração na maior parte dos estudos no Brasil, em regiões com água de abastecimento público fluoretada em níveis ótimos, com o predomínio também da categoria de severidade "muito leve" (SILVA e PAIVA 1995, GASPAR et al. 1995, NARVAI et al. 1997, BUENDIA e ZAINA 1997).

Isto significa que apesar da necessidade de vigilância à saúde em relação a esta alteração em função do risco potencial do incremento da mesma decorrente da difusão maciça de fluoretos, como descrevem CLARCK et al. (1994), e do retorno da fluoretação das águas no município no final de 1996, esta parece ainda não se constituir um problema de saúde pública, como também descrevem os resultados do levantamento epidemiológico realizado no estado de São Paulo (SÃO PAULO 1999), no estudo de ALCÂNTARA (1998) em Curitiba e de SILVA e PAIVA (1995) em Belo Horizonte, todos envolvendo populações de escolares.

Identificou-se, em relação ao estudo anterior desenvolvido no município por REIS et al. (1999), discrepâncias na prevalência da fluorose dentária, já que no atual estudo foram quase inexistentes os casos de fluorose moderada. Esta diferença pode ser atribuída às especificidades das populações de estudo examinadas- o trabalho destes autores investigou apenas 4 escolas na idade de 7 anos de idade, enquanto o atual estudo envolveu uma amostra da população escolar aos 12 e 15 anos de idade, aos dentes examinados- apenas os incisivos centrais e todo o arco dentário respectivamente; a subjetividade inerente ao exame da fluorose dentária, visto que os 
examinadores não foram os mesmos em ambos os levantamentos, bem como as diferenças nas condições do exame.

As menores prevalências de fluorose dentária foram encontradas nos distritos de Brotas e Pau da Lima, aos 12 anos de idade e Pau da Lima e Cajazeiras aos 15 anos de idade. Detectou-se diferenças estatisticamente significantes (5\%) entre as áreas no teste do qui-quadrado, com maiores prevalências para o distrito da Liberdade, em ambas as idades.

Ocorrências mais altas como as identificadas em alguns distritos neste estudo têm sido atribuídas ao efeito combinado do uso e ingestão de produtos dentários de outras fontes sistêmicas de flúor, bem como as diferenças no acesso aos bens públicos (como o saneamento básico) e de consumo individual (MENDONÇA et al. 1998, DEN BESTEN 1999).

Embora esta seja uma possível explicação para as diferenças entre as regiões, vale ressaltar que as discrepâncias encontradas nos distritos da Liberdade, Pau da Lima e Brotas aos 12 anos de idade, e Liberdade, Pau da Lima, Cajazeiras e Subúrbio Ferroviário aos 15 anos de idade, indicam diferenças na interpretação da fluorose dentária entre os examinadores. Os exames na Liberdade foram realizados por um único examinador, enquanto que outro examinador responsabilizou-se pelos distritos de Pau da Lima e Cajazeiras. Isto é, embora tenha sido feita a calibração da equipe e obtidos coeficientes de concordância satisfatórios (WHO 1997), a subjetividade inerente ao estudo da fluorose dentária pode ter interferido na análise por áreas.

Além disso, como o cálculo amostral foi realizado utilizando-se como referência os indicadores de cárie, na análise da fluorose dentária, a mesma mostrou- 
se insuficiente para produzir estimativas mais precisas em cada área geográfica, podendo esta ter sido afetada também por escolha de grupos específicos de maior risco à esta alteração.

Ao se avaliar a ocorrência de fluorose segundo nível sócio-econômico, definido pela inserção do escolar por tipo de financiamento do estabelecimento de ensino, os alunos de escolas públicas, tanto aos $12(\mathrm{OR}=0,72 ; 0,57-0,89) 95 \% \mathrm{IC}$ como aos 15 anos de idade $(\mathrm{OR}=0,71 ; 0,55-0,91) 95 \% \mathrm{IC}$ apresentaram menor prevalência, tanto na análise descritiva como na regressão logística. Este resultado é interpretado pelos autores de diversas formas. SAMPAIO et al. (1999) e MALTZ e SILVA (2001) destacam que no melhor nivel econômico, seria maior a possibilidade de acesso a produtos fluorados e, portanto, maior o risco desta alteração, como identificado neste trabalho.

Entretanto, estes mesmo autores e VILLA e GUERRERO (1996) também relatam que na presença de alterações nutricionais, mais comuns no menor nível de renda, poderia ocorrer maior absorção do fluoreto ingerido e isto, conseqüentemente, provocaria um aumento da prevalência de fluorose neste grupo. Mesmo esta sendo uma hipótese biologicamente plausivel, os dados empíricos não apontam neste sentido.

Apesar de todas as dificuldades colocadas na literatura para a operacionalização das variáveis sociais e econômicas na saúde bucal (PETERSON 1990, LOCKER 1993), o uso do tipo de estabelecimento de ensino, com uma abordagem instrumental, mesmo não sendo capaz de resgatar os processos históricos 
na determinação das doenças e medidas distributivas que as mediem, foi capaz de identificar as diferenças e iniqüidades tanto na cárie como na fluorose dentária.

Além da eqüidade em saúde, outros desafios colocam-se na construção de uma atenção à saúde bucal mais justa no município- especialmente a garantia da universalidade do acesso e integralidade da atenção, ainda longe de serem alcançadas na estruturação dos sistemas locais de saúde, processo este construído através de avanços è retrocessos na última década.

Dentre as possibilidades deste estudo, se ressalta a capacidade de produzir estimativas confiáveis nas idades de 12 e 15 anos para o município em relação a cárie e fluorose dentária, caracterizar as ações e serviços de saúde desenvolvidos e identificar as possíveis áreas de risco para os agravos abordados. É visível a necessidade de constituir um sistema de informação em saúde bucal, para que este possa ser utilizado na avaliação de impacto e cobertura das práticas e serviços de saúde.

Destaca-se a necessidade de aprofundamento deste trabalho na identificação de subgrupos de risco à fluorose dentária em cada distrito sanitário e de mapeamento de outras variáveis sociais, econômicas, culturais/comportamentais ou biológicas marcadoras dos agravos à saúde bucal.

Observa-se também a relevância de estudos epidemiológicos continuados destes agravos no município, de forma a avaliar o impacto da re-introdução da fluoretação das águas de abastecimento público na prevalência e severidade dos mesmos, no sentido de construir um sistema de atenção à saúde bucal voltado para a vigilância à saúde. 


\section{CONCLUSÕES}

A partir deste estudo pode-se concluir:

1- O CPO-D e a prevalência de cárie dentária no município de Salvador correspondeu a 1,44 e $49 \%$ aos 12 anos de idade, e de 2,66 e $34,9 \%$ aos 15 anos de idade respectivamente;

2- Existe uma tendência de redução dos indicadores de cárie dentária para o município nos últimos cinco anos, embora em menor proporção do que na década anterior;

3- Identifica-se iniqüidades na distribuição da cárie dentária segundo distrito sanitário, com melhores condições para as regiões de Pau da Lima (CPO$\mathrm{D}=1,13$ e 1,40), Cajazeiras (CPO-D=1,14 e 1,82) e Subúrbio Ferroviário (CPO-D=1,13 e 2,10), aos 12 e 15 anos de idade respectivamente;

4- Os valores médios de cárie dentária para escolares de 12 e 15 anos de idade tanto no sistema privado (CPO-D=1,37 e 2,69) como no público (CPO$D=1,46$ e 2,38 ), encontram-se abaixo da meta proposta pela OMS, para o ano 2000, de no máximo 3 dentes atacados por cárie, na idade de 12 anos;

6- Nos escolares da rede privada predominam os dentes restaurados, enquanto que naqueles das escolas públicas os dentes cariados, em ambas idades;

7- Não foram encontradas diferenças significativas nos indicadores de cárie dentária (CPO-D e percentual de indivíduos livres de cárie) entre os escolares da rede privada e pública, em ambas idades; 
8- A prevalência de fluorose dentária no município de Salvador foi de $29,6 \%$, sendo $31,4 \%$ aos 12 anos de idade e $27,6 \%$ aos 15 anos de idade;

9- Aos 12 anos, os distritos com menores proporções desta alteração foram Pau da Lima (18,2\%), Brotas (18,4\%) e Cabula-Beiru (19,4\%); e aos 15 anos de idade os distritos Pau da Lima $(14,6 \%)$, Cajazeiras $(13,5 \%)$ e Subúrbio Ferroviário $(13,0 \%)$ foram os de menor prevalência;

10-Aos 12 e 15 anos de idade, o distrito da Liberdade foi o que apresentou maior proporção de indivíduos acometidos por fluorose dentária- $72,4 \%$ e $57,3 \%$ respectivamente;

11- Observou-se maior proporção de escolares livres de fluorose nas escolas públicas ( $70 \%$ aos 12 anos e $74 \%$ aos 15 anos) em relação às privadas $(64,1 \%$ aos 12 anos e $68,3 \%$ aos 15 anos) diferença estatisticamente significativa em ambas idades;

12-A fluorose dentária parece ainda não se constituir um problema de saúde pública no município de Salvador-BA e reforça-se a necessidade da vigilância à saúde desta alteração, através do monitoramento da sua prevalência após a reintrodução da fluoretação das águas de abastecimento público, bem como a vigilância sanitária de todas as fontes de consumo de água potável e de produtos infantis contendo flúor. 


\section{REFERÊNCIAS BIBLIOGRÁFICAS}

Abelin T, Brzezinsk ZJ, Carstairs VDD. Measurement in health promotion and protection. Geneva: WHO, European Series n. 22; 1987. p. 1-27.

Adde CA. Avaliação crítica da fluorose dentária quando da associação de métodos sistêmicos e tópicos de fluoração em escolares da cidade de São Paulo, após 10 anos de fluoração das agues de abastecimento público. São Paulo-SP; 1997. [Tese de Doutorado- Faculdade de Odontologia da Universidade de São Paulo].

Akerman M. Diferenciais intra-urbanos em São Paulo: um estudo de caso de macrolocalização dos problemas de saúde. In: Barata, RB; Barreto, ML, Almeida Filho, N; Veras, RP (org). Equidade e Saúde- contribuições da Epidemiologia. Rio de Janeiro: Fiocruz, ABRASCO; 1997. p.177-188.

Akpata ES, Fakiha Z, Khan N. Dental fluorosis in 12-15 year old rural children exposed to fluorides from well drinking water in the Hail region of Saudi Arabia. Community Dental Oral Epidemiol 1997; 25:324-7.

Alcântara CM. Prevalência de fluorose dental em escolares de Curitiba. Rev ABO Nac 1998; 6(5): 304-7.

Alcaide AL, Veronezi O. Prevalência de fluorose dental na cidade de Icém. Rev APCD 1979; 33: 23-25.

Almeida C. Eqüidade e reforma setorial na América Latina: um debate necessário. Cad Saúde Pública 2002; 18 (suppl): 22-36.

Amstutz RD, Rozier RG. Community risk indicators for dental caries in schoolchildren: an ecologic study. Community Dent Oral Epidemiol 1995; 23: 12937.

Ando A, Coimbra BWR, Santos NP, Sampaio L. Efeito anticariogênico do flúor. [Apresentado no Centro Acadêmico da Faculdade de Odontologia da Universidade de São Paulo-CUBO; 1973; São Paulo, Brasil].

Baldani MH, Narvai PC, Antunes JLF. Cárie dentária e condições sócio-econômicas no Estado do Paraná, Brasil,1996. Cad Saúde Pública 2002; 18(3): 755-763.

Bamard PD. Dental conditions in high school students, Sydney, 1972. Australian Dent Journal 1976; 21(6): 513-6.

Barmes DE. A global view of oral disease: today and tomorrow. Community Dent Oral Epidemiol 1999; 27:2-7. 
Black D, Morris SN, Smith C. Inequalities in Health. The Black Report. London: Peguin Books, 1982. p. 51-89.

Borrell, C. Métodos utilizados no estudo das desigualdades sociais em saúde. In: Barata, RB (org). Condições de vida e situação de Saúde. São Paulo: ABRASCO, 1997. p. 167-95.

Bragamian RA, Russel AL. An epidemiologic study of dental caries in race and geographic área. Journal Dent Res 1971; 50(6): 1553-6.

Brasil. Constituição da República Federativa do Brasil, São Paulo: IMESP; 1988.

Brasil. Instituto Brasileiro de Geografia e Estatística. Malha municipal digital do Brasil. Bahia: Fundação IBGE; 1997.

Brasil. Instituto Brasileiro de Geografia e Estatística. Cadastro de cidades e vilas do Brasil. 2000. Disponivel em < URL:http://www.ibge.gov.br>, [2000, dez 12].

Brasil. Ministério da Educação e Cultural- INEP. Censo educacional 2000. Disponivel em <URL: htpps://www2.inep.gov.br>, [2001 Jan 04].

Brasil. Ministério da Saúde/ FSESP. Fluoretação das águas de abastecimento público. Brasilia-DF, 1975.

Brasil. Ministério da Saúde/ Conselho Federal de Odontologia. I Conferência Nacional de Saúde Bucal: relatório final. Brasília-DF, 1986.

Brasil. Ministério da Saúde. Levantamento epidemiológico em saúde bucal: Brasil, zona urbana, 1986. Brasília-DF, 1988.

Brasil. Ministério da Saúde. CPO-D médio nas capitais brasileiras, 1996. Disponível em <URL: http:// www. saude.gov.br/programas/bucal>, [1999 Out 20].

Brasil. Ministério da Saúde. Resolução 196/96 do Conselho Nacional de Saúde sobre a regulamentação da pesquisa em seres humanos, 1997. Brasília- DF, 1997.

Brasil. Ministério da Saúde. DATASUS. Informações técnicas de estados e municípios brasileiros. Disponivel em <URL:http://www.saude.gov.br/ datasus.htm>, [2000 Nov 21].

Bratthall D. Introducing the Significant Caries Index together with a proposal for a new oral health goal for 12-years-old. Int Dent Journal 2000; 50: 378-384.

Buendia OC, Zaina J. Será o flúor vilão? Rev Paulista de Odontologia 1997; XIX: 36-44. 
Buscariolo IA. Prevalência de fluorose dentária associada ao uso sistêmico e tópico de fluoretos em escolares da região sul da cidade de São Paulo após 14 anos de fluoração das águas de abastecimento público. São Paulo; 2001. [Tese de Doutorado- Faculdade de Odontologia da Universidade de São Paulo].

Cabral MBBS, Cangussu MCT, Liesenfeld MH, Vianna MIP. A construção democrática de um novo modelo de atenção à saúde bucal- Projeto UNI-BA. Rev Brasileira de Odontologia em Saúde Coletiva 2000; ed.especial: 55-62.

Campos DL, Farias DG de, Toledo AO de, Bezerra AC. Prevalência de fluorose dentária em escolares de Brasília- Distrito Federal. Rev Odontol Universidade de São Paulo 1998; 12(3): 225-30.

Cangussu MCT. Cárie dental em adolescentes de Salvador-BA- fatores de promoção e proteção à saúde. Salvador-BA, 1998. Salvador-BA; 1998. [Dissertação de Mestrado- Instituto de Saúde Coletiva da Universidade Federal da Bahia].

Capella LF, Carcereri DL, Paiva SM de, Rosso RA, Paixão R de F, Saltori EK et al. Ocorrência de fluorose dentária endêmica. Rev Gaúcha de Odontologia 1989; 36(5): 371-75.

Castellanos PL. Perfis de Mortalidade, Nível de desenvolvimento e iniqüidades sociais na região das Américas. In: Barata, RB; Barreto, ML, Almeida Filho, N; Veras, RP (org). Equidade e Saúde- contribuições da Epidemiologia. Rio de Janeiro: Fiocruz, ABRASCO; 1997, p.137-162.

César CLG, Narvai PC, Gattás VL, Figueiredo GM. "Medo do dentista" e demanda aos serviços odontológicos em municípios da zona oeste da região metropolitana de São Paulo. Odontologia e Sociedade 1999; 1(1/2): 39-44.

Chaves MM, Fraenkel JM. Princípios básicos para a organização de um serviço dentário escolar. Revista SESP 1956: 469-484.

Chaves M. Odontologia Social. $3^{\mathrm{a}}$ ed. Rio de Janeiro: Artes Médicas, 1986.

Clarck DC, Hann HJ, Williamson MF, Berkowitz J. Influence of exposure to various fluoride technologies on the prevalence of dental fluorosis. Community Dent Oral Epidemiol 1994; 22: 461-4.

Clovis J. The impact of demographic, economic and social trends on oral health care. PROBE 1994; 28(3): 93-8. 
Cochran WG. Técnicas de Amostragem. Brasil, Portugal: Fundo cultural, 1965.

Cortes DF, Ellwood RP, O'Mullane DM, Bastos JR. Drinking water fluoride levels, dental fluorosis and caries experience in Brazil. Journal of Pub Health Dent 1996; 56(4): 226- 8 .

Costa MCN, Teixeira MGLC. A concepção do "espaço" na investigação epidemiológica. Cad Saúde Pública 1999; 15(2): 271-9.

Dallari SG. Os Estados brasileiros e o direito à saúde. São Paulo: HUCITEC; 1995.

De La Rosa M. Dental caries and socioeconomic status in mexican children. Journal of Dent Research 1978; 57(3): 453-7.

Dean AG, Dean JA, Burton AH, Dicker RC. Epi Info, version 5: a word processing, database, and statistics program for epidemiology on micro- computers. Center of Disease Control, Atlanta, Georgia, USA, 1990.

DenBesten PK. Biological mechanisms of dental fluorosis relevant to the use of fluoride supplements. Community Dent Oral Epidemiol 1999; 27: 41-7.

Diehnelt DE, Kyak HA. Socioeconomic factors that affect international caries levels. Community Dent Oral Epidemiol 2001; 29: 226-33.

Diniz J. Contribuição ao estudo do sistema incremental de atendimento odontológico. Salvador-BA, 1987. [Tese de Doutorado- Faculdade de Odontologia da Universidade Federal da Bahia].

Downer MC, Blinkhorn AS, Holt RD, Wight C, Attwood D. Dental caries experience and defects of dental enamel among 12-year-old children in North London, Edinburgh, Glasgow and Dublin. Community Dent Oral Epidemiol 1994; 22: 2835.

Dummer PMH. Factors influencing the caries experience of a group of children at ages of 11-12 and 15-16 years: results from an ongoing epidemiological survey. Journal Dent Res 1990; 18 (1): 37-48.

Eklund SA, Moller IJ, Leclereq MH. Calibrating examiners for oral health epidemiological surveys. Geneva: Worl Health Organization; 1996.

El Nadef MAI, Honkala E. Fluorosis in relation to fluoride levels in Central Nigéria. Community Dent Oral Epidemiol 1998; 26: 26-30.

Ely HC, Pretto SM. Fluorose e cárie dentária: um estudo epidemiológico em cidades do Rio Grande do Sul com diferentes níveis de flúor nas águas de abastecimento. Rev Odonto Ciênc 2000; 15(3): 143-73. 
Elley KM, Langford JW. The use of a classification of residential neighbourhoods (ACORN) to demonstrate differences in dental health of children resident within South Birmingham health district and different socio-economic backgrounds. Community Dent Health 1992; 10: 131-8.

Estève J, Benhamou E, Raymond L. Statistical methods in cancer research, vol. IV. Descriptive epidemiology. Lyon (Paris); 1994. (WHO series, n. 128)

Fejerskov $\mathrm{O}$ et al. Fluorose dentária- um manual para profissionais da saúde. São Paulo: Santos; 1994.

Forni 'TIB. Caracterização de levantamentos epidemiológicos de fluorose dentária no estado de São Paulo-SP. São Paulo-SP; 2000. [Dissertação de Mestrado- Faculdade de Saúde Pública da Universidade de São Paulo].

Forte FDS, Freitas CHSM, Sampaio FC, Jardim MC de AM. Fluorose dentária em crianças de Princesa Izabel, Paraíba. Pesqui Odontol Bras 2001; 15(2): 87-90.

Freire MCM, Pereira MF, Batista SMO, Borges MRS, Barbosa MI, Rosa AGF. Prevalência de cárie e necessidade de tratamento em escolares de 6 a 12 anos da rede pública de ensino. Rev Saúde Pública 1999; 33(4): 385-90.

Freire PS. Primeiros resultados com a fluoração de águas no Brasil. Revista SESP 1956:322-340.

Gaspar MR. Opacidades de origem não fluorótica e fluorose dentária em áreas com baixa $(0,2 \mathrm{ppmF})$ e ótima $(0,7 \mathrm{ppmF})$ concentração de flúor na água de abastecimento. RBO 1995; 52(2): 13-8.

Gaughwin A, Spencer AJ, Brennan DS, Moss J. Oral health of children in South Australia by socio-demographic characteristics and choice of provider. Community Dent Oral Epidemiol 1999; 23:93-102.

Gelbier S. National Health Service and social inequalities in dental health. British Dent Journal 1998; 185(1): 28-9.

Gerschman S, Vianna MLW. A miragem da pós- modernidade. Democracia e políticas sociais no contexto da globalização. Rio de Janeiro: Fiocruz, 1997.

Gillcrist JA, Brumley DE, Blackford JU. Community socioeconomic status and children's dental health. Journal Am Dent Assoc 2001; 132(2): 216-22.

Gonini CAJ. Fluorose dentária em crianças nascidas entre 1986-1989, usuárias da rede de unidades básicas de saúde de Londrina: freqüência, severidade e 
fatores associados. Londrina-PR, 1999. [Dissertação de Mestrado- Departamento de Saúde Materno Infantil e Saúde Coletiva da Universidade Estadual de Londrina].

Gwatkin DR. Health inequalities and the health of the poor: what do we know? What can we do? Bull of WHO 2000; 78(1): 3-17.

Hausen $\mathrm{H}$, Heinonem OP, Paunio I. Caries in permanent dentition and social class of children participanting in public dental care in fluoridated and non fluoridated areas. Community Dent Oral Epidemiol 1981; 9: 289-91.

Heintze SD, Bastos JR, Bastos R. Urinary fluoride levels and prevalence of dental fluorosis in three Brazilian cities with different fluoride concentrations in the drinking water. Community Dent Oral Epidemiol 1998; 26: 316-23.

Hjern A, Grindefjord M, Sundberg H, Rosén M. Social inequalities in oral health and use of dental care in Sweden. Community Dent Oral Epidemiol 2001;29: 167-74.

Hyde RW. Socio-economic aspects of dental caries: a community and individual study of dental caries in selectees. New Engl Journal Med 1944; 230: 506-10.

Illsley R, Baker D. Contextual variations in the meaning of health inequality. Soc Sci Med 1991; 32(4): 359- 65.

Jones CM, Woods K, Taylor GO. Social deprivation and tooth decay in Scottish schoolchildren. Health Bull 1997; 55(1): 11-5.

Kelsey $\mathrm{J}$, Thompson WD, Evans AS. Methods in observational epidemiology. New York: Oxford University Press; 1986.

Kleinbaum DG, Kupper LL, Morgenstern H. Epidemiologic research. New York: John Wiley e Sons Inc., 1982. p. 19-25; 78-81.

Kleinbaum DG. Logistic regression- a self learning text. New York: Springer Verlag; 1994.

Kloos H, Haimanot RT. Distribution of fluorosis in Ethiopia and prospects for control. Tropical Medicine and Int Health 1999; 4(5): 355-64.

Knupp RRS. Correlação do fator sócio- econômico com tratamentos odontológicos. RBO 1997; 54(1): 14-17.

Lawson A, Biggeri A, Bohning S, Lesaffre E, Viel JF, Bertollini R. Disease mapping and risk assessment for public health. New York: John Wiley e Sons Inc; 1999.

Lewis DW, Banting DW. Water fluoritadion: current effectiveness and dental fluorosis. Community Dent Oral Epidemiology 1994; 22: 153-8. 
Lo GL, Bagramian RA. Prevalence of dental fluorosis in children in Singapore. Community Dent Oral Epidemiology 1996; 24: 25-7.

Locker D. Measuring social inequality in dental health services research: individual, household and area-based measures. Community Dent Health 1993; 10: 139-50.

Locker D, Clarcke M, Murray H. Oral health status of Canadian born and immigrant adolescents in North York, Ontario. Community Dent Oral Epidemiol 1998; 26: $177-81$.

Maltz ME, Farias C. Fluorose dentária em escolares de quatro cidades brasileiras com e sem água artificialmente fluoretada. Rev da Fac de Odontonlogia de Porto Alegre 1998; 39(2): 18-21.

Maltz M, Silva BB, Schaeffer A. Prevalência de fluorose em uma cidade brasileira com água fluoretada, em 1987 e 1997. In: 15. Reunião Anual da Sociedade Brasileira de Pesquisa Odontológica. Águas de São Pedro (SP); 1998: 70.

Maltz M, Silva BB. Relação entre cárie, gengivite e fluorose e nivel socioeconômico em escolares. Rev Saúde Pública 2001; 35(2): 170-6.

Mansbridge JN. The influence of social and economic conditions on the prevalence of dental caries. Arch Oral Biol 1959; 1: 241-53.

Marcelino G, Guimarães MB, Silva PR, Terreri ALM, Guimarães LOC, Saliba NA. Fluorose dentária em escolares da rede pública na cidade de Araçatuba. Rev Instituto Ciências Saúde 1999; 17(2): 89-92.

Martildes MLR. Avaliação do impacto de programas incrementais de atendimento odontológico sobre as condições de saúde bucal de escolares de 12 anos de idade em São José dos Campos- SP, 1991. São Paulo, 1992. [Dissertação de Mestrado- Faculdade de Saúde Pública da USP].

Martisson T. Variation of caries frequency with socio-economic background in unselected and extreme groups of 14-year old children in Malmü. Odontol Revy $1975 ; 26(2)$ : $165-74$.

Mayer JD. Detection of disease causation. In: The role of spatial analyses and geographic data in detection of disease causation, section V, p. 1213-21, 1997.

Mendes EV. Uma agenda para saúde. Rio de Janeiro: Hucitec-Abrasco; 1996.

Mendonça LL, Kirchner UL, Costa RN, Giovannini JFBG, Pinto MR, Luz MAR. Estudo multicêntrico da fluorose dental e da cárie dental em escolares de 7 e 10 anos de Belo Horizonte-Parte I. Rev Pós Graduação- UFMG 1998; 5(2): 101-9. 
Mitchell HH. A study of dental caries in Puerto Rican children. Human Biol 1933; 5: 274-87.

Modesto A, Tanaka FHR, Freitas AD, Cury JA. Avaliação da concentração de fluoreto na água de abastecimento público do município de Rio de Janeiro. RBO 1999; 56(5): 217-21.

Moraes IM. Informação em saúde- espaço estratégico. São Paulo- Rio de Janeiro: Hucitec, ABRASCO; 1994.

Moura MS, Santos-Pinto LAM, Giro EMA, Cordeiro RCL. Cárie dentária relacionada ao nível socioeconômico em escolares de Araraquara. Rev Odontologia UNESP 1996; 25(1): 97-107.

Moysés SJ. Desigualdade em saúde bucal e desenvolvimento humano: um ensaio em preto, branco e alguns tons de cinza. Rev Brasileira de Odontologia em Saúde Coletiva 2000; 1(1): 7-17.

Nadanovski P, Sheiham A. Relative contribution of dental services to the change in caries levels of 12- year-old children in 18 industrialized countries in the 1970's and early 1980's. Community Dent Oral Epidemiol 1995; 23: 331-9.

Narvai PC. Odontologia e saúde bucal coletiva. São Paulo: Hucitec; 1994.

Narvai PC. Está ocorrendo um declínio de cárie no Brasil? Jornal da ABOPREV 1996; 7-12.

Narvai PC, Castellanos RA, Frazão P. Levantamento Epidemiológico de oclusopatias e fluorose dentária em crianças de 5 a 12 anos de idade, no município de São Paulo, em 1996. In: Anais do II Congresso Brasileiro de Saúde Coletiva; 1997, Águas de Lindóia- SP. ABRASCO; 1997, resumo n. 635.

Narvai PC, Castellanos RA, Frazão P. Prevalência de cárie em dentes permanentes de escolares do município de São Paulo-SP. 1970-1996. Rev Saúde Pública 2000; 34(2): 196-200.

Nedel FB, Pereira J, Rocha M. Anos de vida perdidos por mortalidade: um dos componentes da carga de doenças. Rev Saúde Pública 1999; 33(5): 461-69.

Oliveira AGR. Levantamento epidemiológico em saúde bucal- Cárie dental. Brasil,1996. .Disponível em <URL: http:/l www.planetaterra.com.br/saude/ angelonline/ epi_96.pdf >, [1998 Jul 10]. 
Oliveira BH de, Milbourne P. Fluorose dentária em incisivos superiores permanentes em crianças de escolas públicas do Rio de Janeiro, RJ. Rev Saúde Pública 2001; 35(3): 276-82.

Paim JS, Costa MCN. As desigualdades na distribuição dos óbitos no município de Salvador, 1980. Cad Saúde Pública 1986; 2(3): 312-33.

Paiva SM, Paixão R de F, Capella LF, Carcereri DL, Rosso DA, Freitas ARR de et al. A Fluorose dentária. RGO 1993; 41(1): 57-58.

Pattusi MP. As desigualdades na distribuição da cárie dentária em escolaress de 12 anos residentes em diferentes regiões sócio-econômicas do Distrito Federal, Brasil, 1997. Rev Brasileira de Odontologia em Saúde Coletiva 2000; 1(1): 19-28.

Pereira AC, Cunha MC, Meneghim MC. Prevalência de cárie dentária e fluorose em escolares de áreas fluoretadas e não fluoretadas. In: 15². Reunião Anual da Sociedade Brasileira de Pesquisa Odontológica. Águas de São Pedro (SP); 1998: 121.

Peres KGA, Bastos JRM, Latorre MRDO. Severidade de cárie em crianças e relação com aspectos sociais e comportamentais. Rev Saúde Pública 2000; 34(4): 402-8.

Peterson PE. Social inequalities in dental health. Community Dent Oral Epidemiol 1990; 18: 153-8.

Petridou E, Athanassouli T, Panagopoulos H, Revinthi K. Sociodemographic and dietary factors in relation to dental health among Greek adolescents. Community Dent Oral Epidemiol 1996; 26: 307-11.

Pinto A. Distribuição de renda na América Latina e desenvolvimento. $2^{\mathrm{a}}$ edição. São Paulo: Zahar; 1976, p. 11-37.

Pinto VG. Relacionamento entre padrões de doença e serviços de atenção odontológica. Rev Saúde Pública 1989; 23(6): 509-14.

Pinto VG. Saúde bucal: odontologia social e preventiva. $3^{\mathrm{a}}$ ed. São Paulo: Santos; 1992.

Prefeitura Municipal do Salvador. Secretaria Municipal de Saúde. Plano Municipal de Saúde 1994-1997. Salvador- BA; 1994.

Prendergast MJ, Beal JF, Clayton JR. The use of sociodemographic profiling of patients to monitore changes in the provision of care by the Community Dental Service. Community Dent Health 1999; 16: 213-5. 
Reis SRA, Mendonça LL, Cabral MBBS, Silva CAL, Souza FM, Fraga IC et al. Fluorose dental, estado nutricional e cárie dental em escolares de diferentes estratos econômicos de Salvador, Bahia: parte I. RPG Rev pos-grad 1999; 6(4): 387-94.

Ribas TRC, Armonia PL, Saraceni Junior G. Avaliação da fluorose dentária em escolares do colégio São Vicente de Paulo, situado na zona leste do município de São Paulo. Rev de Odontol da Univ de Santo Amaro 1999; 4(2): 62-5.

Ribeiro JF. Prevalência da cárie e mortalidade dentária em estudantes de 12 e 15 anos, na cidade de Guaratinguetá, estado de São Paulo, segundo a idade, o sexo e o nivel sócio-econômico. Rev Fac Odontol São José dos Campos 1974; 3(1): 19-45.

Riley 'JC, Lennon MA, Ellwod RP. The effect of water fluoritadion and social inequalities on dental caries in 5 year-old children. Intern Journal of Epidemiol 1999; 28: 300-5.

Rothman KJ. Epidemiologia moderna. Madrid: Diaz de Santos AS; 1987, p. 86-87.

Rowe NH, Gam SM, Clarck DC, Guire KE. The effect of age, sex, race and economic status on dental caries experience of the permanent dentition. Committee to review the Ten-State Nutrition Survey of 1968-70. Pediatrics 1976; 57(4):457-61.

Sampaio FC. Prevalência de cárie e fluorose dentária em cidades da Paraíba com teores residuais de fluoretos na água de abastecimento. CCS 1993; XII: 11-9.

Sampaio FC, Ramm von der Hehr F, Ameherg P, Petrucci GD, Hatloy A. Dental fluorosis and nutritional status of 6 to 11-year-old children living in rural areas of Paraiba, Brazil. Caries Res 1999; 33: 66-73.

São Paulo (Estado), 1999. Secretaria de Saúde e Faculdade de saúde Pública da Universidade de São Paulo. Núcleo de Estudos e Pesquisas de Sistemas de Saúde e Núcleo de Apoio ao Desenvolvimento de Sistemas de Saúde. Levantamento epidemiológico em saúde bucal: Estado de São Paulo, 1998. 93p.

Scavuzzi AIF. Estudo da prevalência de cárie dentária e doença periodontal em gestantes- Distrito Sanitário Docente Assistencial Barra/Rio Vermelho, Salvador-BA. Salvador- BA; 1995. [Tese de Mestrado- Faculdade de Odontologia da Universidade Federal da Bahia].

Secretaria Estadual de Saúde do Estado da Bahia (SESAB). Plano Estadual de Saúde 1996- 2000. Salvador-BA, 1996.

Secretaria Municipal de Saúde de Curitiba. Fluorose- um estudo em crianças de 12 anos de Curitiba. Boletim Epidemiológico de Saúde Oral de Curitiba 1997; 1(1): $3-4$. 
Selwitz RH, Nowjack-Raymer RE, Kingman A, Driscollw S. Prevalence of dental caries and dental fluorosis in areas with optimal and above-optimal water fluoride concentrations: 10 year follow up survey. Jounal of Pub Health Dent 1995; 55(2): 85-93.

Sgan-Cohen HD, Lipsky R, Behar R. Caries, diet, dental knowledge and socioeconomic variables in a population of 15 -year-old Israeli schoolchildren. Community Dent Oral Epidemiol 1984; 12:332-5.

Silva ALCC, Paiva SM. Ocorrência de fluorose dentária em escolares de Belo Horizonte. Rev CROMG 1995; I(2): 49-53.

Silva BB, Maltz M. Prevalência de cárie, gengivite e fluorose em escolares de 12 anos de Porto Alegre, RS, Brasil, 1998/1999. Pesqui Odontol Bras 2001; 15(3):20814.

Silva LMV, Paim, JS, Costa, MCN. Desigualdade na mortalidade, espaço e estratos sociais. Rev Saúde Pública 1999; 33(2): 187-97.

Silva MCS, Brito ML dos R, Araújo SM, Carvalho AMO, Alves Neto AA, Pastor IMO et al. Condição dos primeiros molares permanentes em 1.202 escolares da cidade do Salvador na faixa etária de 7 a 14 anos. Rev da Fac Odont da UFBA 1984; 4: 9-25.

Slade GD, Spencer AJ, Davies MJ, Stewart JF. Influence of exposure to fluoride water on socioeconomic inequalities in children's caries experience. Community Dent Oral Epidemiol 1996; 24:89-100.

Souza ACT, Cufino E, Peterson KE, Gardner J, Mamaral MIV, Ascherio A. Variations in infant mortality rates among municipalities in the state of Ceará, Northeast Brazil: an ecological analysis. Intern Journal of Epidemiol 1999; 28: 267-75.

Souza GAA, Faria V. Bahia de todos os pobres. Rio de Janeiro: Ed. Vozes/ Ceprab, 1980.

Souza SMD, Cury JÁ, Narvai PC, Gevaerd SP. Saúde Bucal: prevenção para 100 por cento da população infantil. Rev ABO Nac 1998, 6(3): 182-6.

Stata. Stata Statistical Software: release 6.0. In: 6.0 ed. Texas: Stata Press: University Drive East, College Station; 1999.

Takehara T. Oral health status, manpower and delivery systems in a developed country- Japan. Journal of Pub Health Dent 1991; 51(4): 260-4. 
Tomita NE, Panighel CP de MA, Narvai PC, Lopes ES. Implicações da vigilância à saúde sobre ocorrência de fluorose dental. Rev ABO Nac 1995; 3(5): 318-23.

Treasure ET, Dever JG. Relationship of caries with socioeconomic status in 14-yearsold children from communities with different fluoride histories. Community Dent Oral Epidemiol 1994; 22:226-30.

Uchôa HW, Saliba NA. Prevalência de Fluorose Dental na cidade de Pereira Barretos. Boletim do Serviço de Odontologia Sanitária da Secretaria de Saúde 1970; 6(3): 11-6.

Universidade de São Paulo- Faculdade de Saúde Pública/ Secretaria estadual de Saúde- SP. Levantamento das condições de saúde bucal- estado de São Paulo. 1998- Caderno de Instruções. São Paulo, 1998.

Vargas CM, Manski RJ. Dental expenditures and source of payment by race/ethnicity and others sociodemographic characteristics. Journal of Pub Health Dent 1999; 59(1): 33-8.

Vasconcelos C, Cabral MB, Cangussu MC. Prevalência de cárie dental em préescolares no Distrito Docente Assistencial Barra-Rio Vermelho. Rev da ABOPREV 2000; 3(1): 60-5.

Victora CG, Grassi PR, Schimidt AM. Situação de saúde da criança em área da região Sudeste do Brasil, 1980-92. Tendências temporais e distribuição espacial. Rev Saúde Pública 1994; 28(6): 423-32.

Villa A, Guerrero S. Caries experience and fluorosis in Chilean from different socioeconomic status. Community Dent Oral Epidemiol 1996; 24: 225-7.

Waitzkin $\mathrm{H}$. The social origins of illness: a neglected history. Intern $\mathbf{J}$ of Health Services 1981; 11 (1): 77-103.

Waldman EA, Barata $R$ de CB, Moraes JC de, Guibu IA, Timenetsky M do CST. Gastroenterites e infecções respiratórias agudas em crianças menores de 5 anos em áreas da região Sudeste do Brasil, 1986-87. II- Diarréias. Rev Saúde Pública 1997; 31(1): $62-70$.

Watt $\mathrm{R}$, Sheiham A. Inequalities in oral health: a review of the evidence and recommendations for action. British Dent Jounal 1999; 187(1): 6-12.

WHO. Oral health for the $21^{\text {st }}$ century. Washington: World Health Organization; 1994.

WHO. Oral health surveys. Basic methods. Geneva: World Health Organization; 1997. 
WHO. Area Profile Programme. Significant Caries Index. Disponível em <URL:http://www.whocollab.od.mah.se./expl/sic.>, [ 2002, Jul 11].

Witt MCR. Pattern of caries experience in a 12-year-old Brazilian population related to socioeconomic background. Acta Odontol Scand 1992; 50: 25-30.

Wittenberg RL. Oral health for a health life. Journal of Pub Health Dent 1994; 54(4): 231-3.

Zar JH. Biostatistical analysis. Third edition. New Jersey: Prentice Hall; 1996.

Zioni F, Palos CMC. A questão da ética em tempos de fim de século. 0 mundo da Saúde 2000; 24(1): 17-23. 
Anexos 
Anexo 1- Mapa do município do Salvador com a distribuição por Distrito Sanitário. 1996.

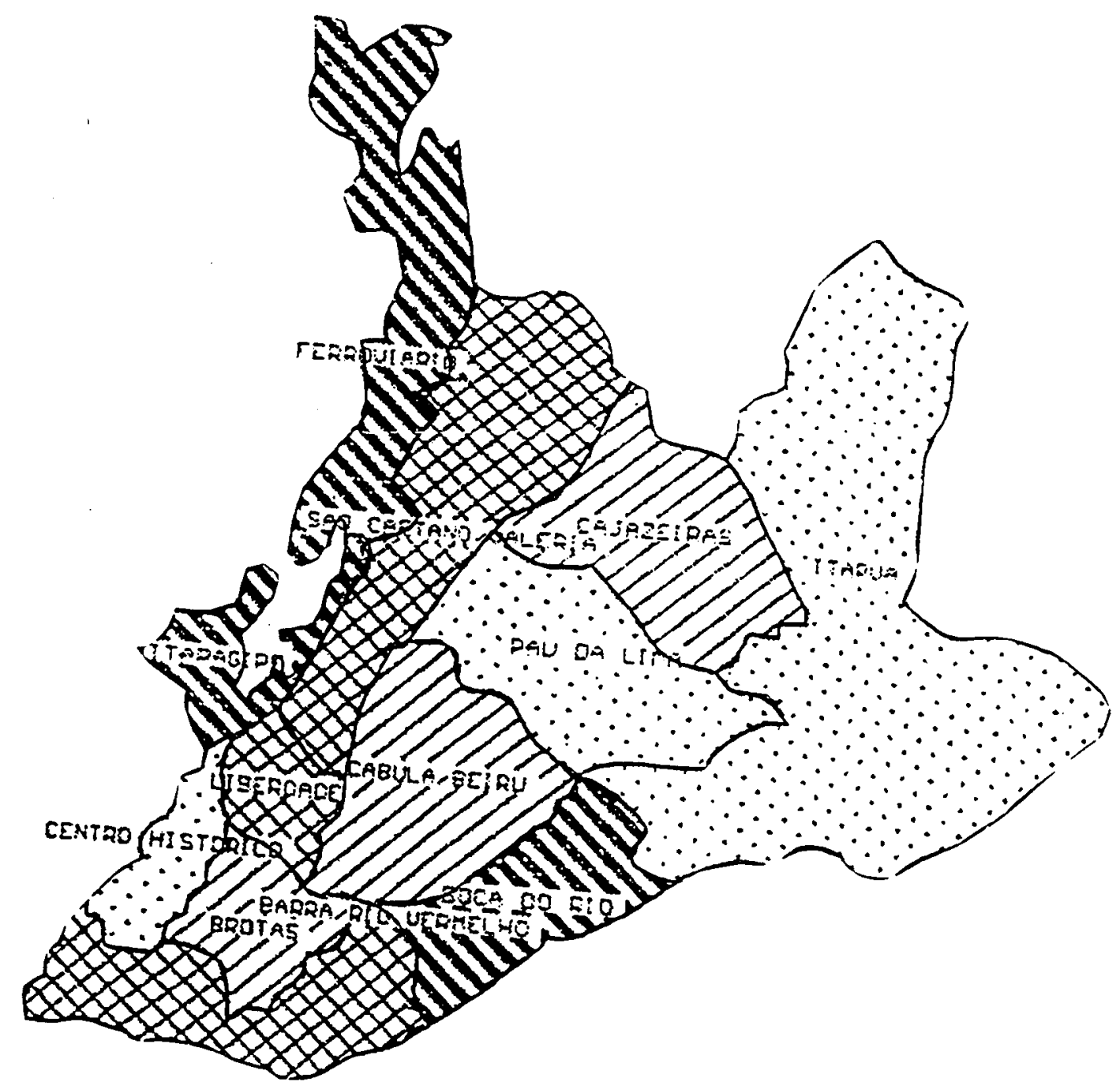

Fonte: Prefeitura Municipal do Salvador- Secretaria Municipal de Saude. Plano Municipal de Saúde 1996-2000. 1996, p. 21 


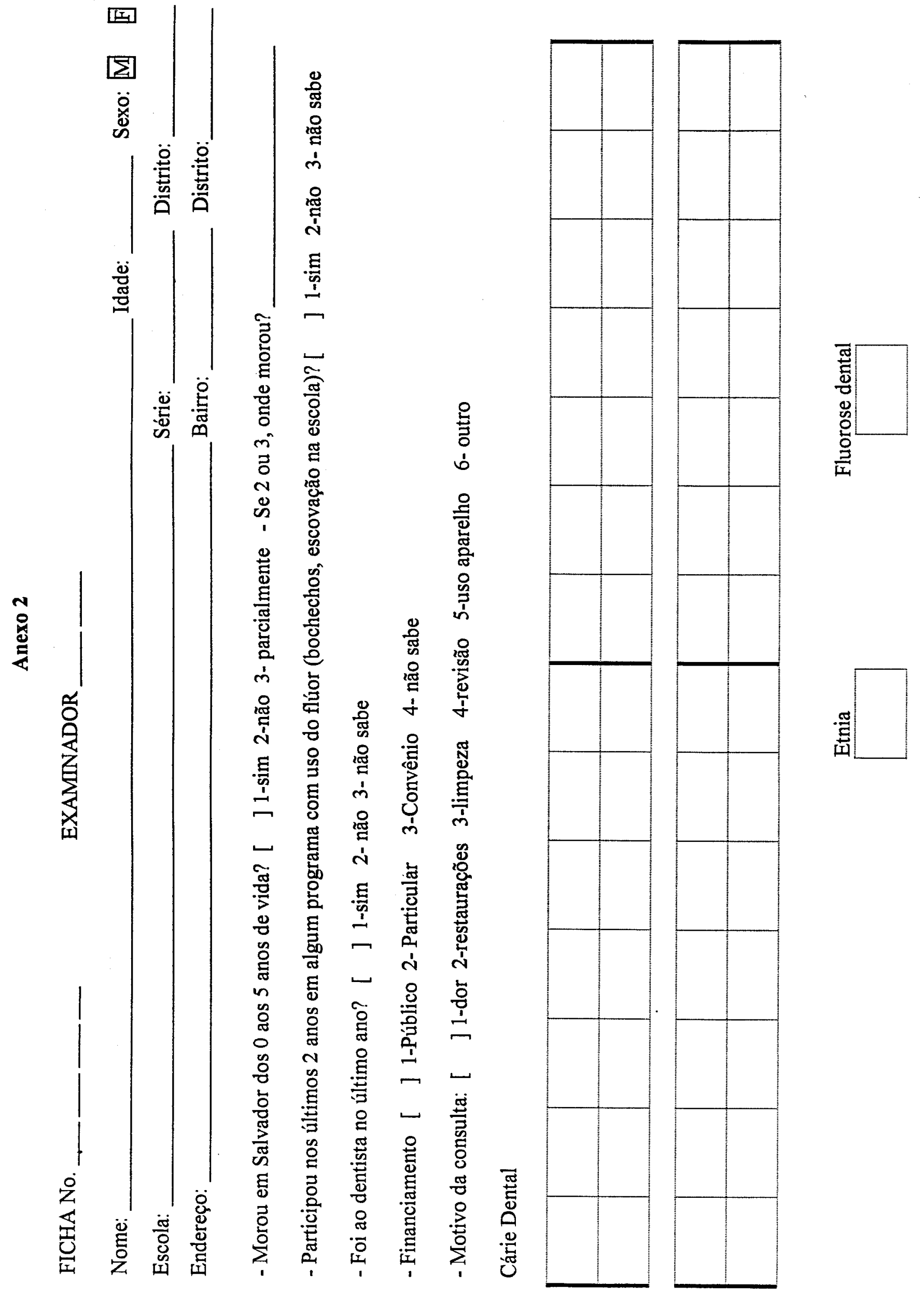


Anexo 3

USP/FSP UFBA/FOUFBA SMS-SSA

Ficha de coleta de dados secundários- "Condições de saúde bucal de adolescentes de 12 e 15 anos do município de Salvador-BA".

\begin{tabular}{|l|l|l|l|l|l|}
\hline $\begin{array}{c}\text { Distritos/variáveis } \\
\text { de pesquisa }\end{array}$ & $\begin{array}{c}\text { No. } \\
\text { dentistas }\end{array}$ & $\begin{array}{c}\text { No. } \\
\text { Pessoal } \\
\text { auxiliar }\end{array}$ & $\begin{array}{c}\text { No } \\
\text { consultórios } \\
\text { em atividade }\end{array}$ & $\begin{array}{l}\text { Programa } \\
\text { específico }\end{array}$ & \\
\hline $\begin{array}{l}\text { Barra- Rio } \\
\text { Vermelho }\end{array}$ & & & & & \\
\hline Boca do Rio & & & & & \\
\hline Itapuã & & & & & \\
\hline Cabula- Beiru & & & & & \\
\hline Itapagipe & & & & & \\
\hline Centro Histórico & & & & & \\
\hline Cajazeiras & & & & & \\
\hline São caetano- & & & & & \\
\hline Valéria & & & & & \\
\hline $\begin{array}{l}\text { Subúrbio } \\
\text { ferroviário }\end{array}$ & & & & & \\
\hline Liberdade & & & & & \\
\hline Brotas & & & & & \\
\hline
\end{tabular}




\section{Anexo 4 \\ Universidade de São Paulo/ Faculdade de Saúde Pública \\ Universidade Federal da Bahia/ Faculdade de Odontologia \\ Termo de Consentimento}

Ao pai, mãe ou responsável por:

FICHA No.

A Faculdade de Saúde Pública da Universidade de São Paulo e a Faculdade de Odontologia da Universidade Federal da Bahia estão realizando uma pesquisa para conhecer as condições de saúde bucal (cárie dental, doença periodontal e fluorose dentária) em adolescentes de 12 e 15 anos na cidade de Salvador-BA. Para isso foram sorteadas 85 escolas públicas e privadas, das mais de 800 escolas da cidade, abrangendo diferentes regiões do município.

Nesse sentido, comunicamos que foi incluída na pesquisa a escola onde seu filho estuda. Para assegurar a validade e a consistência dos dados obtidos, é importante que os jovens selecionados aleatoriamente (por sorteio) possam ser examinados por profissionais qualificados para este fim. Este exame consiste na observação de dentes e gengiva, feita na própria escola, utilizando material descartável e estéril, obedecendo os princípos de segurança e proteção do paciente preconizados pela Organização Mundial da Saúde. Os dados individuais não serão divulgados em nenhuma hipótese, mas os resultados da pesquisa ajudarão muito a prevenir as doenças bucais e melhorar a saúde de todos. Assim, pedimos a sua autorização para esta finalidade e certos de sua compreensão e apoio, agradecemos e nos colocamos a disposição para eventuais esclarecimentos.

Salvador, julho de 2001

Profa. Maria Cristina T. Cangussu- Faculdade de Odontologia da UFBA Coordenadora da Pesquisa

(71) $351-9843$ (71) $9983-9915$

Após ter sido informado sobre as características da pesquisa autorizo a realização do exame.

Salvador, / 2001.

Nome do responsável:

Assinatura do responsável: 


\section{Grupo étnico}

Na nossa pesquisa será adotada para a categorização dos diferentes grupos étnicos a classificação utilizada pela Fundação IBGE, como segue:

\begin{tabular}{|l|l|}
\hline GRUPO ÉTNICO & $\begin{array}{l}\text { CARACTERÍSTICAS BIOLÓGICAS E } \\
\text { FÍSICAS }\end{array}$ \\
\hline Amarelo & $\begin{array}{l}\text { Pele branco- amarela; olhos oblíquos, } \\
\text { repuxados. }\end{array}$ \\
\hline Branco & $\begin{array}{l}\text { Pele branca; cabelo liso ou ondulado fino } \\
\text { (de louro a negro); nariz estreito; lábios } \\
\text { finos (ou de espessura mediana); gengiva } \\
\text { rósea (com suas variações normais devido a } \\
\text { queratinização e vascularização). }\end{array}$ \\
\hline Negro & $\begin{array}{l}\text { Pele castanho- escura ou negra; cabelo } \\
\text { ondulado, encarapinhado ou em anel, } \\
\text { geralmente escuro; nariz largo ou achatado; } \\
\text { gengiva pigmentada pelo acúmulo de } \\
\text { melanina. }\end{array}$ \\
\hline Pardo & $\begin{array}{l}\text { Pele de coloração entre branca e negra } \\
\text { ("mulato", “moreno"), traços evidenciando } \\
\text { miscigenação; impossibilidade de incluir o } \\
\text { individuo nas outras categorias. }\end{array}$ \\
\hline
\end{tabular}

Nota: Em virtude das dificuldades para classificar os indivíduos segundo características étnicas num pais com alto grau de miscigenação como é o Brasil, a escolha da categoria deve ser feita levando-se em consideração os traços predominantes. 